UNIVERSIDADE DE SÃO PAULO

INSTITUTO DE GEOCIÊNCIAS

\title{
ESTUDO COMPARATIVO ENTRE A SIMULAÇÃO SEQUENCIAL GAUSSIANA E A SIMULAÇÃO BASEADA EM WAVELETS APLICADO A QUANTIFICAÇÃO DE MINÉRIO DE CU EM UM DEPÓSITO SINTÉTICO
}

Eduardo Henrique de Moraes Takafuji

Orientador: Prof. Dr. Marcelo Monteiro da Rocha

\author{
DISSERTAÇÃO DE MESTRADO \\ Programa de Pós-Graduação em Geociências: Recursos Minerais e \\ Hidrogeologia \\ SÃO PAULO \\ 2015 \\ Versão Corrigida
}



UNIVERSIDADE DE SÃO PAULO

INSTITUTO DE GEOCIÊNCIAS

\title{
ESTUDO COMPARATIVO ENTRE A SIMULAÇÃO SEQUENCIAL GAUSSIANA E A SIMULAÇÃO BASEADA EM WAVELETS APLICADO A QUANTIFICAÇÃO DE MINÉRIO DE CU EM UM DEPÓSITO SINTÉTICO
}

Eduardo Henrique de Moraes Takafuji

Orientador: Prof. Dr. Marcelo Monteiro da Rocha

\author{
DISSERTAÇÃO DE MESTRADO \\ Programa de Pós-Graduação em Geociências: Recursos Minerais e \\ Hidrogeologia
}

SÃO PAULO

2015 
Ficha catalográfica preparada pelo Serviço de Biblioteca e Documentação do Instituto de Geociências da Universidade de São Paulo

Takafuji, Eduardo Henrique de Moraes Estudo comparativo entre a simulação sequencial Gaussiana e a simulação baseada em Wavelets aplicado a quantificação de minério de $\mathrm{Cu}$ em um depósito sintético. / Eduardo Henrique de Moraes Takafuji. - São Paulo, 2015.

102 p. : il. + anexos

Dissertação (Mestrado) : IGc/USP

Orient.: Rocha, Marcelo Monteiro da

1. Geoestatística 2. Simulação Baseada em Wavelets 3. Estatística multiponto 4. Recursos minerais I. Título 


\begin{abstract}
Agradecimentos
Eu sou eternamente grato a todos que fizeram parte da trajetória da minha vida e me ajudaram a superar as adversidades e chegar aqui. Primeiramente aos meus familiares que sempre estiveram dispostos a me apoiar e incentivar, aos meus pais (Eiji e Abigail) que nunca pecaram na minha educação e são meu exemplo de vida. E à Renata Nakatu por toda a paciência e apoio. Agradeço também aos meus amigos, de infância e da faculdade.

Um voto de reconhecimento a todos os meus mestres, em particular ao Prof. Dr. Marcelo Rocha, que me orientou no mundo da geoestatística. E ao Prof. Dr. Roussos Dimitrakopoulos que me proporcionou a oportunidade de ampliar meus horizontes neste mundo da geoestatística. E finalmente, aos colegas da sala 105/LIG (IGc-USP) e do COSMO (McGill-Canadá).
\end{abstract}



"I can live with doubt, and uncertainty, and not knowing. I think it's much more interesting to live not knowing than to have answers which might be wrong." 



\section{Resumo}

TAKAFUJI, E. H. M., Estudo comparativo entre a Simulação Sequencial Gaussiana e a Simulação Baseada em Wavelets aplicado a quantificação de minério de $\mathrm{Cu}$ em um depósito sintético. São Paulo: Instituto de Geociências, Universidade de São Paulo, 2015. 102 p. Dissertação de Mestrado em Recursos Minerais.

O julgamento da qualidade de um método de estimativa/simulação é mais adequado se os resultados puderem ser comparados a dados reais. Uma vez que na mineração isto é inviável, este trabalho é baseado em um modelo de depósito mineral de cobre - representando a geologia e a distribuição de dados de modo heterogêneos. O modelo reproduz um depósito com preenchimento hidrotermal em uma falha inversa e as rochas encaixantes são meta-arenito e folhelho dobrados.

O objetivo é comparar os resultados obtidos pelo método de Simulação Baseada em Wavelets - método o qual utiliza a estatística espacial de alta-ordem para reproduzir as estruturas da geologia - com o método clássico de Simulação Sequencial Gaussiana, a fim de avaliar um método de geoestatística de multiponto aplicado a variável contínua.

Para comparar os resultados, foi calculado o valor potencial e para qual pilha (minério ou estéril) deveria ir cada bloco. Os resultados mostram que, matematicamente, a Simulação Sequencial Gaussiana obteve resultados melhores, uma vez que destinou melhor seus blocos e perdeu menos dinheiro com estéril na pilha de minério e minério de pilha de estéril. Porém, é notória a influência da imagem de treinamento nos resultados da Simulação Baseada em Wavelets, o que mostra que a Simulação Baseada em Wavelets de variáveis contínuas é promissora se a imagem de treinamento for adequada. $\mathrm{O}$ grande problema é que sua escolha ou criação é demasiadamente complexa, pois necessita de precisão local e global.

Palavras-chave: Geoestatística; Simulação Sequencial Gaussiana; Simulação Baseada em Wavelets (Wavesim). 



\begin{abstract}
TAKAFUJI, E. H. M., Comparison between Sequential Gaussian Simulation and Waveletbased Simulation applied to quantify copper ore in a synthetic deposit. São Paulo: Institute of Geosciences, University of São Paulo, 2015. 102 p. Dissertation in Mineral Resources.
\end{abstract}

The judgment of the quality of an estimation/simulation method is more suitable if the results can be compared to real data. Once in mining that is not feasible, this work is based on a synthetic mineral deposit - represented by a very heterogeneous geology and spatial data distribution. The model reproduces a deposit with hydrothermal filling in an inverse fault and the bedrocks are folded meta-sandstone and phyllite.

The objective is to compare the results obtained by Wavelet-based Simulation method - which uses the spatial high-order statistic to reproduce the geologic structures - with the classic method of Sequential Gaussian Simulation in order to evaluate a multipoint geostatistical method applied to a continuous variable.

To compare the results, the potential value was calculated and to which pile (ore or waste) each block should go. The results show that, mathematically, Sequential Gaussian Simulation's results are better, since its blocks allocated better and lost less money on waste in ore pile and ore in waste pile. However, it is clear the influence of the training image on the results of Wavelet-based Simulation. This shows that the Wavelet-based Simulation of continuous variables is promising if the training image is appropriate. The big problem is that choosing or creating it is too complex, because it requires local and global precision.

Keywords: Geostatistics; Sequential Gaussian Simulation; Wavelet-based Simulation (Wavesim). 



\section{LISTA DE FIGURAS}

FIGURA 1- SEMIVARIOGRAMA TÍPICO E SUAS PROPRIEDADES (YAMAMOTO, 2001A).

FIGURA 2 - POSSÍVEIS COMPORTAMENTOS DO SEMIVARIOGRAMA PRÓXIMO À ORIGEM (YAMAMOTO, 2001A)....... 22

Figura 3 - ANiSOTROPIA GEOMÉTRICA (A), ZonAl (B), MistA (C) (YAMAMOTO, 2001A)...............................23

FIGURA 4 - OS PRINCIPAIS MODELOS TEÓRICOS DE SEMIVARIOGRAMAS (YAMAMOTO, 2001A)............................23

FIGURA 5 - REPRESENTAÇÃO DE UMA VALIDAÇÃO CRUZADA E SUA RETA DE REGRESSÃO (YAMAMOTO, 2001A). . 24

FigurA 6 - COMPARAÇÃO ENTRE OS MÉTODOS DE SELEÇÃo DE AMOSTRAS. A FigURA 6A MOSTRA A CAPTURA DE DADOS COM OS PONTOS MAIS PRÓXIMOS; A FIGURA 6B MOSTRA A CAPTURA DE DOIS DADOS PARA CADA QUADRANTE E A FIGURA 6C MOSTRA UM DADO PARA CADA OCTANTE (YAMAMOTO, 2001A).

FIGURA 7 - FLUXOGRAMA DOS PROCESSOS DA ANÁLISE GEOESTATÍSTICA DE VARIÁVEIS CONTÍNUAS (MODIFICADO

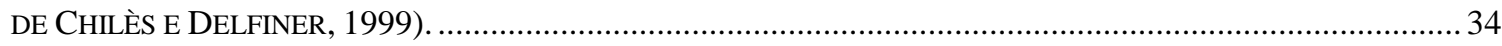

FIGURA 8 - ILUSTRAÇÃO DE COMO FUNCIONA A ESTATÍSTICA DE DOIS PONTOS E DE TRÊS PONTOS ((I) MACHUCAMORY E DIMITRAKOPOULOS, 2013).

FIGURA 9 - DEFINIÇÃO DO MODELO, EXEMPLO DE UM MODELO 2D 3X3 NUMA MALHA 11 X 11 (ARPAT E CAERS, 2007)

FIGURA 10 - EXEMPLO DE IMAGEM DE TREINAMENTO E SEUS PADRÕES OBTIDOS PELO ESCANEAMENTO DE UM MAPA ONDE 0 REPRESENTA UM ARGILITO E 1 ARENITO (ARPAT E CAERS, 2007).

FIGURA 11 - COMPARAÇÃO ENTRE A IMAGEM ORIGINAL (A) E A RECONSTRUÍDA (B) DEPOIS DA REDUÇÃO DE 75\% DOS DADOS ORIGINAIS (CHATTERJEE, DiMitraKopOUlos E MuSTAPHA, 2012).

FIGURA 12 - ESTRUTURA DA ANÁLISE DISCRETA DE WAVELETS DE MÚLTIPLAS RESOLUÇÕES, MOSTRANDO A RELAÇÃO ENTRE COEFICIENTES DE WAVELETS DE DUAS ESCALAS E UM EXEMPLO DE UM VETOR EXTRATOR COM UM MODELO 3 X3 (CHATTERJEE E DIMITRAKOPOULOS, 2011)

FiguRA 13 - A ESQUERDA UM EXEMPLO DE DECOMPOSIÇÃO DE WAVELETS DA LENNA (OUAHABI, 2012) E A DIREITA AS BANDAS DE CADA ESCALA DA DECOMPOSIÇÃO (CHATTERJEE, MuSTAPHA E DiMITRAKOPOULOS, 2015)

FIGURA 14 - FLUXOGRAMA DA ESCOLHA PARA UMA ESCALA ÓTIMA (CHATTERJEE, DIMITRAKOPOULOS E

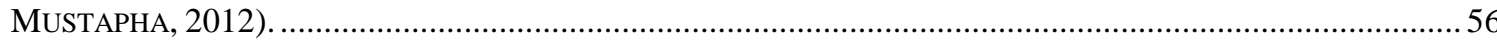

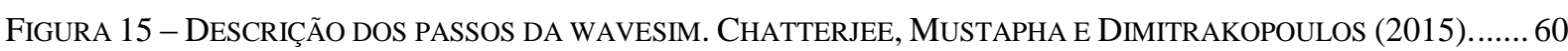

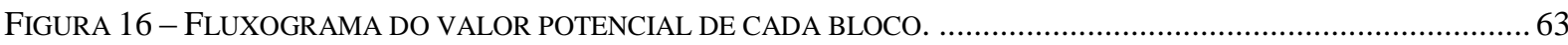

FIGURA 17 - STRINGS DO DATAMINE@ QUE FORMARAM O MODELO GEOLÓGICO SEM A TOPOGRAFIA. ..................64

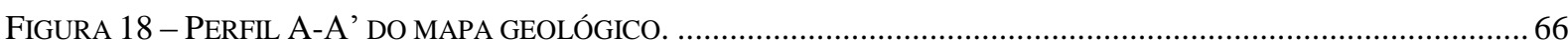

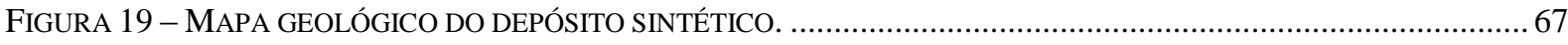

FIGURA 20 - PERFIL REPRESENTANDO AS LITOLOGIAS E O PERÍMETRO DO CORPO DE MINÉRIO INTERPRETADO. ....6 68

FIGURA 21 - MODELO TRIDIMENSIONAL DO CORPO DE MINÉRIO, EM VERMELHO, DEFINIDO A PARTIR DAS

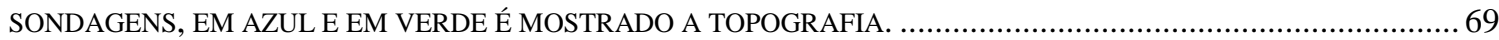

FIGURA 22 - HISTOGRAMA DOS DADOS REAIS DE COBRE DENTRO DO CORPO MINERALIZADO.............................. 69 
FIGURA 23 - HistogRAMA dOS DADOS AMOSTRADOS EM FUROS DE SONDA (DH) DE COBRE DENTRO DO CORPO

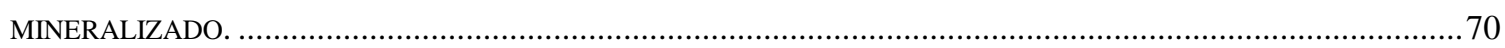

FIGURA 24 - BOXPLOT DOS DADOS REAIS E DOS AMOSTRADOS COM E SEM OUTLIERS.........................................71

FIGURA 25 - VARIOGRAMAS EXPERIMENTAIS COM A QUANTIDADE DE PARES UTILIZADOS PARA SEU CÁLCULO E

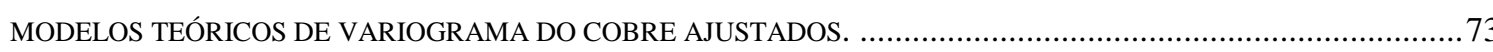

FIGURA 26 - RESULTADO DA KRIGAGEM PARA O VOLUME DO DEPÓSITO INTEIRO (IMAGEM DE TREINAMENTO) E A IMAGEM DA DIREITA É A REGIÃO CONSIDERADA COMO CORPO DO MINÉRIO DESTE VOLUME .......................74

FIGURA 27- HISTOGRAMA DOS TEORES DE COBRE ESTIMADOS POR KRIGAGEM ORDINÁRIA QUE SERÃO UTILIZADOS

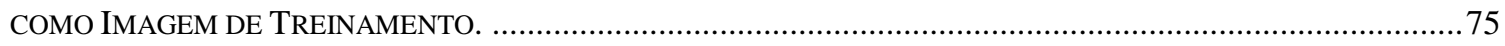

FIGURA 28 - VARIOGRAMA EXPERIMENTAL COM A QUANTIDADE DE PARES UTILIZADOS PARA SEU CÁLCULO E MODELO TEÓRICO DE VARIOGRAMA DA VARIÁVEL COBRE TRANSFORMADA EM UMA GAUSSIANA NORMAL

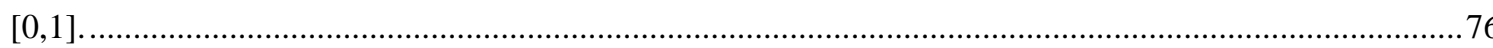

FIGURA 29 - REALIZAÇÃO Nº100 DA SIMULAÇÃO SEQUENCIAL GAUSSIANA PARA OS DADOS DE COBRE DO DEPÓSITO SINTÉTICO. A IMAGEM DA ESQUERDA MOSTRA O MODELO DE BLOCOS TOTAL E DA DIREITA APENAS DO CORPO DE MINÉRIO

FIGURA 30 - REALIZAÇÃO Nº1 DA SimULAÇÃo SEQUENCIAL GAUSSIANA. A IMAGEM DA ESQUERDA MOSTRA O MODELO DE BLOCOS TOTAL E DA DIREITA APENAS DO CORPO DE MINÉRIO. .78

FIGURA 31 - REALIZAÇÃo N65 DA SIMULAÇÃO SEQUENCIAL GAUSSIANA. A IMAGEM DA ESQUERDA MOSTRA O MODELO DE BLOCOS TOTAL E DA DIREITA APENAS DO CORPO DE MINÉRIO. 79

FIGURA 32 - HiSTOGRAMA DO E-TYPE DOS TEORES DE COBRE NOS BLOCOS SIMULADOS PELA SiMULAÇÃO SEQUENCIAL GAUSSIANA.

FIGURA 33 - REALIZAÇÃO N 100 DA WAVESIM PARA OS DADOS DE COBRE DO DEPÓSITO SINTÉTICO. OBSERVA-SE A PRESENÇA DE UM CORPO MINERALIZADO QUE NÃO ENCONTRA CORRESPONDÊNCIA AMOSTRAL.

FIGURA 34 - REALIZAÇÃO Nº1 DA WAVESIM PARA OS DADOS DE COBRE DO DEPÓSITO SINTÉTICO. A IMAGEM DA ESQUERDA MOSTRA O MODELO DE BLOCOS TOTAL E DA DIREITA APENAS DO CORPO DE MINÉRIO. .82

FIGURA 35 - REALIZAÇÃO N65 DA WAVESIM PARA OS DADOS DE COBRE DO DEPÓSITO SINTÉTICO. A IMAGEM DA ESQUERDA MOSTRA O MODELO DE BLOCOS TOTAL E DA DIREITA APENAS DO CORPO DE MINÉRIO.................8 82

FIGURA 36 - HISTOGRAMA DA MÉDIA DO TEOR DE COBRE DOS BLOCOS SIMULADOS PELO MÉTODO WAVESIM.......83

FIGURA 37 - HISTOGRAMA DOS VALORES REAIS DE CADA BLOCO DO DEPÓSITO. .................................................85

FIGURA 38 - HISTOGRAMA DA MEDIA DOS VALORES POTENCIAIS DE CADA BLOCO SIMULADO POR SGS. ..............85

FIGURA 39 - HISTOGRAMA DA MEDIA DOS VALORES POTENCIAIS DE CADA BLOCO SIMULADO POR WAVESIM........86

FIGURA 40 - BOXPLOT DA QUANTIDADE DE COBRE REAL, KRIGADA (KRIG) E SIMULADA PELOS MÉTODOS DE SimulaÇão SEQUENCIAL GausSiana (SGS40) E WAVESIM (WS40).

FIGURA 41 - SOMA CUMULATIVA DOS VALORES POTENCIAIS DE CADA BLOCO PARA TODAS AS REALIZAÇÕES DA SimulaÇão SEQUENCIAL GaUSSIANA E DA SimulaÇÃo BASEADA EM WAVELETS, DOS BLOCOS REAIS E DOS BLOCOS DE KRIGADOS. A IMAGEM (A) SÃO OS VALORES DOS LUCROS POTENCIAIS DE CADA REALIZAÇÃO DA SGS. A IMAGEM (B) SÃO OS VALORES DOS LUCROS POTENCIAIS DE CADA REALIZAÇÃO DA WAVESIM. ENQUANTO A IMAGEM (C) É A JUSTAPOSIÇÃO DE (A) E (B). .88

FIGURA 42 - BOXPLOT DA DISTRIBUIÇÃO DA QUANTIDADE DE BLOCOS ALOCADOS NAS PILHAS CORRETAS, BLOCOS DE ESTÉRIL CONSIDERADOS COMO MINÉRIO E BLOCOS DE MINÉRIO CONSIDERADOS COMO ESTÉRIL. .89 
FIGURA 43 - GRÁFICO BOXPLOT DE QUANTOS REAIS DE MINÉRIO REAL FORAM CLASSIFICADOS COMO ESTÉRIL E

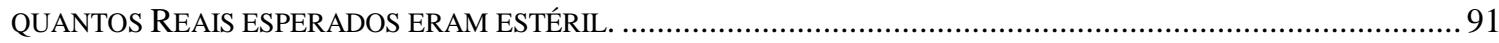




\section{LISTA DE TABELAS}

TABELA 1 -SEMIVARIOGRAMA DA REGIÃO MINERALIZADA INTERNA (QUARTZITO) E A DA EXTERNA (FORA DO

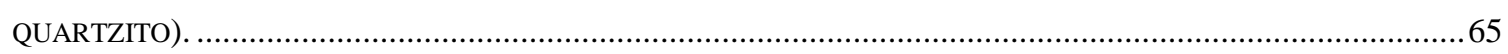

TABELA 2 - ESTATÍSTICAS DESCRITIVAS DOS DADOS REAIS DE COBRE EM TODA A ZONA MINERALIZADA..............70

TABELA 3 - ESTATÍSTICAS DESCRITIVAS DOS DADOS AMOSTRADOS NOS FUROS DE SONDA DENTRO DO CORPO DE

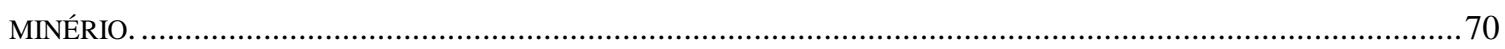

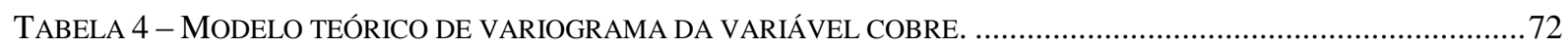

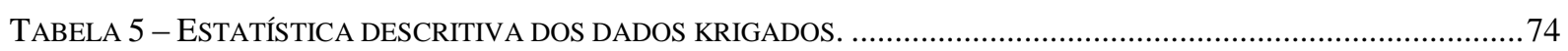

TABELA 6 - PARÂMETROS DO MODELO TEÓRICO DE VARIOGRAMA DO COBRE TRANSFORMADO EM UMA

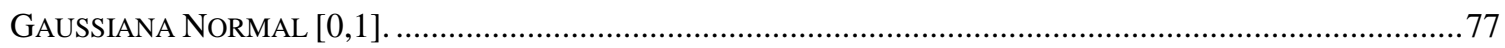

TABELA 7 - ESTATÍSTICAS DESCRITIVAS DO E-TYPE DOS BLOCOS SIMULADOS PARA TEORES DE COBRE................79

TABELA 8 - ESTATÍSTICAS DESCRITIVAS DO E-TYPE DO WAVESIM PARA OS TEORES DE COBRE............................83

TABELA 9 - ESTATÍSTICA DESCRITIVA DA QUANTIDADE DE BLOCOS QUE CADA REALIZAÇÃO ACERTOU, PARA A

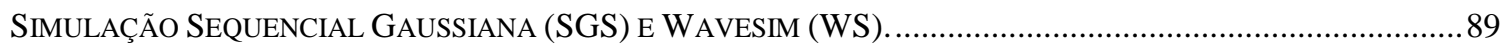

TABELA 10 - ESTATÍSTICA DESCRITIVA DA QUANTIDADE DE BLOCOS QUE CADA REALIZAÇÃO ACERTOU, PARA A

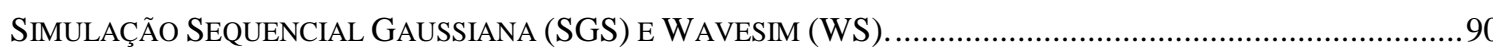

TABELA 11 - ESTATÍSTICA DESCRITIVA DA QUANTIDADE DE BLOCOS QUE CADA REALIZAÇÃO ACERTOU PARA A

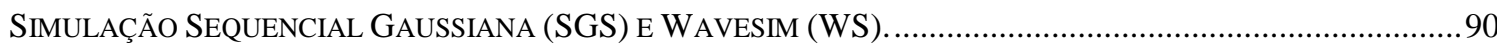

TABELA 12 - ESTATÍSTICA DESCRITIVA DO TOTAL DE REAIS QUE FORAM CONSIDERADOS COMO LUCRO E ERAM PREJUÍZO.

TABELA 13 - ESTATÍSTICA DESCRITIVA DO TOTAL DE REAIS QUE FORAM CONSIDERADOS COMO ESTÉRIL E GERARIAM LUCRO 


\section{Sumário}

1. INTRODUÇÃO ......................................................................................................................

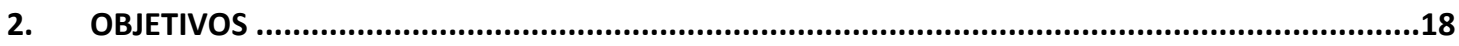

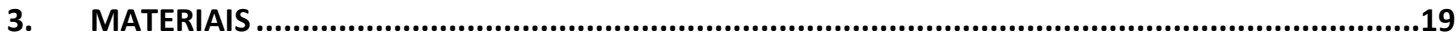

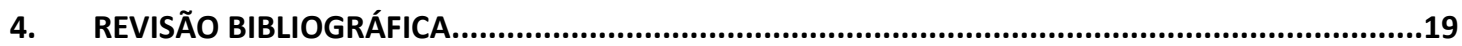

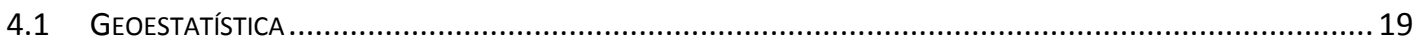

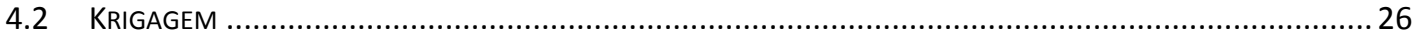

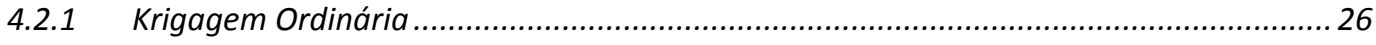

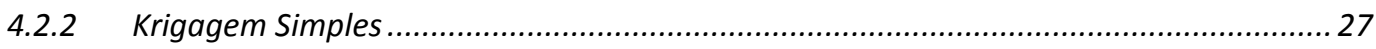

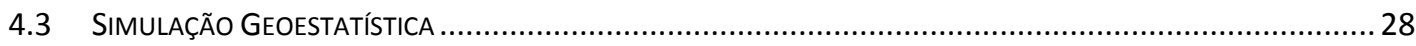

4.3.1 Justificativa da utilização dos métodos de simulação ................................................. 30

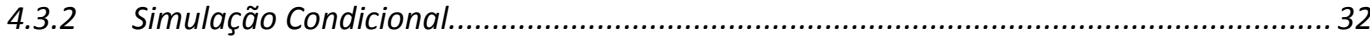

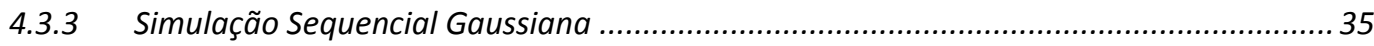

4.3.4 Algoritmo da Simulação Sequencial Gaussiana ............................................................ 38

4.3.5 Transformação gaussiana normal........................................................................... 40

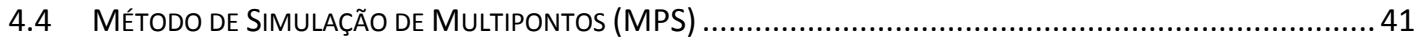

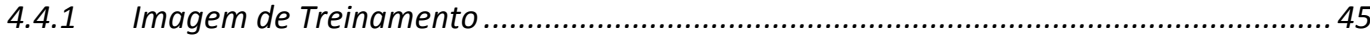

4.4.2 Método de Simulação Baseada em Wavelets (Wavesim) .......................................... 47

4.4.3 Algoritmo da Simulação Baseada em Wavelets.......................................................6 61

5. ANÁLISE DO LUCRO POR BLOCO...........................................................................................62

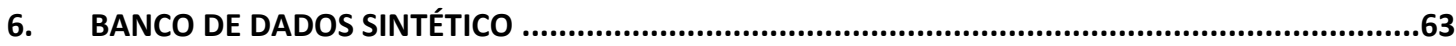

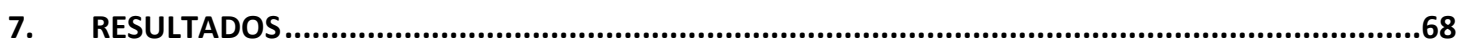

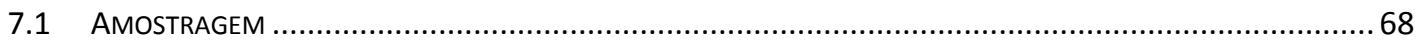

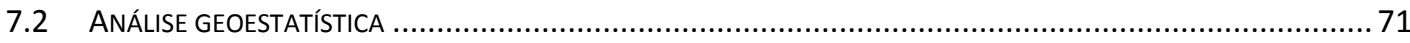

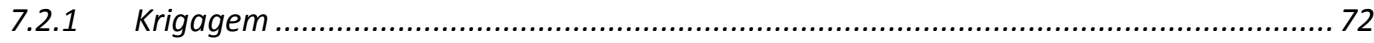

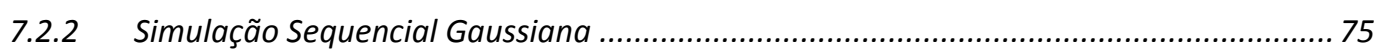

7.2.3 Simulação Baseada em Wavelets (Wavesim)........................................................... 80

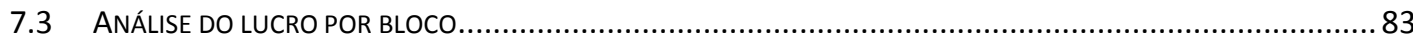

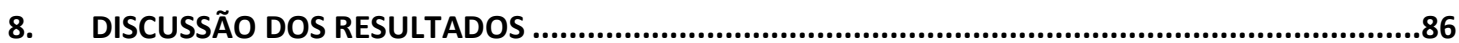

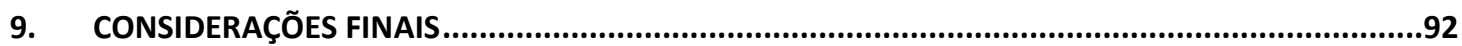

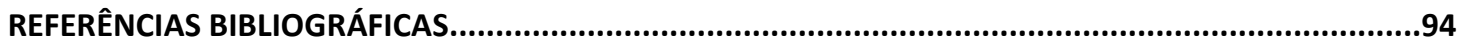


ANEXO 1

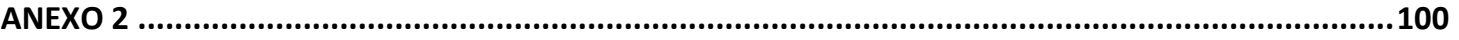




\section{Introdução}

O entendimento da geologia e da distribuição espacial dos teores de minério são fundamentais para um empreendimento mineiro. Para isso, entre outras técnicas de investigação, realizam-se sondagens de reconhecimento da geologia de subsuperfície de onde se coletam as amostras que são descritas por geólogos e analisadas quimicamente, a partir das quais se pode criar um modelo espacial de distribuição de teores, estimando pontos/regiões não amostrados.

Existem diversas técnicas já consolidadas para modelar depósitos minerais e prever características de locais não amostrados, entre elas, destacam-se as técnicas de Krigagem Ordinária, Simulação de Indicadores e Simulação Sequencial Gaussiana. Existem novas técnicas sendo desenvolvidas para aprimorar as medições que, ao contrário das técnicas tradicionais, não dependem de semivariogramas. Portanto, a correlação espacial não é calculada pela estatística de dois pontos do semivariograma, mas sim pela estatística de pontos de alta ordem. Estes novos métodos são chamados de estatísticas de multiponto.

De modo geral, as simulações estocásticas realizam procedimentos muito semelhantes, ou seja, simulam os pontos não conhecidos selecionando aleatoriamente o valor da função densidade de probabilidade condicional da região à qual o ponto pertence. A diferença entre os métodos é a maneira de calcular a função densidade de probabilidade ou simplesmente uma variação da implementação do algoritmo.

As incertezas geológicas têm grande impacto no modelo geológico e, consequentemente, na classificação de recursos/reservas minerais. Considerando as implicações econômicas nas tomadas de decisão, a habilidade de mapear, quantificar e administrar incertezas é fundamental para a avaliação e classificação de recursos minerais. Tradicionalmente, a classificação de recursos minerais é baseada em critérios geométricos, tais como o número de amostras ou sondagens ao redor dos blocos estimados ou, alternativamente, alguma variância derivada da estimativa/simulação. Estes critérios são relativamente fáceis de entender e implementar, entretanto, eles não representam plenamente a variabilidade local das classes dentro do depósito, levando à diminuição da confiança das classes declaradas. 
As simulações estocásticas, geralmente expressas com funções não lineares de variáveis espaciais, são utilizadas para quantificar as incertezas geradas nas previsões. Embora o desempenho de métodos tradicionais bem conhecidos e frequentemente utilizados - como a Simulação Sequencial Gaussiana (SGS) - tenha sido exaustivamente testado no passado, o desempenho dos novos métodos de simulações, tal como a simulação de multipontos (MPS), ainda estão sendo testados. O aspecto fundamental do MPS é encontrar o padrão (imagem de treinamento) que melhor corresponda ao depósito de onde as amostras foram coletadas, enquanto a simulação de alta-ordem procura por cumulantes espaciais de uma dada ordem que irá gerar funções densidade de probabilidade mais realistas, por utilizar mais informações dos depósitos minerais. O método de multipontos a ser utilizado neste trabalho é a Simulação Baseada em Wavelets (Wavesim), que será comparado ao método de SGS já consolidado.

\section{Objetivos}

O objetivo deste trabalho é aplicar, analisar e comparar os métodos de Simulação Baseada em Wavelets e Simulação Sequencial Gaussiana. Estas simulações têm a finalidade de quantificar a probabilidade dos possíveis cenários juntamente com a avaliação e classificação do minério/estéril. Além disso, é apresentado o algoritmo de cálculo do lucro potencial e classificação dos blocos em pilhas de processamento.

O objetivo específico deste estudo é comparar os gráficos de distribuição acumulada de possíveis lucros, considerando cada realização dos resultados da Simulação Sequencial Gaussiana (SGS) e da Simulação Baseada em Wavelets (Wavesim) com os resultados esperados do depósito sintético de $\mathrm{Cu}$. Como as realizações das simulações são equiprováveis e geram resultados diferentes, pode-se verificar a gama de possíveis lucros e qual a precisão destes resultados. Por fim há o propósito de comparar a quantidade de acertos das simulações e do resultado "real” na classificação do minério de cobre. 


\section{Materiais}

O desenvolvimento deste trabalho foi realizado no Laboratório de Informática Geológica (LIG) utilizando os programas Datamine ${ }^{\circledR}$, SGeMS e R. A geração do banco de dados foi feita no programa Datamine ${ }^{\circledR}$ para a modelagem geométrica e no SGeMS para a geoestatística.

A Simulação Sequencial Gaussiana foi feita com o programa SGeMS e a Simulação Baseada em Wavelets foi feita por um programa desenvolvido no laboratório de geoestatística COSMO, na McGill University, Canadá. A análise de lucro por bloco criada foi escrita na linguagem Python. Por último, as estatísticas descritivas, histogramas e gráficos boxplot apresentados foram feitos no programa $\mathrm{R}$.

\section{Revisão Bibliográfica}

\subsection{Geoestatística}

Rendu (1976) discorre que a análise estatística é a ferramenta lógica para a otimização de decisões na exploração mineral. Entretanto, geólogos normalmente apresentam dificuldades em quantificar suas opiniões e, deste modo, as decisões devem considerar a utilização de funções que representam de forma simplificada suas preferências. Landim (1997) afirma que a geoestatística é uma parte especial da estatística aplicada que trata de problemas referentes às variáveis regionalizadas, as quais apresentam uma aparente continuidade no espaço, sendo representadas por funções numéricas ordinárias que assumem um valor definido a cada ponto no espaço e matematicamente descrevem um fenômeno natural.

Matheron (1963) explica que a variável regionalizada é, em sensu stricto, uma função real definindo um valor em cada ponto do espaço. Primeiramente, ela é localizada no espaço e suas variações ocorrem em uma região mineralizada (corpo do depósito) chamada campo geométrico da regionalização. Comumente é definida como suporte geométrico e este suporte é o volume da amostra, seu formato, tamanho e orientação. Se o suporte geométrico é alterado no depósito, uma nova variável regionalizada é obtida. Em segundo lugar, a variável pode mostrar a continuidade e variação espacial. Por último, a variável pode mostrar 
diferentes tipos de anisotropia. Estas características das variáveis regionalizadas possibilitam obter uma ferramenta matemática simples, o semivariograma, que nada mais é que a curva que representa o grau de continuidade do fenômeno espacial em estudo. O semivariograma é uma função crescente da distância h e, quanto mais espaçadas as amostras estão uma das outras, maior a diferença entre os valores amostrados.

Yamamoto (2001a) conceitua que a teoria das variáveis regionalizadas estuda e representa as propriedades estruturais destas variáveis, com o propósito de resolver os problemas de estimativa. A hipótese intrínseca é o conceito básico desta teoria, que implica que uma função descreve o comportamento espacial da variável regionalizada dentro do espaço e que esta é uma característica intrínseca da regionalização, ou seja, a geoestatística assume que a distribuição das diferenças entre dois pontos amostrais é, em média, a mesma para todo o domínio e que ela depende apenas da distância e orientação entre os pontos. Esta distribuição pode ser representada pela função semivariograma. Segundo Armstrong (1998), o semivariograma é utilizado para quantificar a correlação espacial entre as amostras. Uma vez ajustada uma função matemática (modelo teórico de semivariograma) ao semivariograma experimental, ela pode ser utilizada para prever valores não amostrados por krigagem ou simulação estocástica, métodos tradicionais de geoestatística utilizados atualmente na indústria da mineração.

A função semivariograma pode ser escrita como:

$$
\gamma(\mathrm{h})=\frac{1}{2 n} \sum_{i=1}^{n}\left[\mathrm{Z}\left(\mathrm{x}_{\mathrm{i}}+\mathrm{h}\right)-\mathrm{Z}\left(\mathrm{x}_{\mathrm{i}}\right)\right]^{2}
$$

Sendo: $\gamma(\mathrm{h})=$ variância espacial; $\mathrm{Z}\left(\mathrm{x}_{\mathrm{i}}\right)$ = variável regionalizada no ponto $\mathrm{x}_{\mathrm{i}} ; \mathrm{Z}\left(\mathrm{x}_{\mathrm{i}}+\mathrm{h}\right)$ $=$ variável regionalizada no ponto $\left(\mathrm{x}_{\mathrm{i}}+\mathrm{h}\right)$ e $\mathrm{n}=$ número de pares de pontos separados por uma distância h.

Para calcular o semivariograma em uma malha regular é necessário definir:

(a) Número de direções: quantidade de direções em que o semivariograma experimental será calculado;

(b) Tamanho do passo: distância de separação entre amostras que será considerada para o cálculo do semivariograma;

(c) Número de passos: número de vezes que o passo será incrementado; 
Além disso, se a malha não for regular, é necessário definir algumas tolerâncias:

(d) Tolerância angular: ângulo de busca dentro do qual as amostras serão consideradas sendo de determinada direção para o cálculo do semivariograma;

(e) Tolerância do passo: porcentagem da distância do passo. Esta tolerância faz com que os pares de pontos sejam considerados em classes de distâncias.

Um exemplo de modelo de semivariograma com patamar típico é mostrado na Figura 1, e suas principais propriedades são:

(a) Amplitude: distância a partir da qual as amostras passam a ser espacialmente independentes. É a distância máxima onde as amostras apresentam correlação espacial - esta região é denominada campo estruturado. A partir desta distância alcança-se o campo aleatório onde as amostras são espacialmente independentes;

(b) Patamar: valor máximo da variância espacial próximo ao qual os pontos do semivariograma experimental se estabilizam;

(c) Efeito Pepita (ou variância aleatória): ocorre quando o valor da função semivariograma é diferente de zero a distâncias muito próximas à origem.

(d) Variância espacial: diferença entre o patamar $\left(\mathrm{C}_{0}+\mathrm{C}\right)$ e o efeito pepita. É a região onde a variância é função da distância.

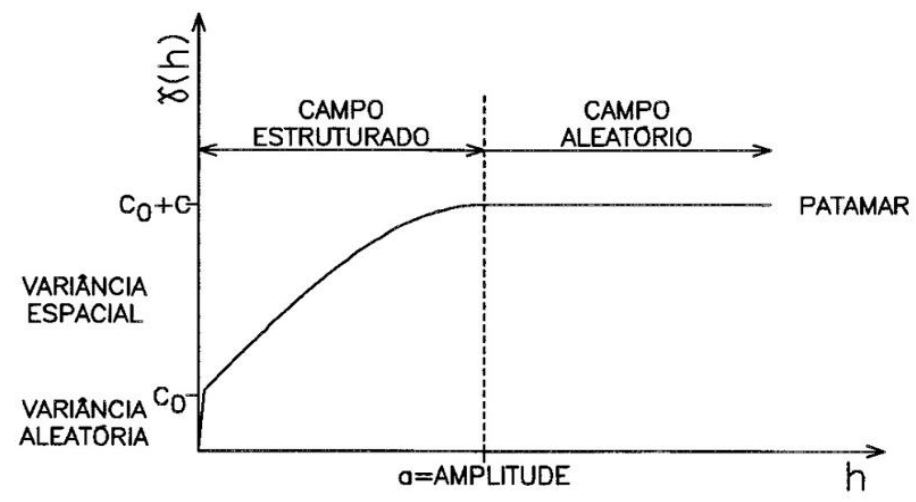

Figura 1-Semivariograma típico e suas propriedades (Yamamoto, 2001a). 
Conforme Armstrong (1998) é possível distinguir quatro padrões de comportamento próximo à origem do semivariograma (Figura 2):

(a) Parabólico: indica que a variável regionalizada é contínua (Figura 2A);

(b) Linear: indica que a variável regionalizada é contínua, porém menos do que aquela com comportamento parabólico (Figura 2B);

(c) Efeito Pepita: apresenta a descontinuidade próxima à origem, causada por erros na amostragem e/ou variabilidade natural dos dados em distâncias pequenas (Figura 2C);

(d) Efeito pepita puro: aleatoriedade total. As variáveis $\mathrm{Z}(\mathrm{x}+\mathrm{h})$ e $\mathrm{Z}(\mathrm{x})$ não são correlacionáveis a quaisquer valores de h, não importando o quão perto eles estiverem. É a total falta de estruturação do semivariograma (Figura 2D).
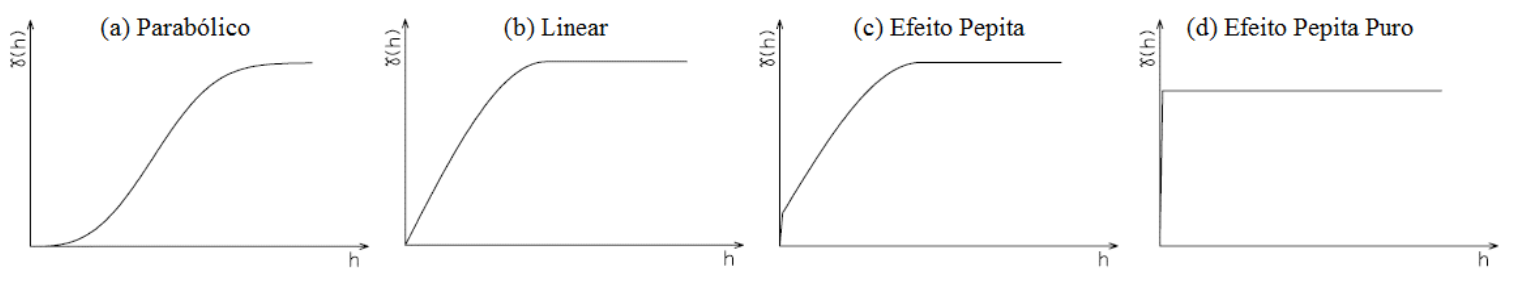

Figura 2 - Possíveis comportamentos do semivariograma próximo à origem (Yamamoto, 2001a).

Segundo Yamamoto (2001a), existe anisotropia quando o semivariograma for calculado em diferentes direções do domínio e este mostrar variações distintas. Para identificá-la, deve-se calcular o semivariograma em quatro direções $\left(0^{\circ}, 45^{\circ}, 90^{\circ}, 135^{\circ}\right)$ se os dados estiverem distribuídos em domínio bidimensional ou para cinco direções adicionando a direção vertical - se for tridimensional. Depois de calculado, verifica-se a existência de uma direção que apresente maior amplitude ou maior patamar, ou ambos.

Yamamoto (2001a) mostra que podem ser reconhecidos três tipos de anisotropia, conforme exemplificada na Figura 3.

(a) Anisotropia geométrica: a amplitude varia conforme as direções, porém sob um patamar constante (Figura 3A);

(b) Anisotropia zonal: o patamar varia com amplitude constante (Figura 3B);

(c) Anisotropia mista: tanto a amplitude quanto patamar variam de acordo com a direção observada (Figura 3C). 

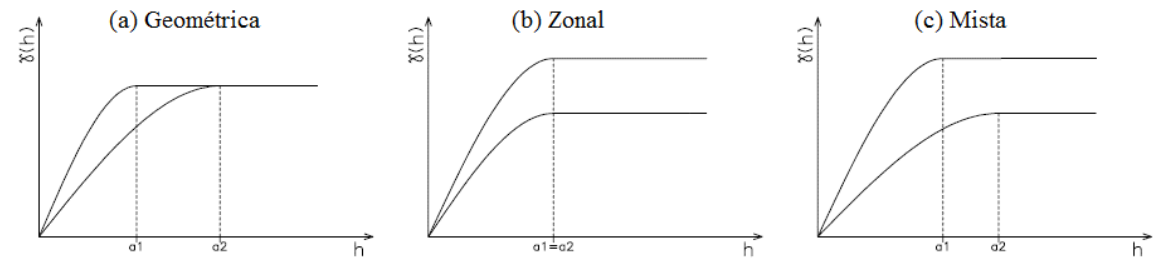

Figura 3 - Anisotropia Geométrica (A), Zonal (B), Mista (C) (Yamamoto, 2001a).

Deutsch (2002) salienta que os pontos calculados que formam o semivariograma experimental não são utilizados diretamente nas etapas de estimativa como krigagem e simulação estocástica e, para utilizá-los, deve-se se ajustar uma função matemática adequada ao semivariograma experimental, que é o modelo teórico de semivariograma. Este ajuste é realizado de forma interativa, a partir dos parâmetros interpretados no semivariograma experimental (número de estruturas, modelo, variância espacial, e amplitude). Se visualmente o modelo teórico não for satisfatório, novos parâmetros deverão ser fornecidos até o ajuste ser considerado satisfatório. Os principais modelos e suas respectivas formas estão representados na Figura 4.

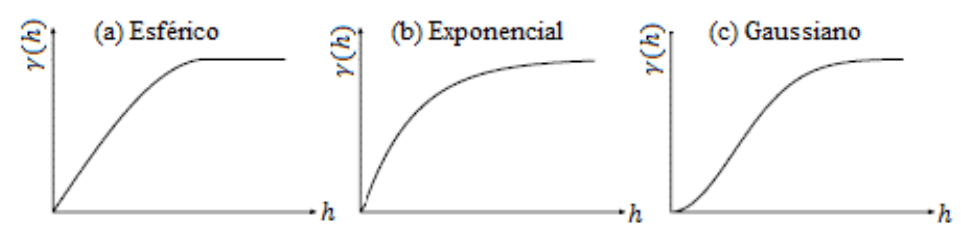

Figura 4 - Os principais modelos teóricos de semivariogramas (Yamamoto, 2001a).

Yamamoto (2001a) mostra que os modelos esférico, exponencial e gaussiano são, respectivamente, determinados pelas funções:

$$
\begin{aligned}
& \left\{\begin{array}{l}
\gamma(h)=C_{0}+C\left[\frac{3}{2}\left(\frac{h}{a}\right)-\frac{1}{2}\left(\frac{h}{a}\right)^{3}\right] ; \text { para } \mathrm{h}<a \\
\gamma(h)=C_{0}+C ; \text { para } \mathrm{h} \geq \mathrm{a}
\end{array}\right. \\
& \gamma(h)=C 0+C\left[1-\exp \left(-\left(\frac{h}{a}\right)\right)\right] \\
& (h)=C 0+C\left[1-\exp \left(-\left(\frac{h}{a}\right)^{2}\right)\right]
\end{aligned}
$$


Para aferir o ajuste do modelo teórico de semivariograma e definir a melhor vizinhança a ser utilizada, deve-se realizar a validação cruzada dos dados. Este procedimento compara os valores dos pontos amostrados com os valores estimados nas localizações amostradas. Esta comparação pode ser feita por meio de um gráfico de dispersão (Figura 5). Quanto menor a dispersão da nuvem de pontos, melhor terá sido a validação cruzada, ou seja, a reta de regressão ajustada à nuvem deve estar próxima à reta de $45^{\circ}$ (Yamamoto, 2001a).

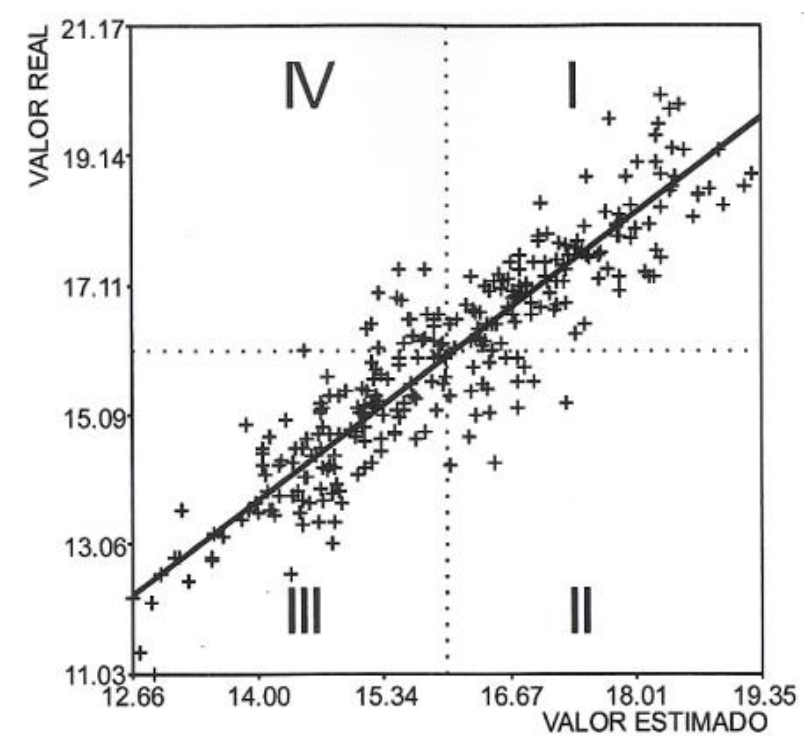

Figura 5 - Representação de uma validação cruzada e sua reta de regressão (Yamamoto, 2001a).

Segundo Yamamoto (2001a), a escolha de amostras para estimar pontos não amostrados deve ser feita de tal modo que garanta uma boa disposição espacial, evitando a escolha de amostras concentradas preferencialmente em uma região. Para isso, deve-se estabelecer critérios de seleção, dividindo o espaço ao redor do ponto a ser estimado em quadrantes ou octantes (Figura 6). Na Figura 6A o critério é apenas a distância, portanto o será utilizado apenas os pontos mais próximos para a estimativa, não importando sua localização no espaço. Na Figura 6B são utilizados quadrantes para particionar o espaço onde as amostras serão procuradas e na Figura 6C o espaço de busca é dividido em octantes. 

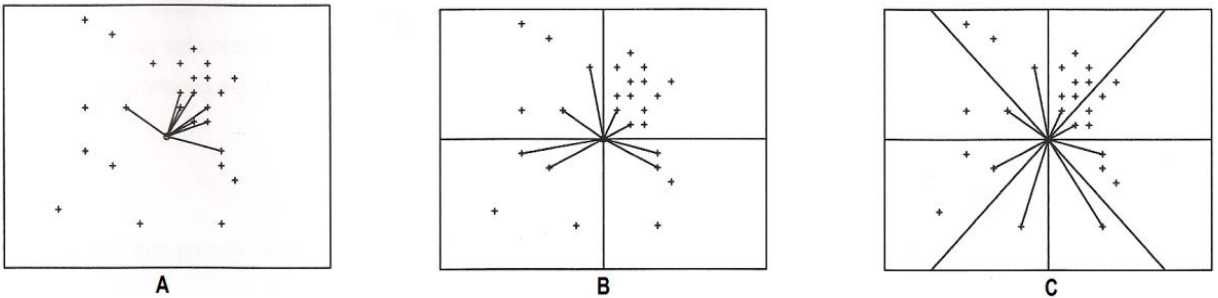

Figura 6 - Comparação entre os métodos de seleção de amostras. A Figura 6A mostra a captura de dados com os pontos mais próximos; A Figura 6 B mostra a captura de dois dados para cada quadrante e a Figura 6C mostra um dado para cada octante (Yamamoto, 2001a).

De acordo com Armstrong (1998), o procedimento para aplicação de técnicas geoestatísticas tradicionais pode ser descrito simplificadamente como:

1. Coleta e validação dos dados. Caso o profissional responsável pela geoestatística não esteja envolvido desde o início do projeto, deve-se descobrir o tipo de amostra e análises utilizadas, assim como qualquer mudança de procedimento, a geologia da área - incluindo falhas, dobras, entre outras - a presença de amostragem preferencial e agrupamentos. Além disso, devem ser definidos os limites da área de estudo, o suporte das variáveis e se os dados são ou não estacionários. De acordo com Miesch (1975), um plano de amostragem eficiente depende do conhecimento da variabilidade do corpo rochoso. Normalmente esta variabilidade é descrita pelos geólogos, embora raramente sejam mensuradas de forma rigorosa;

2. Estatística básica: cálculo da média, variância, correlações, histogramas e diagramas de dispersão. Devem-se procurar valores anômalos e/ou discrepantes e verificar a presença de dados não homogêneos - o que indicaria uma mistura de populações;

3. Cálculo do semivariograma experimental;

4. Ajuste do modelo teórico de semivariograma;

5. Realização da krigagem ou simulação.

Royle (1980) descreve os argumentos a favor da utilização da geoestatística como:

(a) Reconhecer que a variância total é parcialmente aleatória e parcialmente espacial, além disso, ela guia à estimativa não enviesada e apresenta menores erros de estimativa; 
(b) A geoestatística prova que alguns estimadores tradicionais - como os métodos dos polígonos - produzem estimativas enviesadas;

(c) Operações de mina e validações podem ser mantidas sob o controle estatístico e seus desvios são possíveis de cálculo, previsíveis e controláveis devido à natureza não enviesada das estimativas geoestatísticas.

\subsection{Krigagem}

\subsubsection{Krigagem Ordinária}

A krigagem ordinária, segundo Isaaks e Srivastava (1989) é um B.L.U.E. (Best Linear Unbiased Estimator), ou seja, melhor estimador linear não enviesado. Segundo Yamamoto (2001b), a krigagem é um método que permite estimar pontos não amostrados $\mathrm{Z}^{*}\left(\mathrm{Xo}_{\mathrm{o}}\right)$ associados a pontos, áreas ou volumes a partir de um conjunto de $\mathrm{n}$ dados $\left\{\mathrm{Z}\left(\mathrm{x}_{\mathrm{i}}\right), \mathrm{i}=\right.$ 1, n\} disponíveis. O estimador da krigagem ordinária é calculado por:

$$
\mathrm{Z}^{*}\left(\mathrm{x}_{0}\right)=\sum_{i=1}^{n} \lambda_{\mathrm{i}} \cdot \mathrm{z}\left(\mathrm{x}_{\mathrm{i}}\right)
$$

Sendo que os ponderadores $\left(\lambda_{i}, i=1, \ldots, n\right)$ são obtidos pela resolução do sistema de equações de krigagem, que nada mais é do que um sistema de equações lineares. A minimização da variância do erro sujeita à condição de não enviesamento resulta nas equações de krigagem ou sistema de krigagem ordinária (Yamamoto 2001b):

$$
\left\{\begin{array}{l}
\sum_{i} \lambda_{i} \gamma\left(x_{i}-x_{i}\right)-\mu=\gamma\left(x_{0}-x_{i}\right), \text { para } \mathrm{i}=1, \ldots, \mathrm{n} \\
\sum_{i} \lambda_{i}=1
\end{array}\right.
$$

As equações podem ser representadas como:

$$
\left[\begin{array}{ccccc}
\gamma\left(x_{1}-x_{1}\right) & \gamma\left(x_{1}-x_{2}\right) & \ldots & \gamma\left(x_{1}-x_{n}\right) & 1 \\
\gamma\left(x_{2}-x_{1}\right) & \gamma\left(x_{2}-x_{2}\right) & \ldots & \gamma\left(x_{2}-x_{n}\right) & 1 \\
\vdots & \vdots & \ldots & \vdots & \vdots \\
\gamma\left(x_{n}-x_{1}\right) & \gamma\left(x_{n}-x_{2}\right) & \ldots & \gamma\left(x_{n}-x_{n}\right) & 1 \\
1 & 1 & \ldots & 1 & 0
\end{array}\right] \cdot\left[\begin{array}{c}
\lambda_{1} \\
\lambda_{2} \\
\vdots \\
\lambda_{n} \\
\mu
\end{array}\right]=\left[\begin{array}{c}
\gamma\left(x_{0}-x_{1}\right) \\
\gamma\left(x_{0}-x_{2}\right) \\
\vdots \\
\gamma\left(x_{0}-x_{n}\right) \\
1
\end{array}\right]
$$

Onde $\gamma\left(\mathrm{Xn}_{n}-\mathrm{Xn}_{n}\right)$ é a variância espacial entre amostras; $\gamma\left(\mathrm{X}_{0}-\mathrm{Xn}_{n}\right)$ é a variância espacial entre as amostras e o ponto a ser estimado e $\mu$ é o multiplicador de Lagrange, este 
multiplicador é utilizado para minimizar a variância do estimador na restrição da soma dos ponderadores ser igual a 1 (Armstrong, 1998).

\subsubsection{Krigagem Simples}

Journel (1989) mostra a teoria básica da regressão linear para estimar valores desconhecidos de $\mathrm{Z}(\mathrm{x})$ pela combinação linear de $\mathrm{n}$ valores conhecidos $\mathrm{Z}\left(\mathrm{x}_{\mathrm{i}}\right), \mathrm{i}=1, \ldots, \mathrm{n}$. Se estes valores desconhecidos corresponderem aos mesmos atributos de Z(x) esta operação é chamada de krigagem.

Chilès e Delfiner (1999) mostram que para estimar $\mathrm{z}\left(\mathrm{x}_{\mathrm{i}}\right)$ de $\mathrm{N}$ observações $\left(\mathrm{z}\left(\mathrm{x}_{1}\right), \ldots, \mathrm{z}\left(\mathrm{x}_{\mathrm{N}}\right)\right)$ usando o estimador

$$
\mathrm{Z}^{*}(\mathrm{x})=\sum_{i=1}^{n} \lambda_{\mathrm{i}} \cdot \mathrm{z}\left(\mathrm{x}_{\mathrm{i}}\right)+\lambda_{0}
$$

a constante $\lambda_{0}$ e os pesos $\lambda_{\mathrm{i}}$ são selecionados para minimizar no modelo a esperança do erro quadrático $\mathrm{E}\left[\mathrm{Z}^{*}(\mathrm{x})-\mathrm{Z}\left(\mathrm{x}_{0}\right)\right]^{2}$. Primeiramente, este erro pode ser descrito como:

$$
\mathrm{E}\left[\mathrm{Z}^{*}(\mathrm{x})-\mathrm{Z}\left(\mathrm{x}_{0}\right)\right]^{2}=\operatorname{Var}\left[\mathrm{Z}^{*}(\mathrm{x})-\mathrm{Z}\left(\mathrm{x}_{0}\right)\right]+\left[\mathrm{E}\left[\mathrm{Z}^{*}(\mathrm{x})-\mathrm{Z}\left(\mathrm{x}_{0}\right)\right]\right]^{2}
$$

Uma vez que a variância é invariante, apenas o termo do lado direito envolve $\lambda_{0}$ e a fim de minimizar o erro é necessário escolher o $\lambda_{0}$ que cancele com $E\left[Z^{*}(x)-Z\left(x_{0}\right)\right]$, ou seja:

$$
\lambda_{0}=\mathrm{m}\left(\mathrm{x}_{0}\right)-\sum_{i=1}^{n} \lambda_{\mathrm{i}} \cdot \mathrm{m}\left(\mathrm{x}_{\mathrm{i}}\right)
$$

e o estimador da krigagem simples é:

$$
\mathrm{Z}^{*}(\mathrm{x})=\mathrm{m}\left(\mathrm{x}_{0}\right)+\sum_{i=0}^{n} \lambda_{\mathrm{i}} \cdot\left(\mathrm{Z}\left(\mathrm{x}_{\mathrm{i}}\right)-\mathrm{m}\left(\mathrm{x}_{\mathrm{i}}\right)\right)
$$

Onde $\mathrm{m}\left(\mathrm{x}_{0}\right)$ é o valor esperado, $\mathrm{m}\left(\mathrm{x}_{\mathrm{i}}\right)$ é a média dos pontos utilizados e $\lambda_{\mathrm{i}}$ é obtido por um sistema linear de $\mathrm{N}$ equações. $\mathrm{E}$ a notação da matriz do sistema de krigagem simples é $\mathrm{K} \lambda=\mathrm{k}$ e pode ser observada em forma de matriz em Yamamoto e Landim (2013):

$$
\left[\begin{array}{cccc}
C\left(x_{1}-x_{1}\right) & C\left(x_{1}-x_{2}\right) & \ldots & C\left(x_{1}-x_{n}\right) \\
C\left(x_{2}-x_{1}\right) & C\left(x_{2}-x_{2}\right) & \ldots & C\left(x_{2}-x_{n}\right) \\
\vdots & \vdots & \ldots & \vdots \\
C\left(x_{n}-x_{1}\right) & C\left(x_{n}-x_{2}\right) & \ldots & C\left(x_{n}-x_{n}\right)
\end{array}\right] \cdot\left[\begin{array}{c}
\lambda_{1} \\
\lambda_{2} \\
\vdots \\
\lambda_{n}
\end{array}\right]=\left[\begin{array}{c}
C\left(x_{0}-x_{1}\right) \\
C\left(x_{0}-x_{2}\right) \\
\vdots \\
C\left(x_{0}-x_{n}\right)
\end{array}\right]
$$


Onde $C\left(x_{i}-x_{i}\right)$ é a covariância dos n pontos amostrados, $\lambda_{\mathrm{i}}$ é o peso da krigagem a ser calculado e $C\left(x_{0}-x_{i}\right)$ é a covariância do ponto a ser estimado com o n-ésimo ponto amostrado, com $\mathrm{i}=1, \ldots, \mathrm{n}$.

A variância do estimador $\left(\sigma_{S K}^{2}\right)$ é:

$$
\sigma_{S K}^{2}=\mathrm{E}\left[\mathrm{Z}^{*}(\mathrm{x})-\mathrm{Z}\left(\mathrm{x}_{0}\right)\right]^{2}=C\left(x_{0}-x_{0}\right)-\sum_{i=1}^{n} \lambda_{\mathrm{i}} . C\left(x_{0}-x_{n}\right)
$$

\subsection{Simulação Geoestatística}

Deutsch e Journel (1998) explicam que a simulação corrige o efeito de suavização da krigagem e o mapa suavizado gerado pela krigagem é mais apropriado para mostrar tendências gerais, pois preserva as distribuições locais. Por outro lado, mapas de simulação condicional são mais apropriados para estudos que são sensíveis aos padrões de variabilidade, como ocorre nas simulações de fluxo. A simulação estocástica encontra suas principais aplicações em mineração, hidrogeologia e petróleo. O conjunto de mapas de simulações condicionais também fornece subsídio para a elaboração do modelo de incerteza sobre a distribuição espacial das variáveis. Em resumo, a simulação estocástica é um processo que constrói alternativas equiprováveis e modelos de distribuição espacial com alta resolução e é dita condicional se o resultado das realizações honrarem os valores dos dados e sua localização.

Goovaerts (1997) mostra que mapas interpolados suavizados não podem ser utilizados para aplicações sensíveis à presença de valores extremos e seus padrões de continuidade. Ao invés de mapas de estimativas, a simulação estocástica gera mapas ou realizações de valores $\left\{\mathrm{z}^{(\mathrm{l})}(\mathrm{x}), \mathrm{x} \in \mathrm{A}\right\}$, com A sendo a área e l sendo a l-ésima realização, que reproduzem a estatística da maioria dos problemas. O requisito típico para a simulação condicional é garantir que valores amostrados sejam reproduzidos em locais simulados $\left(\mathrm{z}^{(\mathrm{l})}(\mathrm{x})=\mathrm{z}\left(\mathrm{x}_{\mathrm{i}}\right) \forall \mathrm{x}=\mathrm{x}_{\mathrm{i}}, \mathrm{i}=1, \ldots, \mathrm{N}\right)$. Os histogramas dos valores simulados devem reproduzir rigorosamente o histograma dos dados desagrupados.

Sinclair e Blackwell (2004) explicam que a simulação no contexto da mineração significa imitação de condições. No que se refere especificamente à estimativa, geralmente envolve a tentativa de criar uma matriz de valores que apresentam as mesmas características 
estatísticas e espaciais. Entretanto, os valores são gerados em uma escala muito mais local do que aquela para a qual a informação verdadeira está disponível. A simulação não é uma estimativa, é um conjunto bi ou tridimensional de valores com a mesma natureza estatística que os dados originais.

Os mesmos autores discorrem que é importante perceber por que as simulações são necessárias quando existem dados e estimativas. As flutuações locais verdadeiras na distribuição espacial são suavizadas pela maioria dos métodos de estimativa, de modo que estas estimativas não refletem as variações locais. Matrizes de valores simulados são construídas para variar na mesma escala que as variáveis de interesse na amostra. Na estimativa, a preocupação é minimizar a variância do erro, enquanto em simulações, a preocupação é reproduzir a dispersão da variância dos dados reais.

Deutsch e Journel (1998) conceituam a simulação estocástica como o processo para obter alternativas equiprováveis através de realizações conjuntas de variáveis aleatórias dos modelos de funções aleatórias. Estas realizações, normalmente calculadas em malhas regulares, representam imagens possíveis da distribuição espacial. Cada realização, também chamada de imagem estocástica, reflete as propriedades que foram impostas no modelo de função aleatória, portanto, quanto mais propriedades dos dados amostrados forem inferidas e incorporadas às propriedades do modelo de função aleatória ou aos algoritmos de simulação, melhor será o modelo da função aleatória e melhores serão as realizações simuladas.

Segundo Caers (2011), é necessário assumir que a distribuição condicional dos locais não amostrados pode ser representada por uma função de distribuição gaussiana. Isto significa que a distribuição marginal (histograma) da variável a ser simulada é gaussiana, embora raramente aconteça, uma vez que na natureza a maioria dos dados obtidos na amostragem não são gaussianos. Deste modo, deve-se transformá-los para uma distribuição gaussiana.

De acordo com Deutsch e Journel (1998), os erros humanos e de medidas podem ser considerados como eventos ou processos independentes e nas ciências da terra os processos geológicos/biológicos que geraram os fenômenos observados raramente são independentes um do outro. Além disso, se o fenômeno espacial for gerado pela soma de fontes independentes com distribuição espacial similar, então sua distribuição espacial pode ser 
modelada como um modelo de função aleatória multigaussiana. Esta consideração heurística é o suficiente para fazer o modelo gaussiano ser a melhor escolha para modelagem de variáveis contínuas.

O custo da simplicidade matemática da técnica gaussiana é de caráter de máxima entropia, o que implica em desordem espacial máxima, além daquele imposto pela correlação do semivariograma (Journel e Deutsch, 1993). Uma consequência é que não há o potencial para simular caminhos conectados de valores extremos, o que afeta os resultados de simulações de fluxo, por exemplo, outra é que a Simulação Sequencial Gaussiana apresentará menos estruturas espaciais em seus resultados do que um reservatório real (Deutsch, 2002).

\subsubsection{Justificativa da utilização dos métodos de simulação}

A geoestatística tenta solucionar a suavização da krigagem por meio de simulação estocástica. Infelizmente, a simulação é apenas um paliativo, uma vez que se ganha em precisão global, porém se perde em precisão local. Realizações estocásticas não estão livres de erros e interpretações da realidade. Na falta de uma solução perfeita, a escolha entre krigagem e simulação deve ser decidida com base no que é mais relevante para cada aplicação específica: o mínimo erro de estimativa local (precisão local) obtida pela krigagem ou a continuidade espacial correta (precisão global) obtida pela simulação estocástica, que, por sua vez, assume que cada realização é equiprovável e o histograma da amostragem é bom o suficiente para representar o histograma real, ou seja, que a amostragem fornece boa aproximação do real (Olea, 2003).

De acordo com Journel (1980), a produção de minérios em depósitos marginais, ou seja, teores médios baixos e próximos ao teor de corte, exigem melhores taxas de produção, técnicas de processamento mais sofisticadas e investimentos maiores. Por sua vez, os investidores exigem maior precisão no cálculo das massas totais e dos teores e, simultaneamente, a redução dos erros de estimativa e, consequentemente, a melhoria do processamento de minério. As técnicas de simulações condicionais criam modelos numéricos de qualquer depósito. Assim como se pode usar um modelo de avião em um túnel 
de vento para simular o desempenho do voo, modelos de depósitos podem ser utilizados para testar a eficiência das pesquisas ou de processos de mineração.

Em um empreendimento mineiro, os fatores de risco são diversos, entre eles podem ser citadas as condições políticas e sociais, instabilidade do mercado e a quantidade e a qualidade do minério. O conhecimento da análise de sensibilidade dos parâmetros de incerteza é de extrema importância antes de decidir a continuação de um projeto. A análise de sensibilidade considerando apenas o fator econômico normalmente é feita, porém não é o suficiente, pois mesmo que as estimativas de produção sejam boas, elas podem se desviar da realidade. Este desvio pode ser caracterizado através do conceito de variância da estimativa fornecido pela geoestatística. Entretanto, a variância da estimativa é meramente um número e não expressa bem a consequência do possível desvio no projeto. Por isso, a simulação fornece um resultado melhor (Journel, 1980), uma vez que considera todas as possibilidades equiprováveis para estudar os possíveis cenários e calcular a incerteza dos resultados esperados.

Deutsch e Journel (1998) explicam que na maioria dos algoritmos de interpolação, incluindo a krigagem, o objetivo é fornecer a melhor estimativa local de uma variável ou seu padrão de comportamento sem considerar especificamente a estatística espacial das estimativas. Na simulação, a reprodução de características globais e estatísticas (histograma, covariância) tem precedência sobre a precisão local - fornecendo representações globais alternativas cuja reprodução de padrões de continuidade espacial prevalece. Por outro lado, a krigagem fornece um conjunto de representações locais, onde prevalece a precisão local.

A técnica probabilística de simulação condicional fornece diversas realizações possíveis de um depósito, cada uma representa o depósito simulado de maneira similar ao depósito real e apresenta as mesmas características geológicas e geoestatísticas. Algumas das aplicações das simulações condicionais são: estudo da quantidade de amostras para um determinado objetivo e avaliação preliminar de recursos e reservas minerais potenciais em corpos de minério com poucas amostras; estudo de sensibilidade de estimativa de recursoreserva; estudo detalhado da sensibilidade de recuperação de recursos geológicos in-situ, como a unidade mínima de lavra, quantidade de informações futuras, agrupamento dos pacotes ricos e pobres do minério e diluição do minério; seleção do melhor método de lavra e equipamento - devido ao melhor conhecimento da variância espacial do depósito, assim 
como os períodos de maior e menor produção; determinação dos teores de corte e taxas de produção e suas variações no tempo (Journel, 1980). Além disso, pode-se fazer o estudo da continuidade de teores, planejamento de lavra, otimização de processamento e análise de risco financeiro (Sinclair e Blackwell, 2004).

\subsubsection{Simulação Condicional}

Sinclair e Blackwell (2004) explicam que as matrizes de dados simulados que mantêm a mesma distribuição de densidade (histograma) e caráter de autocorrelação que estão ligados espacialmente para reproduzir os dados existentes são chamadas de simulações condicionais. Uma simulação condicional e a realidade podem ser consideradas realizações da mesma função aleatória. Estas simulações são normalmente utilizadas para aplicações que envolvem teores de minério/estéril.

Sinclair e Blackwell (2004) discorrem que as simulações condicionais não podem ser vistas como um processo de estimativa confiável ou aceitável, uma vez que simulação e estimativa têm finalidades diferentes. A simulação permite variações locais de valores da variável a ser examinada, particularmente em relação ao impacto que estas variações locais têm sobre os planos de amostragem, procedimentos de estimativa, planejamento de lavra e questões financeiras. A estimativa, no entanto, é feita para identificar o minério e o estéril numa escala em que a separação física pode ser alcançada.

Segundo Chilès e Delfiner (1999), uma simulação não condicional da função aleatória $\left\{\mathrm{Z}(\mathrm{x}): \mathrm{x} \in \mathrm{R}^{\mathrm{n}}\right\}$ é simplesmente uma realização de $\mathrm{Z}(\mathrm{x})$ selecionada aleatoriamente de um conjunto de todas as possíveis realizações. Sua construção exige conhecimento das distribuições espaciais da função aleatória representada por $Z(x)$. A função aleatória $S(x)$ tem número finito de realizações, quando estas realizações assumem os mesmos valores que os observados nos pontos amostrados, estes podem ser considerados para representar melhor a variável regionalizada $\mathrm{z}(\mathrm{x})$, esta é chamada simulação condicional. Equivalentemente, é uma concretização da função aleatória com distribuição espacial condicional. O fluxograma de toda análise geoestatística, incluindo da simulação condicional, é apresentado na Figura 7. 
Simulações condicionais são qualitativamente úteis para obter figuras reais da variabilidade espacial. Quantitativamente são a ferramenta de escolha para avaliar o impacto da incerteza espacial sobre os resultados de procedimentos complexos, tais como a modelagem de um sistema dinâmico ou a otimização econômica do desenvolvimento de uma fonte natural. O objetivo da simulação condicional, no entanto, não é reproduzir os mecanismos genéticos que geraram o fenômeno observado, mas apenas imitar suas variações espaciais da forma mais realista possível. Os resultados da simulação devem sempre ser vistos com olhar crítico e verificados contra o fundo da aplicação - o que é muito importante quando se estudam problemas como a conectividade, fluxo de fluido ou transporte - que obriga a considerar, de forma explícita ou não, um modelo especificado além de seus momentos de segunda ordem (Chilès e Delfiner, 1999).

Chilès e Delfiner (1999) explicam que a resposta para o número ideal de realizações a serem feitas depende do objetivo e da estrutura do fenômeno. Quando um depósito estacionário for modelado em área muito maior que a busca, apenas uma simulação pode ser o suficiente para representar a variedade de possíveis situações locais. Entretanto, se a área de estudo for não estacionária - como um reservatório de petróleo, por exemplo - uma única realização fornece apenas uma resposta em termos de fluxo e produção. Desta forma, é necessária a simulação de diversas realizações para capturar a gama de possíveis resultados. Se forem feitas 100 realizações de cada simulação da função aleatória, ao invés de uma única, para estimar um momento de segunda ordem numérica, cada simulação da função aleatória levaria ao mesmo resultado, porém com flutuações. É compreensível que as conclusões com relação à conectividade ou ao fluxo de fluido sejam diferentes, especialmente se houver interesse em situações extremas. Para avaliar o alcance dos resultados possíveis é necessário construir várias simulações. Geralmente 100 simulações são consideradas um bom número para esta avaliação, no entanto, isto depende muito dos interesses nos parâmetros de distribuição. Se os dados estiverem enviesados e/ou se houver fundamental atenção aos valores extremos, um maior número de simulações se fará necessário, ressaltando que as previsões de valores extremos geralmente não possuem robustez na estimativa dos valores e que as simulações condicionais não são igualmente prováveis, algumas são extremas e outros estão próximas à média. O número de realizações necessárias depende de quantas realizações são necessárias para modelar a incerteza (Deutsch e Journel, 1998). 

Fluxograma do Estudo Geoestatístico de Variáveis Contínuas

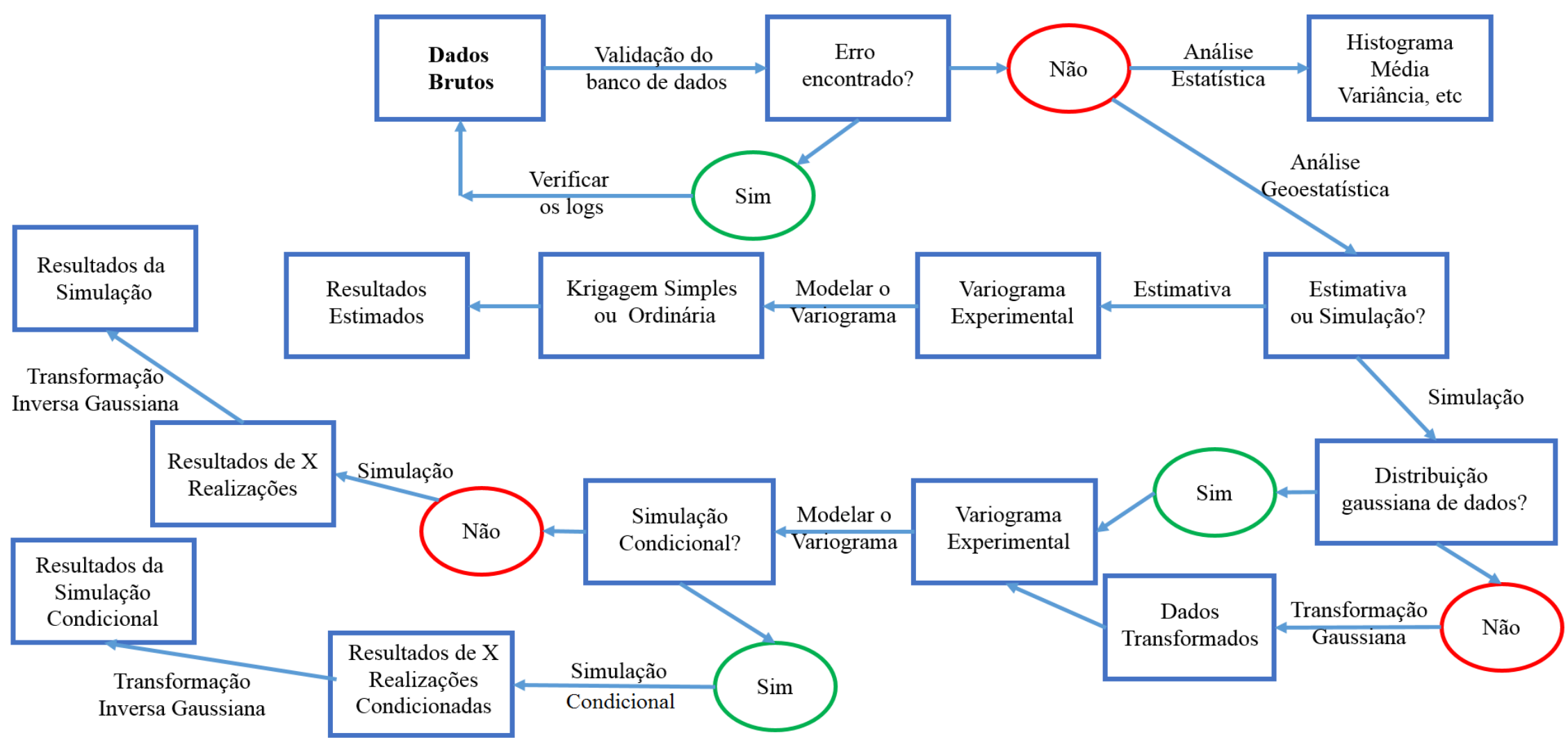

Figura 7 - Fluxograma dos processos da análise geoestatística de variáveis contínuas (Modificado de Chilès e Delfiner, 1999). 



\subsubsection{Simulação Sequencial Gaussiana}

Segundo Deutsch (2002), as propriedades matemáticas que fazem a Simulação Sequencial Gaussiana funcionar não estão limitadas à sua distribuição gaussiana. A reprodução da covariância da krigagem se mantém independente da distribuição dos dados. A correção da variância é por adição de um resíduo aleatório que funciona independentemente da forma da distribuição residual. Há um bom motivo para que esta distribuição seja utilizada: o uso de qualquer outra distribuição não leva a uma distribuição global correta dos valores simulados. A média, a variância e o semivariograma dos dados podem estar corretos, porém, a forma da distribuição não, pois, no espaço gaussiano, todas as distribuições são gaussianas. Além disso, o teorema do limite central diz que a adição sequencial de resíduos aleatórios para obter valores simulados conduz à distribuição gaussiana. Para tanto, utiliza-se a média zero e a variância igual à variância da krigagem.

De acordo com Chilès e Delfiner (1999), deve-se considerar um vetor-valor da variável aleatória $\mathrm{Z}=\left(\mathrm{Z}_{1}, \mathrm{Z}_{2}, \ldots, \mathrm{Z}_{\mathrm{n}}\right)^{\prime}$ para cada realização de um subvetor $\left(\mathrm{Z}_{1}, \mathrm{Z}_{2}, \ldots, \mathrm{Z}_{\mathrm{M}}\right)^{\prime}$, que é conhecido e igual a (z1,Z2,..,ZM). A distribuição do vetor condicionado a $\mathrm{Z}$ em $\mathrm{Z}_{\mathrm{i}}=\mathrm{Zi}, \mathrm{i}=1$, $2, \ldots, \mathrm{M}$, pode ser fatorizado na forma:

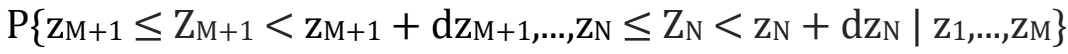

$$
\begin{aligned}
& =\mathrm{P}\left\{\mathrm{ZM}_{\mathrm{M}+1} \leq \mathrm{Z}_{\mathrm{M}+1}<\mathrm{ZM}+1+\mathrm{dz}_{\mathrm{M}+1} \mid \mathrm{Z}_{1}, \ldots, \mathrm{ZM}\right\} \\
& . \mathrm{P}\left\{\mathrm{ZM}_{\mathrm{M}+2} \leq \mathrm{Z}_{\mathrm{M}+2}<\mathrm{ZM}_{\mathrm{M}+2}+\mathrm{dz}_{\mathrm{M}+2} \mid \mathrm{Z}_{1}, \ldots, \mathrm{ZM}_{\mathrm{M}}, \mathrm{ZM}_{\mathrm{M}+1}\right\}
\end{aligned}
$$

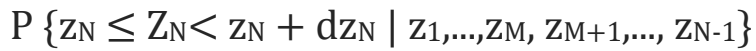

Segundo Chilès e Delfiner (1999), pode-se simular o vetor Z sequencialmente por uma seleção aleatória de $\mathrm{Z}_{\mathrm{i}}$ a partir de uma distribuição condicional $\mathrm{P}\left\{\mathrm{Z}_{\mathrm{i}}<\mathrm{Zi}, \ldots, \mathrm{Zi}-1\right\}$ para i $=\mathrm{M}+1, \ldots, \mathrm{N}$ e incluir o resultado $\mathrm{z}_{\mathrm{i}}$ em um banco de dados condicional para a próxima etapa. Este processo é absolutamente geral e pode ser usado em particular com $Z_{i}$ de forma que $Z_{i}=Z\left(x_{i}\right)$, onde $Z(x)$ é uma função aleatória e $x_{i}$ são pontos amostrados $(i=1,2, \ldots, M)$ e os pontos onde se deseja simular a função aleatória $(i=M+1, \ldots, N)$, o que possibilita a 
construção de uma simulação não condicional $(M=0)$ e uma simulação condicional $(M>$ 0), produzindo simulações que correspondem não apenas à covariância, mas também à distribuição espacial.

A forma de calcular a probabilidade condicional apresentada em (14) é desconhecida, exceto no caso ideal de um vetor gaussiano aleatório, onde o método é normalmente empregado. Para uma função aleatória gaussiana com média conhecida, a distribuição condicional de $\mathrm{Z}_{\mathrm{i}}$ é Gaussiana com média $\mathrm{Z}_{\mathrm{i}}^{*}$ e variância $\sigma^{2} \mathrm{ki}$, onde $\mathrm{Z}^{*} \mathrm{i}$ é o estimador krigagem simples de $Z_{i}$ de $\left\{Z_{j}: j<i\right\}$, e $\sigma^{2}$ ki associado à variância de krigagem (Chilès e Delfiner, 1999).

Chilès e Delfiner (1999) explicam que para realizar uma simulação estocástica condicional, deve-se considerar uma função aleatória $\mathrm{Z}(\mathrm{x})$ conhecida com $\mathrm{N}$ amostras $\mathrm{x}_{\mathrm{i}}, \mathrm{i}$ $=1,2, \ldots, N$. A simulação não condicional $S(x)$ é independente de $Z(x)$, porém tem a mesma covariância de $\mathrm{Z}(\mathrm{x})$. Para condicionar esta simulação é necessário fixar os pontos amostrados, esta operação passa o $\mathrm{S}(\mathrm{x})$ para $\mathrm{T}(\mathrm{x})$.

Considere $\mathrm{Z}^{*}(\mathrm{x})$ como o estimador da krigagem de $\mathrm{Z}(\mathrm{x})$ no ponto $\mathrm{x}$, baseado nos dados $\mathrm{Z}\left(\mathrm{x}_{0}\right)$ :

$$
\mathrm{Z}(\mathrm{x}) \quad=\quad \mathrm{Z}^{*}(\mathrm{x})+\left[\mathrm{Z}(\mathrm{x})-\mathrm{Z}^{*}(\mathrm{x})\right]
$$

Valor verdadeiro $=$ estimador da krigagem + erro da krigagem

O erro da krigagem não é conhecido uma vez que $\mathrm{Z}(\mathrm{x})$ é desconhecido. Então, considere a igualdade para $\mathrm{S}(\mathrm{x})$, onde $\mathrm{S}^{*}(\mathrm{x})$ é o estimador da krigagem obtido como se a simulação fosse conhecida apenas no ponto $\mathrm{x}_{0}$ (Chilès e Delfiner, 1999).

$$
S(x)=S^{*}(x)+\left[S(x)-S^{*}(x)\right]
$$

$\mathrm{O}$ valor verdadeiro de $\mathrm{S}(\mathrm{x})$ é conhecido e, consequentemente, seu erro $\mathrm{S}(\mathrm{x})-\mathrm{S}^{*}(\mathrm{x})$. Com a decomposição de $\mathrm{Z}(\mathrm{x})$, o erro desconhecido - pela simulação deste erro - gera a simulação condicional T(x) definida por Chilès e Delfiner (1999):

$$
\mathrm{T}(\mathrm{x}) \quad=\mathrm{Z}^{*}(\mathrm{x})+\left[\mathrm{S}(\mathrm{x})-\mathrm{S}^{*}(\mathrm{x})\right]
$$

Simulação condicional $=$ estimador da krigagem + erro da krigagem simulado 
De acordo com Deutsch e Journel (1998), a função densidade acumulada condicional da variável regionalizada $\mathrm{Z}(\mathrm{x})$ que modela a incerteza de valores não amostrados é caracterizada pela esperança condicional (média) e sua variância, considerando que a distribuição dos $\mathrm{N}$ dados $\mathrm{z}(\mathrm{x})$ é gaussiana normal:

A esperança condicional (média) é o estimador da krigagem simples:

$$
\begin{aligned}
& \mathrm{E}\left\{\mathrm{Z}\left(\mathrm{x}_{0}\right) \mid \mathrm{z}\left(\mathrm{x}_{\mathrm{i}}\right)=\mathrm{zi}_{\mathrm{i}} \mathrm{i}=1, \ldots, \mathrm{N}\right\} \sim\left[\mathrm{z}^{*}\left(\mathrm{x}_{0}\right)\right] \\
& {\left[\mathrm{z}^{*}\left(\mathrm{x}_{0}\right)\right]=\mathrm{m}\left(\mathrm{x}_{0}\right)+\sum_{i=1}^{N} \lambda_{\mathrm{i}}\left[\mathrm{Zi}_{\mathrm{i}}-\mathrm{m}\left(\mathrm{x}_{\mathrm{i}}\right)\right]}
\end{aligned}
$$

Onde $\mathrm{m}(\mathrm{x})$ é $\mathrm{E}[\mathrm{Z}(\mathrm{x})]$ o valor esperado da variável aleatória $\mathrm{Z}(\mathrm{x})$ e os $\mathrm{n}$ pesos são obtidos pela resolução do sistema de krigagem simples.

A variância condicional é a variância da krigagem simples:

$$
\left.\operatorname{Var}\left\{\mathrm{Z}\left(\mathrm{x}_{0}\right) \mid \mathrm{z}\left(\mathrm{x}_{\mathrm{i}}\right)=\mathrm{zi}_{\mathrm{i}} \mathrm{i}=1, \ldots, \mathrm{N}\right)\right\}=\mathrm{C}\left(\mathrm{x}_{0}, \mathrm{x}_{\mathrm{i}}\right)-\sum_{i=1}^{N} \lambda_{\mathrm{i}} \mathrm{C}\left(\mathrm{x}_{0}, \mathrm{x}_{\mathrm{i}}\right)
$$

Chilès e Delfiner (1999) conceituam que como a krigagem é um interpolador exato, no ponto onde se tem $\mathrm{Z}^{*}\left(\mathrm{x}_{0}\right)=\mathrm{Z}\left(\mathrm{x}_{0}\right)$ e $\mathrm{S}^{*}\left(\mathrm{x}_{0}\right)=\mathrm{S}\left(\mathrm{x}_{0}\right)$, então $\mathrm{T}^{*}\left(\mathrm{x}_{0}\right)=\mathrm{T}\left(\mathrm{x}_{0}\right)$. A prova que $\mathrm{T}(\mathrm{x})$ preserva a covariância regionalizada de $\mathrm{Z}(\mathrm{x})$ e $\mathrm{S}(\mathrm{x})$, no caso da krigagem simples, é obvia, uma vez que $\mathrm{Z}(\mathrm{x})-\mathrm{Z}^{*}(\mathrm{x})$ não é correlacionado com $\mathrm{Z}^{*}\left(\mathrm{x}^{\prime}\right)$ para todo $\mathrm{x}^{\prime}$, como:

$$
\operatorname{Cov}\left(\mathrm{Z}(\mathrm{x}), \mathrm{Z}\left(\mathrm{x}^{\prime}\right)\right)=\operatorname{Cov}\left(\mathrm{Z}^{*}(\mathrm{x}), \mathrm{Z}^{*}\left(\mathrm{x}^{\prime}\right)\right)+\operatorname{Cov}\left(\mathrm{Z}(\mathrm{x})-\mathrm{Z}^{*}(\mathrm{x}), \mathrm{Z}^{*}\left(\mathrm{x}^{\prime}\right)-\mathrm{Z}^{*}\left(\mathrm{x}^{\prime}\right)\right)
$$

Desde que S e Z sejam independentes, a covariância de T é a soma da covariância de $\mathrm{Z}^{*}$ e de $\mathrm{S}-\mathrm{S}^{*}$, que se iguala da $\mathrm{Z}-\mathrm{Z}^{*}$. Consequentemente:

$$
\operatorname{Cov}\left(\mathrm{T}(\mathrm{x}), \mathrm{T}\left(\mathrm{x}^{\prime}\right)\right)=\operatorname{Cov}\left(\mathrm{Z}(\mathrm{x}), \mathrm{Z}\left(\mathrm{x}^{\prime}\right)\right)
$$

Chilès e Delfiner (1999) mostram que a média de uma grande quantidade de simulações condicionais independentes em um determinado ponto tende ao valor estimado pela krigagem e sua variância tende a variância de krigagem. Em termos figurativos, a simulação condicional vibra entre os dados em um envoltório definido pelo desvio padrão da krigagem. É esperado que a simulação condicional se comportasse como o campo real, mas sem estimá-lo. Ainda em termos figurativos, a simulação T(x), como um estimador de $\mathrm{Z}(\mathrm{x})$, irá se comportar muito mal, com sua variância sendo o dobro da variância de krigagem: 
$T(x)-Z(x)=\left[Z^{*}(x)-Z(x)\right]+\left[S(x)-S^{*}(x)\right]$

E seu momento de segunda ordem:

$\mathrm{E}[\mathrm{T}(\mathrm{x})-\mathrm{Z}(\mathrm{x})]^{2}=2 \sigma^{2} \mathrm{k}(\mathrm{x})$

Segundo Chilès e Delfiner (1999) a prova que a substituição dos erros preserva a covariância é válida para a krigagem (ou cokrigagem) com vizinhança global. Se o número de dados é muito alto, é necessário utilizar a vizinhança local. Um projeto cuidadoso do algoritmo de vizinhança de busca é necessário para evitar a introdução de descontinuidades falsas devido a mudanças de vizinhança, uma vez que estas descontinuidades não são facilmente diferenciadas pela instabilidade normal das simulações.

\subsubsection{Algoritmo da Simulação Sequencial Gaussiana}

Remy, Boucher e Wu (2011) descrevem que o algoritmo de Simulação Sequencial Gaussiana utiliza o formalismo da simulação sequencial para simular uma função gaussiana e, para isto, é requisito fornecer o modelo do semivariograma dos dados transformados em uma Gaussiana Normal (N[0,1]), e não dos dados originais, isto garante a reprodução do modelo com flutuações ergóticas nos resultados da simulação. Como os resultados estão no espaço gaussiano, é necessário transformá-los de volta ao espaço original após a simulação. Ainda segundo Remy, Boucher e Wu (2011), para determinar a função densidade acumulada condicional em cada nó da malha, o algoritmo pode ser aplicado com a utilização da krigagem simples, krigagem originária, krigagem com média local ou krigagem de tendência. Porém, a teoria garante a reprodução do semivariograma apenas quando a krigagem simples é utilizada.

De acordo com Deutsch e Journel (1998), cada variável é simulada sequencialmente de acordo com sua função densidade acumulada condicional, caracterizada através de um sistema de krigagem simples. Os dados condicionantes são todos os dados originais e os valores previamente simulados encontrados dentro da vizinhança do local a ser simulado. A simulação condicional de uma variável contínua $\mathrm{Z}(\mathrm{x})$ apresenta as seguintes etapas: 
1. Determinar a função densidade acumulada da variável $\mathrm{Z}(\mathrm{x})$ que represente toda a área de estudo e não apenas a amostragem "x" disponível;

2. Usar a função densidade acumulada da variável $\mathrm{Z}(\mathrm{x})$ para realizar a transformação normal dos dados " $\mathrm{x}$ " para " $y$ " com a função densidade acumulada normal;

3. Checar a normalidade bivariada dos dados " $y$ " normalizados. Se o modelo multigaussino não puder ser retido, então considerar modelos alternativos como a mistura gaussiana de populações ou um algoritmo baseado em indicadores para a simulação estocástica;

4. Se o modelo da função aleatória multigaussiana puder ser adotado para variável "y":

4.1 - Definir um caminho aleatório que visite cada nó da malha apenas uma vez. Em cada nó x, reter um número específico de dados condicionantes na vizinhança, incluindo os dados e os valores previamente simulados;

4.2 - Usar a krigagem simples com o modelo de semivariograma normalizado para determinar os parâmetros (média e variância) da função densidade acumulada da variável aleatória "Y(X)" no local "X";

4.3 - Obter um valor simulado $\mathrm{y}^{(\mathrm{l})}(\mathrm{x})$ da função densidade acumulada condicional;

4.4 - Adicionar o valor simulado $\mathrm{y}^{(\mathrm{l})}(\mathrm{x})$ ao banco de dados;

4.5 - Ir ao próximo nó e repetir o procedimento, até que todos os nós tenham sido simulados.

5. Transformação inversa dos valores gaussianos simulados $\left\{\mathrm{y}^{(1)}(\mathrm{x}), \mathrm{x} \in \mathrm{A}\right\}$ em valores simulados da variável original $\left\{\mathrm{y}^{(\mathrm{l})}(\mathrm{x})=\varphi^{-1}\left(\mathrm{y}^{(\mathrm{l})}(\mathrm{x})\right), \mathrm{x} \in \mathrm{A}\right\}$.

Se múltiplas realizações forem desejadas $\left\{\mathrm{y}^{(\mathrm{l})}(\mathrm{x}), \mathrm{x} \in \mathrm{A}\right\}, \mathrm{l}=1, \ldots, \mathrm{L}$, as etapas descritas devem ser repetidas $\mathrm{L}$ vezes com um caminho aleatório diferente para cada realização. A sequência da configuração dos dados é diferente, assim, diferentes sistemas de krigagem simples devem ser criados e resolvidos (Deutsch e Journel, 1998).

Em teoria, os nós a serem simulados podem ser visitados em qualquer sequência, contanto que todos os dados originais e os dados previamente simulados sejam utilizados 
para criar as funções densidade acumuladas condicionais. Entretanto, como apenas os dados dentro da vizinhança de busca são utilizados, continuidades artificiais podem ser geradas ao longo do caminho aleatório de visita dos nós se a vizinhança não for escolhida adequadamente (Goovaerts, 1997).

\subsubsection{Transformação gaussiana normal}

Deutsch e Journel (1998) explicam que a primeira condição necessária para a estacionariedade da função aleatória $\mathrm{Y}(\mathrm{x})$ ser multigaussiana é que sua função densidade acumulada seja normal.

$$
\operatorname{Prob}\{\mathrm{Y}(\mathrm{x}) \leq \mathrm{y}\}=\mathrm{G}(\mathrm{y}), \forall \mathrm{y}
$$

Onde $\mathrm{G}(\cdot)$ é a função densidade acumulada gaussiana normal e $\mathrm{Y}(\mathrm{x})$ é a variável a ser normalizada. A variável é normal se a média for zero e a variância um. Infelizmente, a maioria dos dados nas ciências da terra não apresenta simetria gaussiana nos histogramas. Porém, isto não é um problema, uma vez que a transformação não linear pode transformar qualquer função densidade acumulada contínua em outra função densidade acumulada, desde que $\mathrm{Z}(\mathrm{x})$ seja multigaussiana.

Sejam $\mathrm{Z}$ e $\mathrm{Y}$ duas variáveis aleatórias com as funções densidades acumuladas $\mathrm{F}_{\mathrm{z}}(\mathrm{z})$ e $F_{y}(y)$ respectivamente. A transformação $Y=\varphi(Z)$ identifica a probabilidade acumulada correspondente aos p quantis de $\mathrm{Z}$ e $\mathrm{Y}$.

$$
\begin{aligned}
& F_{Y}\left(y_{p}\right)=F_{Z}\left(z_{p}\right)=p, \forall p \in[0,1] \\
& \text { consequentemente: } \\
& y=F_{Y}^{-1}\left(F_{Z}(z)\right)
\end{aligned}
$$

com $\mathrm{FY}^{-1}(\cdot)$ sendo o inverso da função densidade acumulada ou função quantil da variável aleatória Y:

$$
\mathrm{y}_{\mathrm{p}}=\mathrm{FY}^{-1}(\mathrm{p}), \forall \mathrm{p} \in[0,1]
$$


Se Y apresenta uma distribuição normal padrão com a função densidade acumulada $\mathrm{Fy}(\mathrm{y})=\mathrm{G}(\mathrm{y})$, a transformação $\mathrm{G}^{-1}(\mathrm{Fz}(\cdot))$ é a transformação normal score.

Na prática, os $\mathrm{n}$ dados amostrais z são ordenados de forma crescente. A frequência acumulada correspondente ao k-ésimo maior valor de $\mathrm{z}$ é $\mathrm{F}_{\mathrm{z}}\left(\mathrm{z}^{(\mathrm{k})}\right)=\mathrm{k} / \mathrm{n}$. Então a transformação normal de $\mathrm{z}^{(\mathrm{k})}$ é o $\mathrm{k} / \mathrm{n}$ quantil de uma função densidade acumulada normal padrão $\mathrm{y}^{(\mathrm{k})}=\mathrm{G}^{-1}\left(\frac{k}{n}\right)$.

\subsection{Método de Simulação de Multipontos (MPS)}

Caers e Zhang (2002) explicam que a geoestatística tradicional baseada em semivariogramas é inadequada, uma vez que o semivariograma é muito limitado para capturar a heterogeneidade geológica dos dados, já a técnica intitulada de multipontos não utiliza o semivariograma, mas sim estruturas denominadas imagens de treinamento. As imagens de treinamento podem representar estruturas geológicas complexas e curvilíneas como regiões com muitas dobras e falhas ou simplesmente canais meandrantes - melhor que os métodos geoestatísticos baseados em semivariogramas, que não capturam matematicamente esta complexidade. A estatística de multipontos empresta os padrões das imagens de treinamento e os coloca nos resultados estocásticos simulados. No entanto, este método utiliza dos mesmos princípios da geoestatística tradicional baseada em semivariogramas, portanto baseia-se na estacionariedade e ergodicidade que muitas vezes são esquecidos. Estes princípios estabelecem que a imagem de treinamento utilizada nas técnicas de multipontos não pode ser escolhida arbitrariamente e, ainda, que nem todas as informações geram imagens adequadas.

Ainda de acordo com Caers e Zhang (2002), os algoritmos para qualquer tipo de estimativa ou simulação geoestatística exigem que a estacionariedade de segunda ordem (momento estatístico de segunda ordem ou variância) seja assumida, uma vez que se baseiam no fato de que a mesma função pode ser aplicada e repetida em cada célula da malha. A população amostrada é muitas vezes referida como a zona de estacionaridade, ou seja, uma região que permite a partilha de informação em conjunto. Tal decisão não é relevante apenas para as estatísticas, como histogramas, mas também para as estatísticas de mais alta-ordem, 
como assimetria (momento de terceira ordem), curtose (momento de quarta-ordem) e assim por diante. De acordo com Magalhães (2011), o momento de variáveis aleatórias é definido por $\mathrm{E}\left[\mathrm{X}^{\mathrm{k}}\right]$, para $\mathrm{k}=1,2, \ldots, \mathrm{K}$, sendo a ordem do momento da variável $\mathrm{X}$, desde que essa quantidade exista. Se $\mathrm{E}[\mathrm{X}]=\mu<\infty$, definimos o momento central de ordem $\mathrm{k}$ por $\mathrm{E}[(\mathrm{X}-$ $\mu)^{\mathrm{k}}$, sempre que essa quantidade exista. De modo similar, o momento absoluto de ordem $\mathrm{k}$ da variável aleatória $\mathrm{X}$ é definido por $\mathrm{E}\left[|\mathrm{X}|^{\mathrm{k}}\right]$.

Caers e Zhang (2002) explicam que na geoestatística tradicional, a prática recomenda não utilizar as informações geradas por passos além do campo geométrico, uma vez que não são confiáveis. Neste caso, considerações semelhantes terão que ser feitas para o uso da estatística de multipontos. Algoritmos de simulação geoestatística reproduzem as estatísticas de entrada, como o semivariograma e o histograma - sob certas "oscilações de ergodicidade". A simulação de um domínio densamente amostrado resultará em estatísticas de uma realização que correspondem exatamente às estatísticas do modelo. Entretanto, quando a simulação é feita em um domínio finito, algumas estatísticas têm variações menores do que outras. Sendo assim, a ergodicidade desempenha um papel importante tanto na estimativa dos parâmetros do modelo quanto em sua simulação (Caers e Zhang, 2002).

Segundo Journel e Zhang (2006), a estatística de multipontos vai muito além da estatística convencional (histograma) e da estatística de dois pontos (covariograma). Ela pode simular realizações com alta entropia - regiões de geologia complexa e alta heterogeneidade geológica e de teores - enquanto oferece flexibilidade em considerar diversas imagens de treinamento alternativas com vários níveis de estruturas geológicas mais simples, ou seja, de baixa entropia.

Entre os principais algoritmos de multipontos estão: ENESIM (Extended Normal Equation Simulation), SNESIM (Single Normal Equation Simulation), FILTERSIM (Filterbased Simulation), SIMPAT (Simulation with Patterns), DISTPAT (Distance-based Pattern Simulator), WAVESIM (Wavelet-based Simulation) e HOSIM (High-Order Simulation). Atualmente os mais utilizados são os SNESIM e o FILTERSIM, disponíveis no programa SGeMS.

Para Chatterjee, Dimitrakopoulos e Mustapha (2012), a simulação de variáveis contínuas ou categóricas espacialmente correlacionadas - como unidades geológicas e teores de elementos químicos de depósitos minerais, ou fácies sedimentares e atributos pertinentes 
de reservatórios de petróleo e aquíferos - é uma tarefa desafiadora. As bem conhecidas técnicas baseadas em semivariogramas (estatística de dois pontos) são limitadas em modelar adequadamente espaços complexos e, para resolver esta limitação, uma técnica de estatística de alta-ordem tem sido desenvolvida na forma de modelos de múltiplos pontos.

O principal objetivo dos métodos de simulação de multipontos é achar o melhor padrão de um banco de dados de padrões considerando as amostras condicionantes. O primeiro algoritmo de multipontos foi apresentado por Guardiano e Srivastava (1993) e a técnica se chama ENESIM. Durante a simulação, os dados condicionantes são comparados com os padrões da imagem de treinamento. O algoritmo SNESIM apresentado por Strebelle (2002) gera uma árvore de busca dos padrões da imagem de treinamento e modela a função densidade acumulada condicional dos padrões. Este algoritmo procura por uma réplica exata dos dados condicionantes e, como nem sempre a réplica exata pode ser encontrada no banco de padrões, alguns dados condicionantes não são utilizados.

O algoritmo SIMPAT - proposto por Arpat e Caers (2005) - considera a imagem de treinamento como uma coleção de padrões, onde um padrão pode ser selecionado para corresponder localmente o mais próximo possível dos dados condicionantes. A principal vantagem do algoritmo é que nenhum dado condicionante é desconsiderado. Por outro lado, a maior limitação deste algoritmo é que o banco de padrões inteiro é analisado para encontrar o melhor padrão correspondente a um determinado nó, por isso o tempo computacional é extremamente alto.

O algoritmo FILTERSIM apresentado por Zhang, Switzer e Journel (2006) tem como maior vantagem o fato de não excluir nenhum ponto condicional para corresponder a um padrão do banco de padrões. Diferentes filtros são aplicados para obter valores de filtros de contagem. Os padrões, por sua vez, são agrupados baseados em seus filtros de contagem e colocados em classes diferentes. Cada classe é representada pelo seu respectivo protótipo, que é o valor médio de todos os padrões nesta classe. Durante a simulação, os dados condicionantes são comparados com as classes e é encontrado o protótipo mais próximo. Diferentemente do SIMPAT, o FILTERSIM não procura no banco de padrões inteiro, pois ele não está procurando o correspondente exato e sim o melhor correspondente.

Em 2010, Honarkhah e Caers apresentaram o algoritmo de simulação baseado na distância (DISTPAT) para melhorar a eficiência das classificações de padrões, os resultados 
mostraram que esta simulação tem atuação melhor que a do FILTERSIM. Como em todas estas simulações baseadas em padrões, o padrão é desenhado aleatoriamente na classe. Não há a geração da função densidade acumulada condicional para cada classe como visto no SNESIM. O sucesso da técnica depende do quão bem os padrões são classificados, uma vez que o padrão obtido é aleatório na classe que melhor a corresponde e nenhuma estatística está envolvida nisto.

Outra abordagem da simulação de multipontos foi proposta por Dimitrakopoulos, Mustapha e Gloaguen (2010) e consiste em uma técnica baseada em cumulantes espaciais que são combinações de momentos de alta ordem de multipontos. A Figura 8 (a) mostra a coleta da estatística espacial de dois pontos (variograma), portanto, é baseada apenas em uma direção para o cálculo da variância espacial. Enquanto a estatística de alta ordem utiliza diversas direções e distâncias para capturar variância espacial da distribuição espacial. No caso da Figura 8 (b) a variância espacial utilizou duas direções e duas distâncias distintas e esta é uma estatística de três pontos.

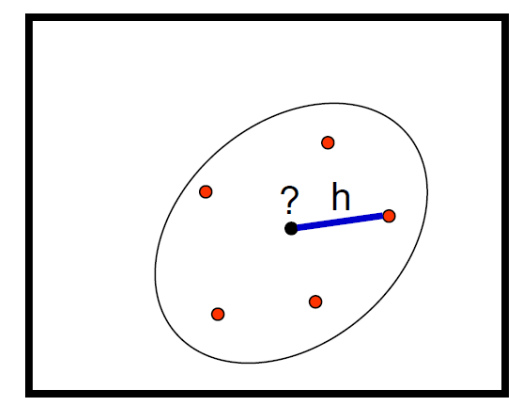

(a) Estatística de dois pontos

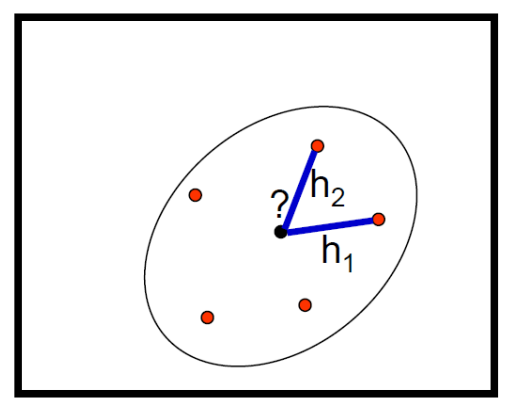

(b) Estatística de três pontos

Figura 8 - Ilustração de como funciona a estatística de dois pontos e de três pontos ((I) MachucaMory e Dimitrakopoulos, 2013) .

Neste método, a função densidade acumulada condicional é gerada por polinômios de Legendre, que, por sua vez, são calculados utilizando mapas de cumulantes gerados a

I Machuca-Mory D. F. e Dimitrakopoulos R., 2013, Notas das aulas da disciplina Stochastic Orebody Modelling (MIME 525) da McGill University 
partir das imagens de treinamento. Esta técnica é voltada para os dados e não para a imagem de treinamento e reproduz a estatística espacial de alta ordem dos dados. O número de coeficientes na série varia com respeito ao número de amostras utilizadas para calcular o valor em um determinado ponto e a ordem da série (Mustapha et al., 2013).

Uma técnica diferente de simulação condicional apresentada por Gloaguem e Dimitrakopoulos (2009) utiliza a dependência inter-escalar no domínio das wavelets. A vantagem deste método é que a abordagem do condicionamento direto é fácil, embora seja complicado ajustar os dados condicionantes no domínio das wavelets (Chatterjee, Dimitrakopoulos e Mustapha, 2012).

\subsubsection{Imagem de Treinamento}

De acordo com Caers e Zhang (2002) e Journel e Zhang (2006), as imagens de treinamento são, essencialmente, um banco de dados de padrões geológicos a partir do qual as estatísticas de vários pontos - incluindo o semivariograma - podem ser emprestadas. A repetição de padrões deve ser suficiente para estimar ou extrair um conjunto de estatísticas de vários pontos a partir do tamanho da imagem. Este tamanho é exigido sob o princípio de ergodicidade e, juntamente com seu tamanho relativo ao maior padrão a ser reproduzido no modelo, são fatores importantes. Ao estimar os parâmetros de um domínio finito ou ao simular modelos em uma região finita, todas as estatísticas - incluindo estatísticas de multipontos - tendem a oscilar e a se tornar maiores à medida que as distâncias em que estas estatísticas calculadas são maiores. Deve ficar claro que meros modelos de afloramento, fotografias de depósitos ou sistemas de deposição análogos ou até mesmo desenhos simples não podem, necessariamente, ser utilizados como imagens de treinamento se não seguirem esses princípios subjacentes de ergodicidade e estacionaridade.

Lyster, Deutsch e Ortiz (2004) relatam que a imagem de treinamento deve ser considerada inteiramente representativa da área a ser simulada e deve conter todas as suas características geológicas. Para tanto, Caers e Zhang (2002) explicam que a imagem de treinamento substitui o semivariograma como medida de heterogeneidade geológica e é mais intuitiva, uma vez que é possível observar - antes de qualquer simulação ou estimativa geoestatística - quais serão os padrões a serem reproduzidos. É mais fácil recusar uma 
imagem de treinamento baseada em uma inspeção ou interpretação visual da realidade geológica a recusar um modelo semivariograma ou suposição multigaussiana. Depois de encontrada a imagem de treinamento ideal, uma combinação, rotação e modelagem são necessárias e estes procedimentos são similares ao ajuste do modelo teórico de semivariograma.

Ortiz (2003) explica que a reprodução da imagem de treinamento não é o objetivo, mas sim a captura da sua essência e, assim, poder simular um modelo que compartilhe as características multivariadas da distribuição real. A função de distribuição condicional considera a configuração de multipontos na vizinhança e isto é feito pela discretização da função de distribuição condicional em quadros de indicadores. A probabilidade de um local em particular estar abaixo de um limiar é dada pela frequência de sua ocorrência na configuração multipontos na imagem de treinamento. A distribuição multivariada é aproximada pelas frequências extraídas a partir da imagem de treinamento. Se uma configuração multiponto não é encontrada vezes o suficiente para estimar com confiabilidade sua frequência, a busca é reduzida e uma configuração diferente é considerada. Em geral, o objetivo de usar uma imagem de treinamento é a obtenção de modelos que conduzem à melhor tomada de decisão, o que não pode ser expresso diretamente como um conjunto de restrições matemáticas durante o processo de inferir estatísticas de multipontos a partir da imagem de treinamento, por isso são utilizados métodos heurísticos (Ortiz, 2003).

O escaneamento da imagem de treinamento é feito por um modelo previamente definido, como observado no item (a) da Figura 9. Este modelo é o formato de como a busca é realizada ao redor de um ponto central u. Os valores dos pontos ao redor são guardados no banco de dados dos padrões. Então o modelo é deslocado ao nó central vizinho, como pode ser visto na Figura 10 e todo procedimento é repetido. O caminho total do modelo apresentado na Figura 9 é mostrado na parte esquerda da Figura 10 e o resultado guardado no banco de dados de padrões do escaneamento de um modelo bidimensional pode ser observado na parte a direita da mesma figura. 


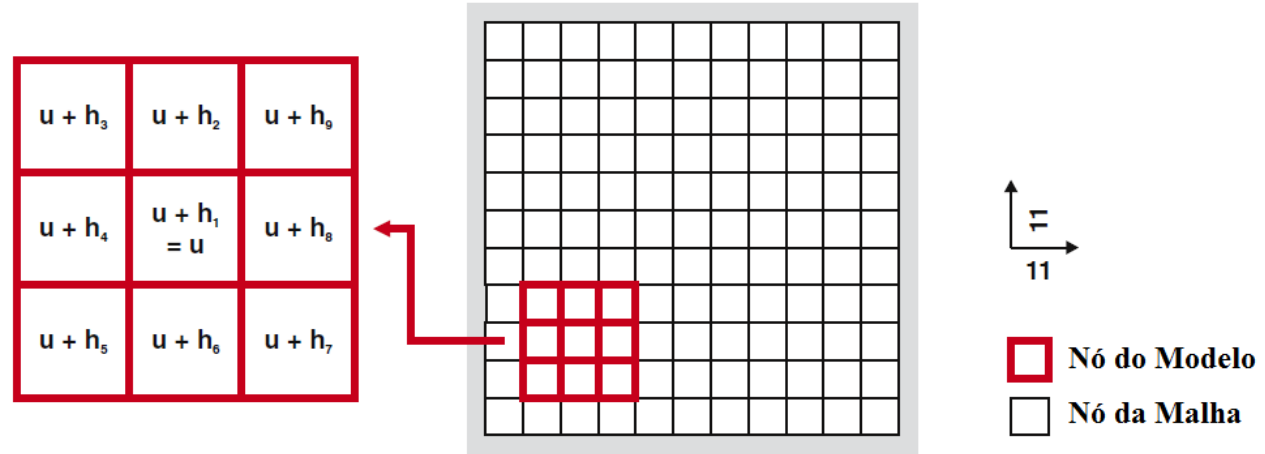

(a) Modelo 2D 3 x 3

(b) Malha 2D 11x11

Figura 9-Definição do modelo, exemplo de um modelo 2D 3x3 numa malha $11 \times 11$ (Arpat e Caers, 2007).
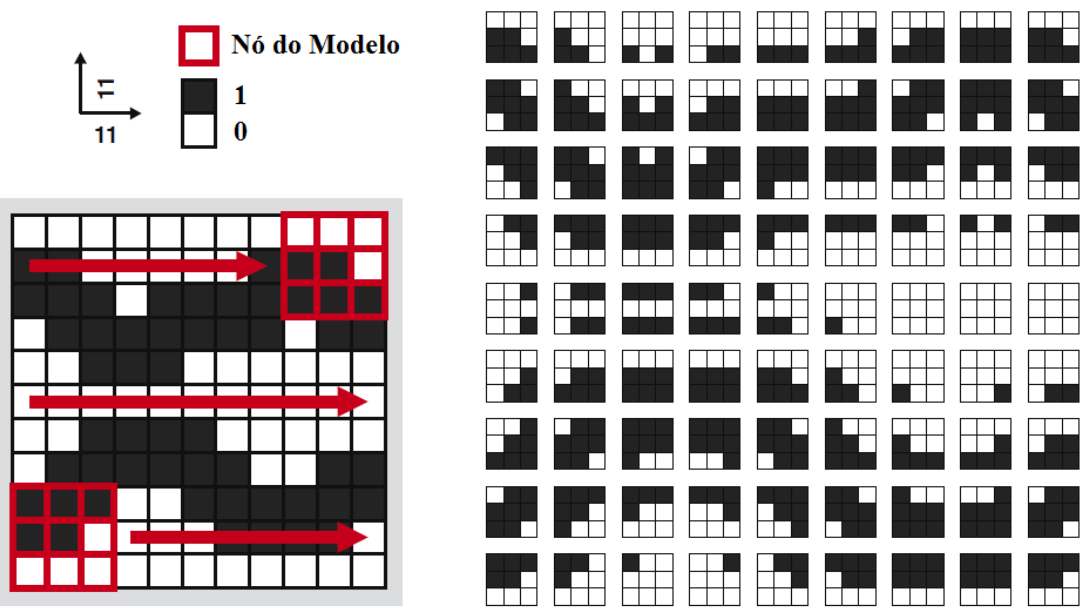

Figura 10 - Exemplo de imagem de treinamento e seus padrões obtidos pelo escaneamento de um mapa onde 0 representa um argilito e 1 arenito (Arpat e Caers, 2007).

\subsubsection{Método de Simulação Baseada em Wavelets (Wavesim)}

Grapes (1995) explica que wavelets são funções matemáticas que cortam os dados em componentes de frequência diferentes, então, estuda-se cada componente com uma resolução associada à sua escala. Eles têm vantagens sobre os métodos tradicionais de Fourier na análise de situações físicas, onde o sinal contém descontinuidades e mudanças bruscas. As wavelets foram desenvolvidas de forma independente no campo da matemática, física quântica, engenharia elétrica e geologia sísmica. Intercâmbios entre estes campos nos últimos dez anos levaram a muitas novas aplicações, como compressão de imagem, 
turbulência, visão humana, radar e previsão de terremotos. A ideia fundamental atrás das wavelets é a análise de acordo com a escala.

Wavelets são funções que satisfazem certos requisitos matemáticos e são usados na representação de dados ou outras funções. Esta ideia não é nova, a aproximação usando superposição de funções existe desde o início de 1800, quando Joseph Fourier descobriu que ele poderia sobrepor senos e cossenos para representar outras funções. No entanto, na análise de wavelets, a escala usada para estudar os dados desempenha papel especial. Os algoritmos de wavelets processam dados em diferentes escalas ou resoluções. Se um sinal for observado com uma "grande janela", serão observáveis recursos brutos. Da mesma forma, em um sinal com a "janela pequena", as pequenas características (detalhes) serão destacadas. Metaforicamente, o resultado na análise de wavelets é como ver a floresta e as árvores. Por muitas décadas os cientistas desejaram funções mais apropriadas que os senos e cossenos, componentes da base da análise de Fourier, para aproximações de sinais com mudanças bruscas. Com a análise de wavelets, podem-se aproximar funções que estão contidas ordenadamente em domínios finitos. As wavelets são muito bem adequadas para aproximar dados com descontinuidades abruptas (Grapes, 1995).

O procedimento de análise wavelet é a adoção de uma função protótipo de wavelet, chamado de função mãe do wavelet. A análise temporal é realizada com uma versão do protótipo de wavelet contraído, de alta frequência, enquanto a análise de frequência é realizada com uma versão dilatada, de baixa frequência, da mesma wavelet, pois, o sinal original ou função pode ser representado em termos de expansão de wavelet (usando coeficientes numa combinação linear das funções de wavelet). As operações de dados podem ser realizadas utilizando apenas os coeficientes de wavelets correspondentes. Se for escolhida a função wavelet que melhor se adapta aos seus dados ou truncar os coeficientes abaixo de um limiar, os dados são representados de forma esparsa, o que torna este algoritmo uma ótima ferramenta para a compressão de dados (Grapes, 1995).

Chatterjee, Dimitrakopoulos e Mustapha (2012) mostram que os algoritmos de simulação de padrões consistem de duas etapas: a primeira é a geração do banco de padrões a partir do escaneamento das imagens de treinamento utilizando um modelo previamente definido e, na segunda, o padrão que melhor corresponde aos dados condicionantes é procurado no banco de padrões. 
Mustapha et al. (2013) discorrem que o método de Simulação Baseada em Wavelets é um método de simulação de multipontos baseado em padrões, que utiliza transformações discretas para representar a heterogeneidade geológica. A classificação de padrões é feita depois de reduzir a dimensão dos padrões pela decomposição de wavelets. A simulação é calculada sequencialmente identificando a classe que melhor corresponde aos dados condicionantes e pela amostragem aleatória do padrão nesta classe. A classe é representada pelo protótipo de classe. Para a simulação, a similaridade do protótipo de classe com os dados condicionantes é calculada e um padrão aleatório é gerado a partir da classe de melhor correspondência.

Chatterjee, Dimitrakopoulos e Mustapha (2012) apresentam o Wavesim como um algoritmo de simulação baseado em padrões utilizando análises de wavelets, alternativo aos outros métodos de simulação de multipontos. $\mathrm{O}$ banco de dados de padrões é feito de maneira semelhante ao de outras técnicas multipontos. Este banco é classificado por coeficientes de sub-bandas aproximadas de wavelets para cada padrão. Esta sub-banda pode capturar a maioria das variabilidades dos padrões e ao mesmo tempo diminuir a dimensão do banco de padrões. A classificação do banco de dados de padrões utiliza a técnica de agrupamento denominada $K$-Means. Para a simulação de dados categóricos, no nó central do modelo, a função densidade acumulada condicional de cada classe é desenvolvida utilizando a probabilidade de cada categoria desta classe. Entretanto, para dados contínuos, seleciona-se uma amostra aleatória da classe que melhor correspondê-la, ou seja, a função densidade acumulada condicional não é calculada.

Segundo Mustapha et al. (2013), uma representação baseada em wavelets é introduzida onde a dimensão das classificações de padrões podem ser reduzidas pela seleção da escala da decomposição por wavelets. O termo escala se refere à resolução ou suporte para qual um dado comprimento de onda da imagem de treinamento é definida.

As principais limitações da técnica de redução dimensional baseada em filtros, segundo Mustapha et al. (2013), são:

(a) É sempre complicado representar um padrão complexo apenas utilizando alguns filtros de valores e não há garantia que estes filtros irão representar adequadamente o padrão. 
(b) O método baseado em filtros não mostra nenhuma prova teórica ou numérica de que a variabilidade dos dados é representada.

De acordo com Chatterjee e Dimitrakopoulos (2011), a análise de wavelets de múltiplas resoluções é feita de acordo com a escala, então a decomposição dos dados em diferentes bancos de dados também é realizada de acordo com sua escala e fornece informações espaciais e de frequência. Um banco de dados bidimensional pode ser considerado uma função quadrática integrável no espaço de Hilbert - que é o espaço Euclidiano formado por vetores complexos de $\mathrm{n}$ dimensões (Duarte, 2003). Devido à sua propriedade de múltiplas resoluções, a função wavelet fornece uma série de funções básicas ortogonais pela escala e deslocada da função base original, que é conhecida como função mãe de wavelets.

Segundo Chatterjee, Dimitrakopoulos e Mustapha (2012), os padrões são extraídos pelo escaneamento das imagens de treinamento com um modelo e então são guardados em um banco de dados de padrões. A redução das dimensões dos padrões no banco de dados de padrões é realizada pela decomposição de wavelets em certa escala e a sub-banda aproximada é utilizada para a classificação destes padrões no banco de dados. Esta classificação é feita pelo algoritmo de agrupamento K-Means e suas classes são representadas por um protótipo. Para a simulação de variáveis categóricas, a função densidade acumulada condicional de cada classe é gerada baseada na frequência das categorias individuais no nó central do modelo. Durante o processo de simulação, a similaridade dos eventos dos dados condicionantes com os protótipos de classes são medidas utilizando o $L_{2}$-norm - que é o ajuste lp (least power), designação genérica dos ajustes nos quais se minimiza a soma dos valores absolutos dos erros elevados ao quadrado, ou seja y = $\sum_{i=1}^{n}\left|\mathrm{r}_{\mathrm{i}}-\mathrm{d}_{\mathrm{i}}\right|^{2}$, onde $\mathrm{r}_{\mathrm{i}}$ representa o resultado obtido e $\mathrm{d}_{\mathrm{i}}$ o resultado correto (Duarte, 2003). Quando as variáveis categóricas são simuladas, a função densidade acumulada condicional da classe mais semelhante é utilizada para sortear os padrões desta classe. Por sua vez, quando variáveis contínuas são simuladas, um padrão aleatório é desenhado a partir da classe selecionada.

De acordo Chatterjee, Dimitrakopoulos e Mustapha (2012), considere ti(u) como o valor da imagem de treinamento ti onde $u \in G_{t i}$ e $G_{t i}$ é uma malha regular cartesiana 
discretizando a imagem de treinamento, $\mathrm{ti}_{\mathrm{T}}(\mathrm{u})$ indica um vetor ti(u) com o modelo $\mathrm{T}$ centrado no nó u, sendo:

$$
\operatorname{ti}_{\mathrm{T}}(\mathrm{u})=\left\{\mathrm{ti}\left(\mathrm{u}+\mathrm{h}_{1}\right), \operatorname{ti}\left(\mathrm{u}+\mathrm{h}_{2}\right), \ldots, \mathrm{ti}\left(\mathrm{u}+\mathrm{h}_{\alpha}\right), \ldots, \mathrm{ti}\left(\mathrm{u}+\mathrm{h}_{\mathrm{nT}}\right)\right\}
$$

onde os vetores $h_{\alpha}$ são os vetores que definem a geometria dos $\mathrm{n}_{\mathrm{T}}$ nós do modelo $\mathrm{T}$ e $\alpha=\left\{1,2, \ldots, \mathrm{n}_{\mathrm{T}}\right\}$. $\mathrm{O}$ vetor $\mathrm{h}_{1}=0$ representa o local central $\mathrm{u}$ do modelo $\mathrm{T}$.

Chatterjee, Dimitrakopoulos e Mustapha (2012) explicam que o banco de padrões é então obtido pelo escaneamento da ti usando o modelo $\mathrm{T}$ e guardado no vetor tiт(u) do banco. Para uma imagem de treinamento categórica com $M$ categorias, a imagem de treinamento primeiramente é transformada em $M$ conjuntos de valores binários $\operatorname{Im}(\mathrm{u}), \mathrm{m}$ $=1, \ldots, \mathrm{M}, \mathrm{u} \in \mathrm{T}$,

$$
\operatorname{Im}(\mathrm{u})=\left\{\begin{array}{l}
1, \text { se u pertencer a } m_{\text {ésima }} \text { categoria } \\
0, \text { caso contrário }
\end{array}\right.
$$

Assim, um padrão de $\mathrm{M}$ categorias pode ser representado como $\mathrm{M}$ conjuntos de padrões binários, onde o m-ésimo padrão binário com valor 1 representa a presença da categoria m e o valor 0 a ausência desta no modelo. Ressalta-se que para imagens de treinamento de variáveis contínuas, nenhuma transformação é feita e o padrão ti exatamente como extraído da imagem de treinamento. O banco de padrões gerado por imagens de treinamento contínuas ou categóricas com $\mathrm{M}$ categorias é definido como patdbT (Chatterjee, Dimitrakopoulos e Mustapha, 2012).

Após gerar o banco de padrões (patdbT), inicia-se a simulação com a classificação do banco de padrões, que é realizada de modo que apenas alguns membros representativos sejam comparados com os dados condicionantes, então não se pesquisa em todo patdbT. Entretanto, quando a dimensão do modelo for grande, o patdbT também será grande. Qualquer padrão no patbdT é representado por 6 x M filtros de valores - para o caso bidimensional - no caso da imagem ser contínua $M=1$. A representação baseada em padrões de wavelets é introduzida onde as dimensões da classificação de padrões pode ser reduzida selecionando a escala da decomposição de wavelets. Esta fornece uma imagem de sub-banda aproximada e três imagens de sub-bandas de alta frequência depois de uma escala de decomposição de uma imagem de treinamento bidimensional (Chatterjee, Dimitrakopoulos e Mustapha, 2012). 
A imagem aproximada é decomposta para obter a próxima escala de imagens de subbandas. A sub-banda aproximada fornece as informações médias sobre a imagem de treinamento e preserva a maioria das informações de variabilidade dos dados da imagem de treinamento. Se as sub-bandas de alta frequência forem adicionadas à sub-banda aproximada, então a imagem de treinamento é perfeitamente reconstruída. A quantidade de dados em uma sub-banda é $2^{\text {j.d }}$ vezes menor que a quantidade de dados na imagem de treinamento, onde j é o número da escala na decomposição de wavelets e d é a dimensão original da imagem. A Figura 11 mostra um exemplo de uma imagem original e sua reconstrução mantendo apenas a imagem da sub-banda aproximada depois da primeira escala de decomposição. Esta figura mostra também que a imagem é bem reconstruída após reduzir 75\% dos dados da imagem original (Chatterjee, Dimitrakopoulos e Mustapha, 2012).

(a) Imagem original

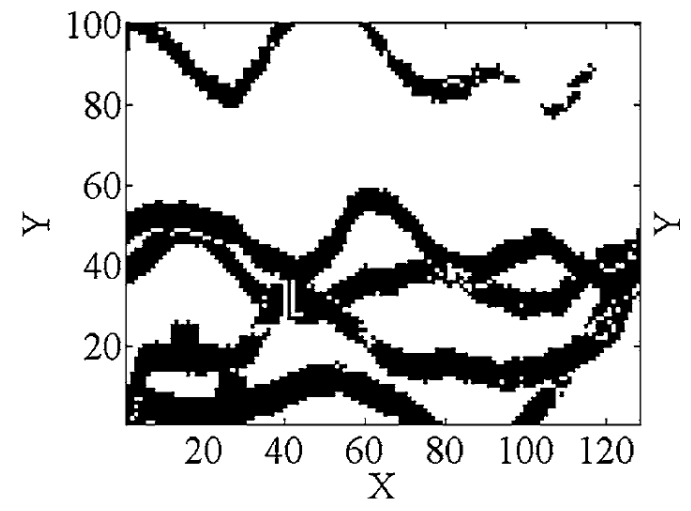

(b) Imagem reconstruída

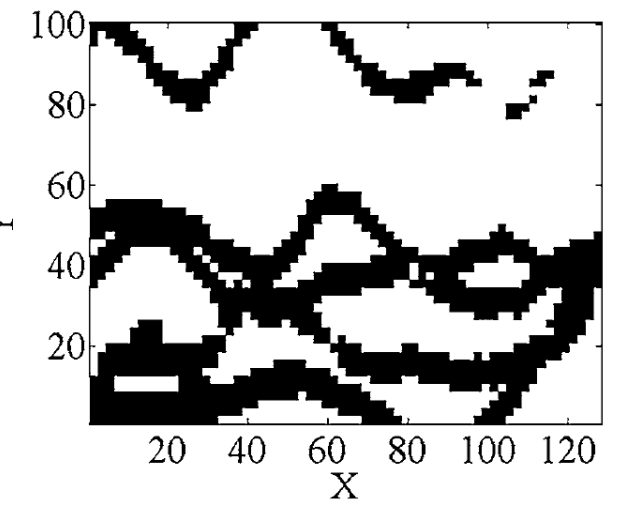

Figura 11 - Comparação entre a imagem original (a) e a reconstruída (b) depois da redução de $75 \%$ dos dados originais (Chatterjee, Dimitrakopoulos e Mustapha, 2012).

Considerando ti $\mathrm{i}_{\mathrm{T}}$ um padrão do patdbT com tamanho $\mathrm{p}$ x p, então se a decomposição de wavelets de um dado padrão é feita, ela pode ser apresentada, segundo Chatterjee, Dimitrakopoulos e Mustapha (2012), como:

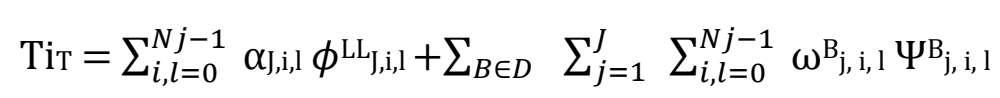

Onde $\mathrm{D}=\{\mathrm{LH}, \mathrm{HL}, \mathrm{HH}\}, \mathrm{N}_{\mathrm{j}}=\mathrm{N} / 2 \mathrm{j}$; J é o número de escalas; L e $\mathrm{H}$ são os filtros passa baixa e passa alta, respectivamente obtidos da função básica da wavelet, $\mathrm{N}=$ p quando $p$ é par, $N=(p+1)$ quando $p$ é ímpar; $\phi_{\mathrm{J}}$ é a função escalar e $\Psi^{\mathrm{B}} \mathrm{J}$ é a função wavelet. Os 
coeficientes da escala e da wavelet $a_{\mathrm{j}-1} \mathrm{e} \omega_{\mathrm{j}-1}$ na escala $j-1$ podem ser calculados experimentalmente pelos produtos:

$$
\begin{aligned}
& a j-1=<t i T, \phi j> \\
& \omega B j-1=<t i, \Psi B j>
\end{aligned}
$$

Cada uma das funções base $\left(\phi_{\mathrm{j}}\right.$ e $\left.\Psi^{\mathrm{B}_{\mathrm{j}}}\right)$ é utilizada para o banco de dados dos coeficientes de imagem de treinamento binária M. Em cada local de pixel, o modelo de valores dos dados vizinhos é torcido por estas funções base para obter os dados da sub-banda aproximada e wavelet para a categoria $\mathrm{m}$. O comprimento do vetor generalizado da subbanda aproximada para as M categorias da imagem, de acordo com Chatterjee, Dimitrakopoulos e Mustapha (2012) é:

$$
\mathrm{LN}=\left(\left(\mathrm{N} / 2^{\mathrm{j}}\right)^{\mathrm{d}} \cdot \mathrm{M}\right)
$$

Onde d é o número de dimensões desta imagem. É observado que o comprimento original do vetor de padrões é $\left((\mathrm{N})^{\mathrm{d}} \mathrm{x} \mathrm{M}\right)$. Entretanto, dependendo do número de escalas $\mathrm{j}$, a dimensão do vetor do padrão original pode ser significantemente reduzida.

Segundo Chatterjee e Dimitrakopoulos (2011), o coeficiente de wavelets exposto no espaço e na frequência é hierárquico em diferentes sub-bandas. A sub-banda é obtida aplicando filtros em imagens bidimensionais na direção x e y. O coeficiente de wavelets é enraizado na estrutura, o que significa que um ponto na escala maior é representado por quatro pontos vizinhos na próxima escala menor, conforme representado na Figura 12. Então, qualquer ponto na escala $\mathrm{j}$ é diretamente relacionado aos quatro pontos vizinhos na escala j-1. A área total coberta por uma imagem de sub-banda em qualquer escala j é a mesma que da imagem original. Entretanto, a área de influência de qualquer ponto ou qualquer sub-banda na escala $\mathrm{j}$ é quatro vezes maior que qualquer ponto na sub-banda na escala j-1. Esta propriedade dos coeficientes de wavelets facilita a modelagem conjunta de dois bancos de dados com diferentes suportes.

Para gerar o banco de dados dos coeficientes de wavelets correspondente ao modelo dos coeficientes da sub-banda aproximada, o tamanho de modelo deve ser definido. Posteriormente, o modelo é utilizado para escanear a sub-banda aproximada da imagem de treinamento. O coeficiente sub-banda aproximada é extraído da imagem de treinamento 
decomposta em wavelets de múltiplas escalas com a janela do modelo e os correspondentes coeficientes do valor central do modelo, como pode ser visto na Figura 12 (Chatterjee e Dimitrakopoulos, 2011).

Uma série de vetores de dados pode ser gerado pelo escaneamento das sub-bandas aproximadas das imagens de treinamento utilizando o modelo, então eles formam um banco de dados de vetores. Para simular os coeficientes de wavelets correspondentes a um ponto particular nas sub-bandas aproximadas simuladas, utiliza-se o mesmo modelo que foi usado para extrair os dados condicionantes da imagem de treinamento, posicionando o centro do modelo sobre o ponto da sub-banda aproximada. Os dados condicionantes serão comparados com o modelo de valores do banco de dados de coeficientes de wavelets (Figura 12) para obter o melhor vetor correspondente. O coeficiente de wavelet correspondente será extraído como os valores do ponto simulado (Chatterjee e Dimitrakopoulos, 2011).

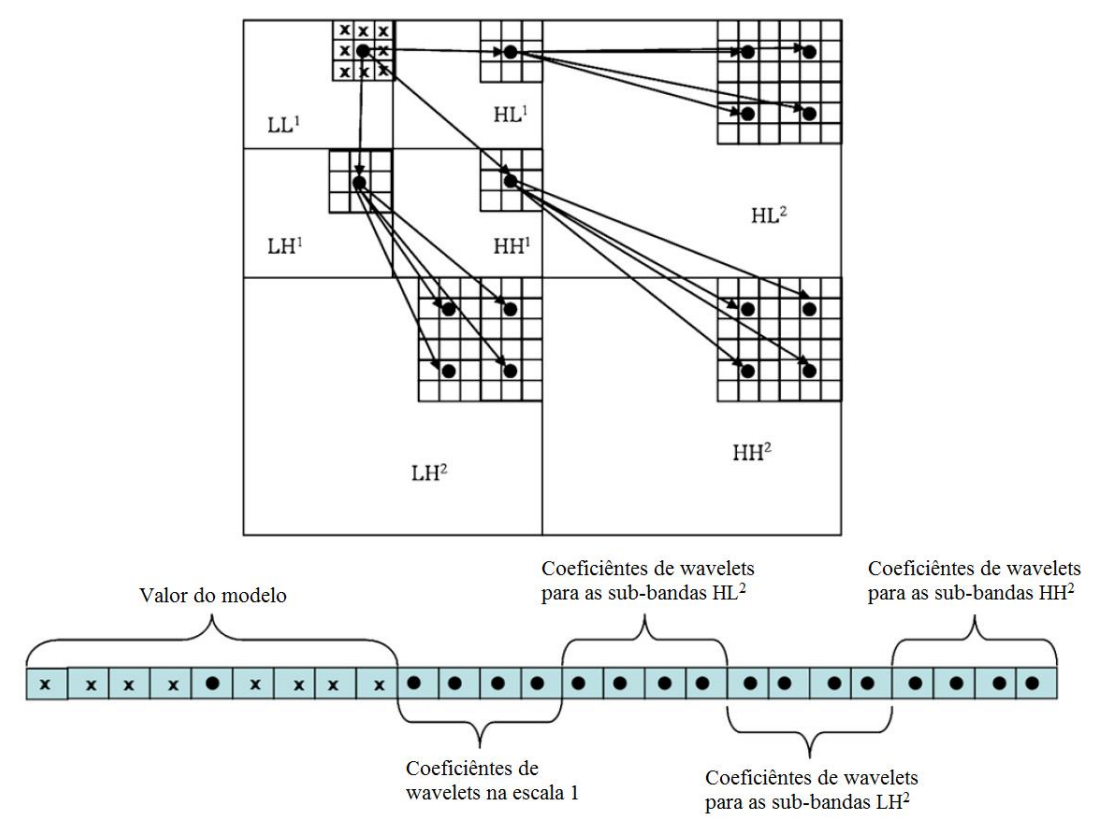

Figura 12 - Estrutura da análise discreta de wavelets de múltiplas resoluções, mostrando a relação entre coeficientes de wavelets de duas escalas e um exemplo de um vetor extrator com um modelo $3 \times 3$ (Chatterjee e Dimitrakopoulos, 2011). 
Um exemplo prático de como são os resultados da decomposição de wavelets é ilustrado na Figura 13, onde a icônica imagem da Lenna é decomposta em 3 escalas e as bandas de cada escala são mostradas ao lado para facilitar a visualização do método.
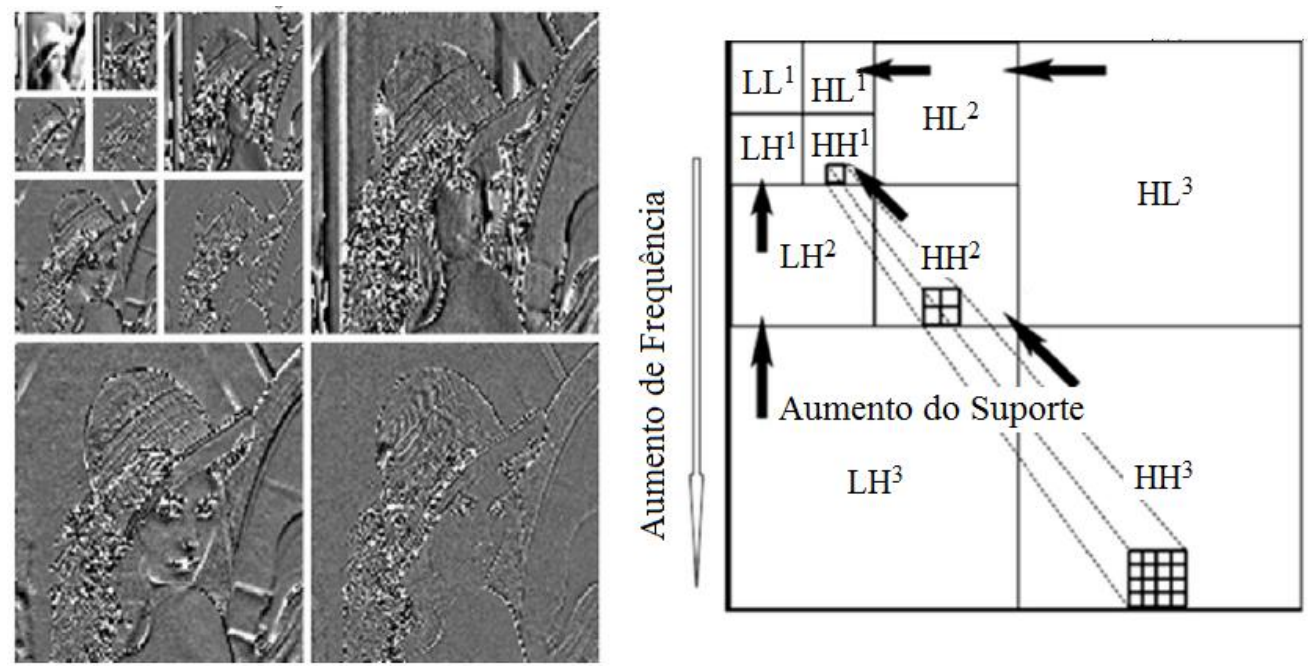

Figura 13 - A esquerda um exemplo de decomposição de wavelets da Lenna (Ouahabi, 2012) e a direita as bandas de cada escala da decomposição (Chatterjee, Mustapha e Dimitrakopoulos, 2015).

Ainda em Chatterjee, Dimitrakopoulos e Mustapha (2012), para a simulação não condicional de uma imagem categórica, a decomposição de wavelets é realizada depois de gerar o banco de padrões a fim de reduzir a dimensão deste banco. O passo crítico da decomposição de wavelets para a redução da dimensão é manter a variabilidade máxima dos dados em poucas dimensões. Na análise de wavelets, a energia é distribuída entre as escalas, no entanto, uma escala ótima deve ser selecionada. Esta escala ocorre quando as características de frequência forem dominantes, quando comparadas com as outras. Para isso, deve-se calcular o valor de entropia da wavelet de cada padrão ti a equação:

$$
\mathrm{E}_{\mathrm{j}}^{\mathrm{ti}}=-\sum_{B \in D} \mathrm{p}^{\mathrm{B}_{\mathrm{j}}} \log \left(\mathrm{p}^{\mathrm{B}_{\mathrm{j}}}\right)
$$

Onde

$$
\mathrm{p}^{\mathrm{B}} \mathrm{j}=\left(\sum_{i, l=0}^{N j-1}\left|\omega^{\mathrm{B}_{\mathrm{j}, \mathrm{i}, \mathrm{l}}}\right|^{2}\right) /\left(\sum_{B \in D} \sum_{i, l=0}^{N j-1}\left|\omega^{\mathrm{B}} \mathrm{j}, \mathrm{i}, \mathrm{l}\right|^{2}\right)
$$

e 


$$
\mathrm{D}=\{L H, H L, H H\} ; \mathrm{N}_{j}=\mathrm{N} / 2^{\mathrm{j}}
$$

Em que j é a escala de decomposição, $\omega^{\mathrm{B}} \mathrm{j}, \mathrm{i}, \mathrm{l}$ é o coeficiente da wavelet na escala $\mathrm{j}$ no local (i, l).

A média da entropia de todos os padrões no banco de padrões é calculada como:

$$
\mathrm{E}_{\mathrm{j}}=\frac{1}{s} \sum_{t i=1}^{s} \mathrm{E}^{\mathrm{t}_{\mathrm{j}}}
$$

Onde s é o número de padrões no banco, o valor da média é comparado pela mudança da escala j e a escala ótima é selecionada onde o valor seja o máximo. O fluxograma do algoritmo de seleção da escala ótima é apresentado na Figura 14. O valor de entropia é calculado inicialmente para escala $\mathrm{j}=1$ e é interrompida quando a escala máxima é atingida, ou seja, a escala máxima ocorre quando não é possível fazer mais a decomposição.

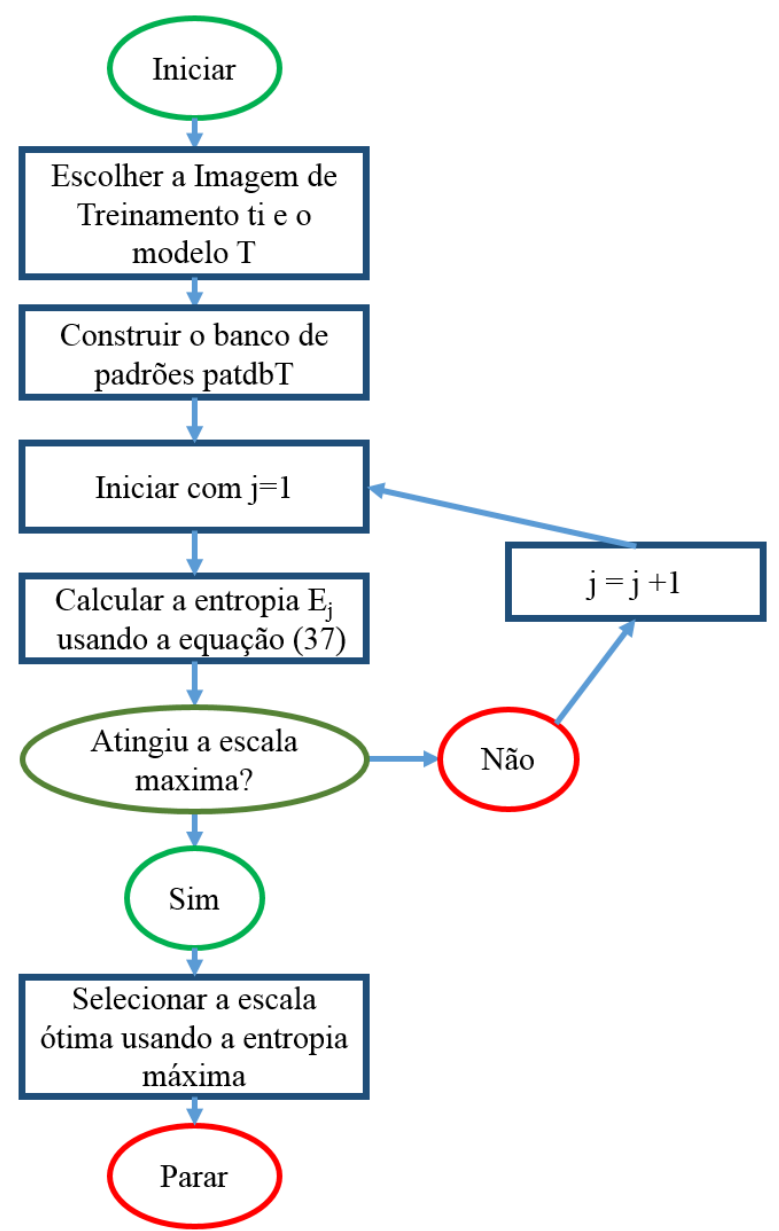

Figura 14 - Fluxograma da escolha para uma escala ótima (Chatterjee, Dimitrakopoulos e Mustapha, 2012). 
Chatterjee, Dimitrakopoulos e Mustapha (2012) explicam que para a classificação do banco de padrões patdbT, a sub-banda aproximada dos padrões é reduzida dependendo do valor de j. Basicamente o patdbT é dividido em um número de classes em que a soma das distâncias entre classes é maximizada. Neste algoritmo, o banco de padrões é classificado baseando-se na seleção de prioridade do número do agrupamento (k). Primeiramente, $\mathrm{k}$ padrões do patdbT são aleatoriamente selecionados, estes $\mathrm{k}$ padrões representam os centroides iniciais das classes. Uma vez que a classificação do patdbT foi feita utilizando sub-banda aproximada dos padrões, uma sub-banda selecionada aleatoriamente de k padrões do patdbT agirá como centroide inicial. Cada padrão do patdbT é atribuído a uma classe com a qual tem a distância mais próxima dos centroides, depois de atribuídos todos os padrões nas classes, a posição dos centroides são recalculadas. Este é um processo iterativo e o algoritmo para quando a posição do centroide não muda mais. $\mathrm{O}$ objetivo do algoritmo de agrupamento K-Means é minimizar a seguinte função objetivo:

$$
\mathrm{J}=\sum_{j=0}^{k} \quad \sum_{i=0}^{n} \quad\left\|\mathrm{t}_{\mathrm{i}}(\mathrm{j})-\mathrm{c}_{\mathrm{j}}\right\|^{2}
$$

Onde $\left\|t_{i}(j)-c_{j}\right\|^{2}$ é a distância quadrática Euclidiana entre o padrão $t_{i}(j)$ e o centroide da classe $c_{j}$ e a medida da distância de $n$ padrões dos seus respectivos centros de agrupamento.

Depois de classificar o patdbT por minimizar a função objetivo (38), as classes são recalculadas. Então são utilizados protótipos durante os processos de simulação, quando a similaridade entre os dados condicionais e a classe é calculada. $\mathrm{O}$ valor do protótipo é obtido calculando a média de todos os padrões que estão em uma determinada classe (Chatterjee, Dimitrakopoulos e Mustapha, 2012).

Chatterjee, Dimitrakopoulos e Mustapha (2012) mostram que o algoritmo de simulação sequencial é utilizado para simulação baseada em padrões. Em cada nó visitado, um evento de dado condicionante é obtido colocando o mesmo modelo da imagem de treinamento, centrado no nó a ser simulado. A similaridade entre o evento dos dados condicionantes e o protótipo de classes é calculada pela função da distância $L_{2}$-norm (quanto menor o valor, melhor é a correspondência):

$$
\mathrm{d}(\mathrm{x}, \mathrm{y})=\sum_{i=1}^{3} \omega_{\mathrm{i}} \cdot\left(\left(1 / \mathrm{n}_{\text {type }}\right) \sum_{j=0}^{\text {Ntype }}(\mathrm{x}(\mathrm{j})-\mathrm{y}(\mathrm{j}))^{2}\right)
$$


$\sum_{i=1}^{3} \omega_{\mathrm{i}}=1$

Onde x são os dados condicionantes; y o protótipo de classe; ntype o número de dados de um tipo particular e $\omega_{\mathrm{i}}$ o peso associado com os tipos de dados. Três diferentes tipos de dados são considerados para a distância calculada: dados amostrados, dados previamente simulados e dados de padrões de nós anteriores. Geralmente os dados amostrados são os dados com maior peso que os outros tipos (Chatterjee, Dimitrakopoulos e Mustapha, 2012).

Ainda em Chatterjee, Dimitrakopoulos e Mustapha (2012) é comentado que se todos os nós dentro de um modelo são conhecidos quando simulando um nó, a distância calculada com um modelo grande pode ser computacionalmente demorada. Para reduzir o tempo computacional do cálculo da distância, coeficientes de sub-banda aproximadas são utilizados depois da decomposição de wavelets dos dados condicionantes. A função da distância pode ser representada como:

$$
\mathrm{d}(\mathrm{x}, \mathrm{y})=\left(\left(1 / \mathrm{n}^{\text {aprox }}\right) \sum_{j=i}^{\text {naprox }}\left(\mathrm{x}^{\operatorname{aprox}}(\mathrm{j})-\mathrm{y}^{\operatorname{aprox}}(\mathrm{j})\right)^{2}\right)
$$

onde naprox é um número do coeficiente de sub-bandas aproximadas depois da decomposição de wavelets, $x^{\text {aprox }}$ é o coeficiente de sub-banda aproximada dos dados condicionantes e yaprox é o coeficiente de sub-banda aproximada do protótipo de classe. Se dentro dos dados condicionantes houver qualquer dado amostrado a equação (39) será utilizada para o cálculo de distância, mesmo que todos os nós dentro do modelo sejam completamente conhecidos (Chatterjee, Dimitrakopoulos e Mustapha, 2012).

Depois de medir a similaridade dos dados condicionantes com o protótipo de classes, a classe que melhor a corresponde é selecionada. A função distribuição acumulada condicional é gerada para cada classe, esta função é desenvolvida pelo cálculo das probabilidades de ocorrência de categorias particulares no nó central do modelo, dividido pelo número total de padrões nesta classe (Chatterjee, Dimitrakopoulos e Mustapha, 2012).

Durante o processo de simulação, após achar a melhor classe que corresponde aos padrões, um número aleatório é gerado. A partir de função densidade acumulada condicional, a categoria no nó central é obtida pela correspondência daquele número aleatório. Então um padrão aleatório é desenhado a partir da classe de padrões correspondente, pelo qual deve ter o mesmo nó central que a categoria obtida pela função 
densidade acumulada condicional. O próximo nó visitado é escolhido a partir de um caminho aleatório. A mesma função de distância e o algoritmo de desenho do padrão são repetidos até que todos os nós sejam simulados (Chatterjee, Dimitrakopoulos e Mustapha, 2012).

Chatterjee e Dimitrakopoulos (2011) explicam que quando a sub-banda simulada em mais de uma variável primária e todos os coeficientes de sub-bandas de wavelets são simulados, a transformação inversa da equação (30) é aplicada aos dados de maior escala para gerar o mapa simulado no domínio do espaço. A transformação inversa é iniciada a partir da escala maior e combina os dados simulados da variável primária e as sub-bandas de wavelets simuladas pelo modelo correspondente à aproximação na escala menor seguinte, e assim por diante. A amostragem é feita pela adição de zeros entre cada coeficiente. As subbandas são, então, envolvidas com a reconstrução dos filtros de escalas para os coeficientes de aproximação e também com a reconstrução dos filtros de wavelets para coeficientes de detalhes. Estes resultados são somados para obter os mapas simulados no domínio espacial.

As etapas relacionadas ao Wavesim são apresentadas na Figura 15. Considerando que a imagem de treinamento já foi escaneada e seus padrões foram decompostos, agrupados e guardados, a simulação inicia com a escolha de uma região aleatoriamente. As amostras desta região são comparadas por $\mathrm{L}_{2}$-norm com os padrões do banco de padrões e, dentro do grupo mais parecido, é sorteado aleatoriamente um padrão o qual será colocado no local sendo simulado e a simulação segue para a próxima região. 


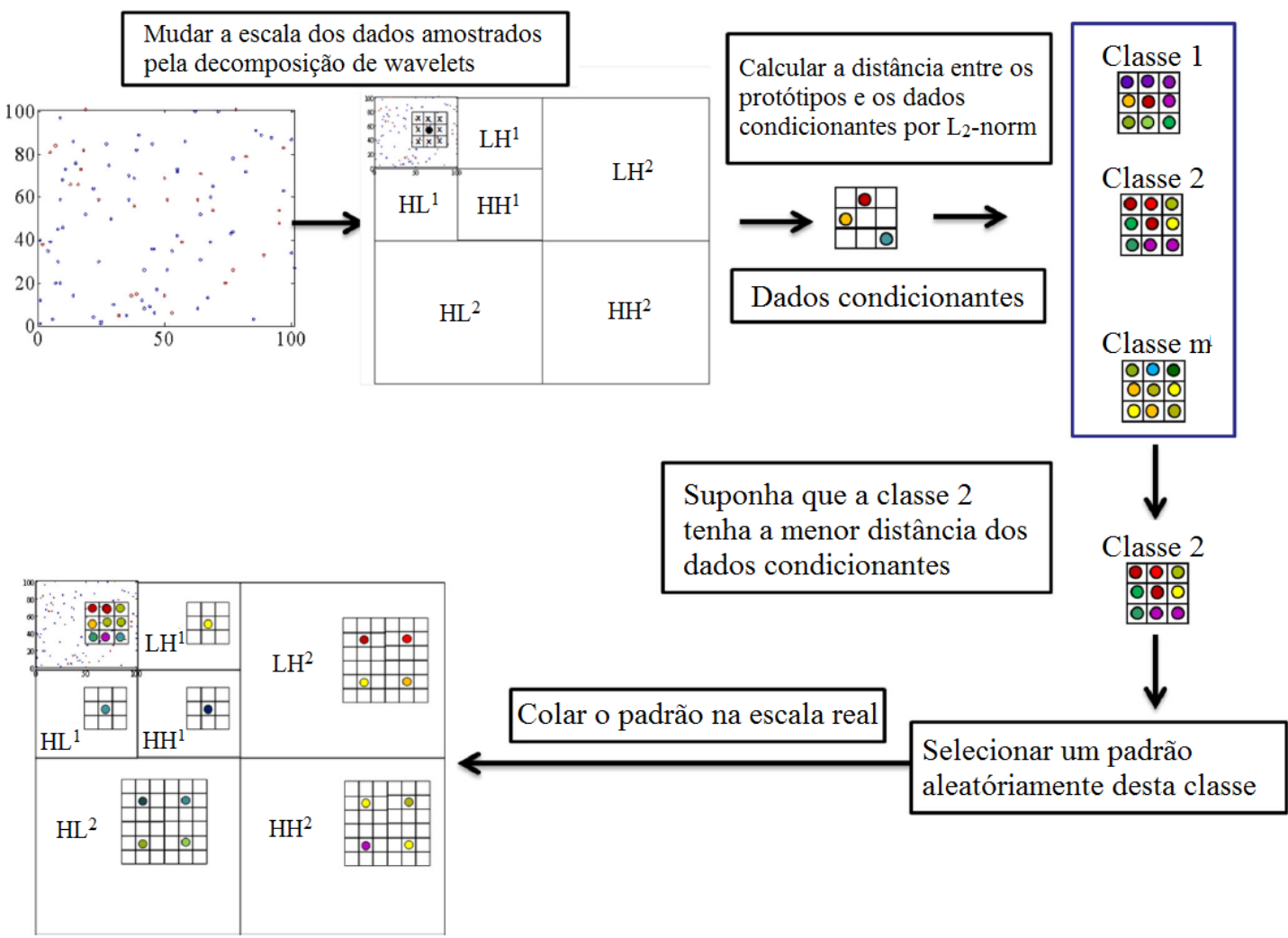

Figura 15 - Descrição dos passos da wavesim. Chatterjee, Mustapha e Dimitrakopoulos (2015).

Chatterjee, Dimitrakopoulos e Mustapha (2012) mostram que as maiores vantagens do Wavesim são:

(a) A classificação de padrões de dados de várias dimensões pode ser feita com baixo esforço computacional, devido à natureza da sub-banda aproximada da decomposição de wavelets, que reduz dimensionalmente os padrões e captura sua variabilidade,

(b) O padrão desenhado da classe pode ser feito a partir de sua probabilidade, que faz uma reprodução melhor, pois a função densidade acumulada condicional foi desenvolvida para cada classe da simulação categórica. 


\subsubsection{Algoritmo da Simulação Baseada em Wavelets}

Segundo Chatterjee, Dimitrakopoulos e Mustapha (2012), o algoritmo do wavesim pode ser descrito como:

1. Escanear a imagem de treinamento ti usando o modelo $\mathrm{T}$. Realizar a decomposição de wavelets dos padrões gerados utilizando a função básica das wavelets e escala. Salvar os coeficientes de wavelets aproximados do banco de padrões. Se a imagem de treinamento é categórica, gerar uma imagem binária $\mathrm{M}$ das categorias da imagem de treinamento antes da decomposição de wavelets;

2. Classificar os padrões baseado apenas nos coeficientes de sub-bandas aproximadas nos números agrupados previamente definidos e calcular o protótipo da classe usando a média de todos os padrões na determinada classe;

3. Definir um caminho aleatório para visitar apenas uma vez cada nó não amostrado;

4. Usar o mesmo modelo T em cada local u não amostrado. A distância do protótipo da classe é calculada através dos dados condicionantes disponíveis com o modelo utilizando as equações (39) ou (41). Selecionar a classe com a distância mínima dos dados condicionantes. Se nenhum dado condicionante estiver disponível utilizar uma classe aleatória;

5. Sortear um padrão aleatório a partir do protótipo de classe e passar o padrão pelo centro do local simulado u. Se algum dado amostrado ou o valor do nó central de qualquer local já simulado está presente em qualquer nó do modelo T na localização u, eles são mantidos antes que a simulação de padrões os apague. Para dados categóricos, uma amostra aleatória é desenhada baseada na função densidade acumulada condicional gerada para cada classe;

6. Adicionar o valor simulado no ponto u a um arquivo diferente para ser utilizado no cálculo da distância;

7. Repetir os passos 4 a 6 para todos os próximos pontos do caminho aleatório definido no passo 3;

8. Repetir os passos 3 a 7 para gerar diferentes realizações utilizando diferentes caminhos aleatórios. 


\section{Análise do lucro por bloco}

A análise de sensibilidade na mineração pode ser executada de diversas maneiras conforme a necessidade, por exemplo para o cálculo dos teores de corte; probabilidade de haver certa quantidade de minério acima de um teor desejado; probabilidade de certo teor de minério em cada bloco entre outras. Neste trabalho, esta análise significa a aplicação de uma equação não linear para calcular o valor potencial (lucro) de cada bloco simulado. Este valor (Vp), por sua vez, é o lucro potencial que cada bloco possui na unidade monetária desejada, se considerados os custos de manutenção, transporte, armazenamento e tratamento do minério para tipos de pilhas i. Estes tipos de pilhas significam custos diferentes que podem ser causados por tratamentos diferentes (diferentes equipamento), equipamentos de transporte diferentes ou quaisquer outros custos que possam variar. Estes custos diferentes podem ser minimizados se forem escolhidos quais blocos devem ir para cada pilha, desta forma o lucro da mineração será maximizado.

O valor potencial Vp de cada bloco (blk) é a multiplicação do teor simulado (Z(x)) pela recuperação da pilha i pelo o preço do minério (MP), pelo volume $\mathrm{V}$ do bloco, pela densidade D do bloco e por 1000 para a correção dimensional da densidade $\left(1000 \mathrm{~kg} / \mathrm{m}^{3}=\right.$ $\left.1 \mathrm{~g} / \mathrm{cm}^{3}\right)$. O resultado é subtraído da soma de todos os custos $\left(C_{i}\right)$ de cada pilha $\mathrm{i}$.

O cálculo do valor de cada bloco (Vp) é feito de acordo com a equação:

$$
\begin{aligned}
& \mathrm{Vp}=\mathrm{Z}(\mathrm{x}) \cdot \mathrm{R}_{\mathrm{i}} \cdot \mathrm{MP} \cdot \mathrm{V} \cdot(\mathrm{D} \cdot 1000)-\mathrm{C}_{\mathrm{i}} \\
& {[\$ / \mathrm{blk}]=[\mathrm{g} / \mathrm{kg}] \cdot[\%] \cdot[\$ / \mathrm{g}] \cdot\left[\mathrm{m}^{3} / \mathrm{blk}\right] \cdot\left[\mathrm{kg} / \mathrm{m}^{3}\right]-[\$ / \mathrm{blk}]}
\end{aligned}
$$

$\mathrm{O}$ arquivo de entrada deve ter a coluna de identificador IJK, coluna densidade - que será calculada pelo método de krigagem ordinária - e as das colunas de diferentes realizações $\left(\mathrm{Z}(\mathrm{x})_{1}, \mathrm{Z}(\mathrm{x})_{2}, \ldots, \mathrm{Z}(\mathrm{x})_{1}, \mathrm{l}\right.$ sendo a l-ésima realização). Além disso, alguns parâmetros devem ser definidos como respostas às seguintes questões:
(a) Qual é o preço do minério?
(b) Qual é o volume dos blocos?
(c) Quantas pilhas de processamento serão utilizadas?
(d) Qual é o custo total de cada bloco?
(e) Qual é a recuperação de cada pilha? 
(f) Quantas realizações há no arquivo?

O fluxograma do funcionamento do programa de análise de lucro por bloco é apresentado na Figura 16.

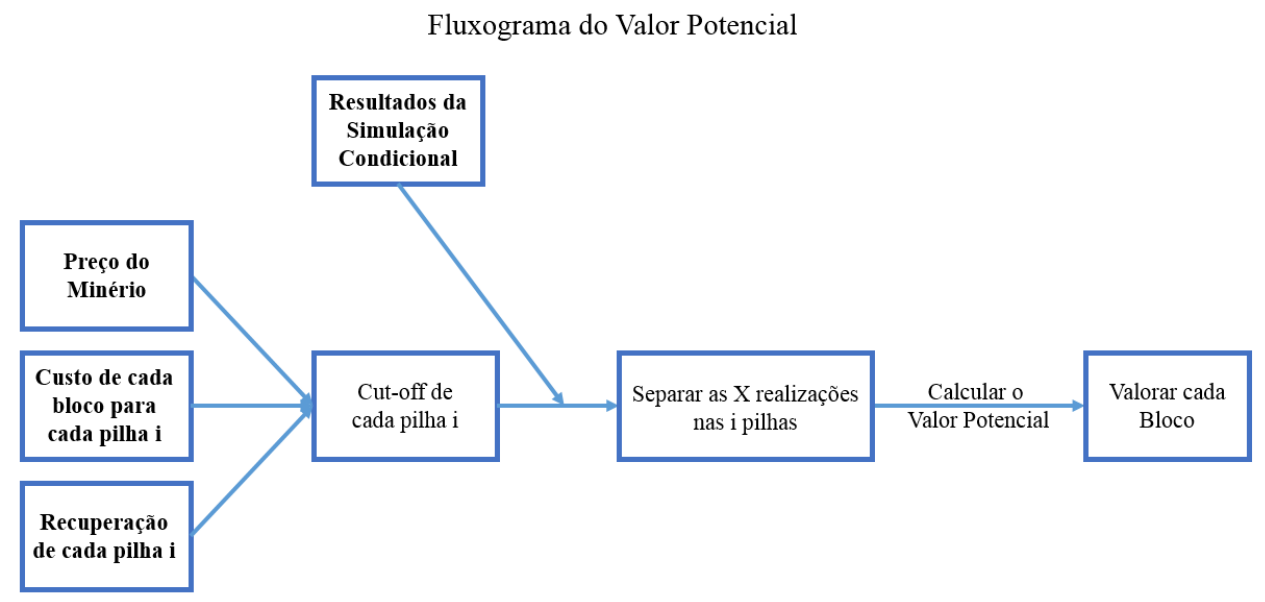

Figura 16 - Fluxograma do valor potencial de cada bloco.

\section{Banco de Dados Sintético}

O depósito sintético foi criado com o intuito de servir para averiguação da qualidade dos métodos geoestatísticos, além disso, é adequado para testar a qualidade de amostragens, assim como otimizar a localização de adensamentos de sondagens futuras, uma vez que se podem fazer furos em qualquer local sem custo e assim verificar a confiabilidade dos resultados com a variação da quantidade de furos de sonda. Estes dados serão liberados para pesquisas futuras.

Um depósito real não é satisfatório para o estudo adequado da confiabilidade dos métodos geoestatísticos, pois os contornos geológicos em subsuperfície não são conhecidos com precisão, bem como a posição e os teores exatos dos corpos de minério, afinal, nem todas as camadas são necessariamente aflorantes e a malha de sondagem pode não interceptá-las. Para garantir todo o conhecimento do depósito mineral, ele deve ser estudado e explotado por inteiro. 
A geologia local é de um depósito polimetálico formado por fluidos hidrotermais quartzosos que penetraram por uma falha de direção norte-sul e inclinação aproximada de $45^{\circ}$ para leste. A rocha encaixante é formada pela intercalação de camadas de meta-arenito e camadas de filitos dobradas, causando alta variabilidade de padrões geológicos, além da alta variabilidade intrínseca aos depósitos de metais nobres como cobre.

Para garantir a verossimilhança, o modelo geológico desenhado utilizando o programa Datamine®, foi definido utilizando a simplificação da geologia de um sítio real de mineração. O modelo é a interpolação de 2 perfis geológicos semelhantes distantes 600 metros conforme ilustrado na Figura 17.

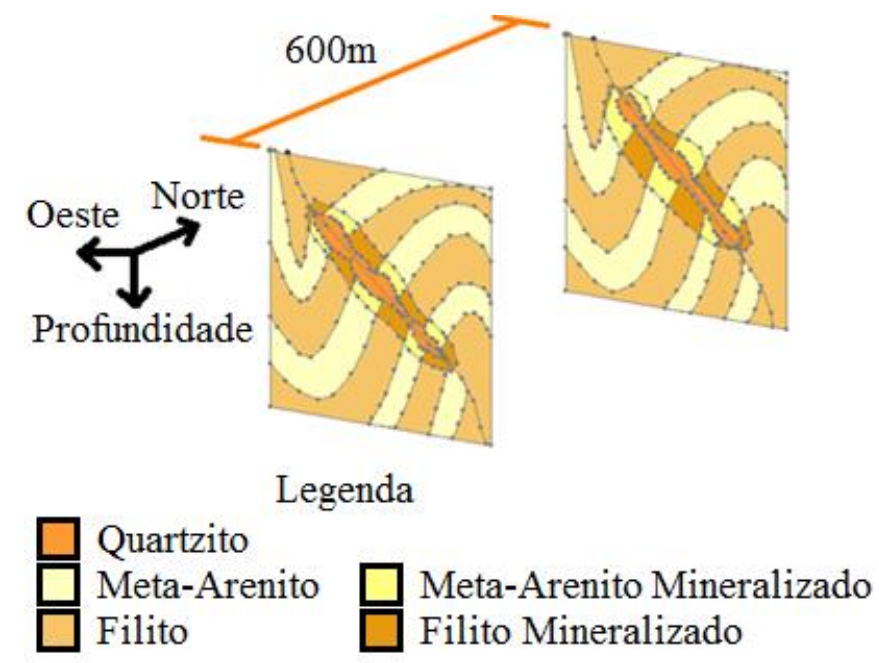

Figura 17 - Strings do Datamine ${ }^{\circledR}$ que formaram o modelo geológico sem a topografia.

A partir dos wireframes (união das strings - contornos geológicos e de influência hidrotermal), foi criado um modelo de blocos com dimensões de um metro na direção X por um metro na direção Y e meio metro de profundidade para ter a melhor resolução espacial possível sem tornar o desenvolvimento demasiadamente demorado. $\mathrm{O}$ depósito tem tamanho aproximado de 300 metros para leste, 600 metros para norte e 300 metros de profundidade. Em cada bloco a geologia do wireframe foi "carimbada". Por fim, foi criado um wireframe da topografia da região e foram selecionados os blocos abaixo desta topografia. 
Os blocos dentro da zona mineralizada foram separados em blocos internos - aqueles que fazem parte do quartzito (zona enriquecida) - e em blocos externos (região mais pobre), os quais são compostos da geologia da rocha encaixante (filito e meta-arenito). Os valores destes blocos foram gerados para a variável cobre por Simulação Sequencial Gaussiana, da qual uma realização foi tomada ao acaso. A simulação não condicional buscou reproduzir um semivariograma real obtido em um depósito equivalente em geologia e variabilidade. Os teores foram gerados dentro da zona mineralizada e fora da mesma utilizando diferentes modelos de semivariogramas, conforme apresentado na Tabela 1. quartzito).

Tabela 1 -Semivariograma da região mineralizada interna (quartzito) e a da externa (fora do

\begin{tabular}{ccc}
\hline & $\begin{array}{c}\text { Zona } \\
\text { Mineralizada }\end{array}$ & Estéril \\
\hline Tipo & Esférico & Esférico \\
Efeito pepita & 0,2 & 0,2 \\
Patamar & 0,8 & 0,8 \\
Eixo Maior & 155 & 255 \\
Eixo Médio & 90 & 170 \\
Eixo Mínimo & 55 & 130 \\
Rotação em Z & 0 & 0 \\
Rotação em X & 0 & 0 \\
Rotação em Y & 45 & 45
\end{tabular}

Foram feitas 100 realizações para cada região e os teores foram associados apenas aos blocos dentro de cada um destes volumes. Os resultados foram, então transformados do domínio gaussiano para o domínio real de acordo com a distribuição original dos dados que foram utilizados para gerar o semivariograma.

Os valores simulados de cobre foram atribuídos aos blocos que já apresentavam a geologia local. Por último, os valores de densidade foram gerados a partir da média ponderada da quantidade de cada minério no bloco e de uma variação da densidade aproximada de cada litotipo. 
O perfil com a topografia, é apresentado na Figura 18, possibilita observar a distribuição das camadas litológicas e ver que em determinadas regiões os minérios são aflorantes - o corpo rico é o quartzito, mas há uma nuvem de minério ao seu redor. Além disso, foi feito o mapa geológico da região que é apresentado na Figura 19. Também é possível ver as dobras da rocha encaixante que foram formadas antes do cisalhamento e mineralização. O perfil (Figura 18) mostra a componente inversa da falha, além do quartzito rico em cobre e as dobras intervaladas de filitos e meta-arenitos que formam a rocha encaixante.

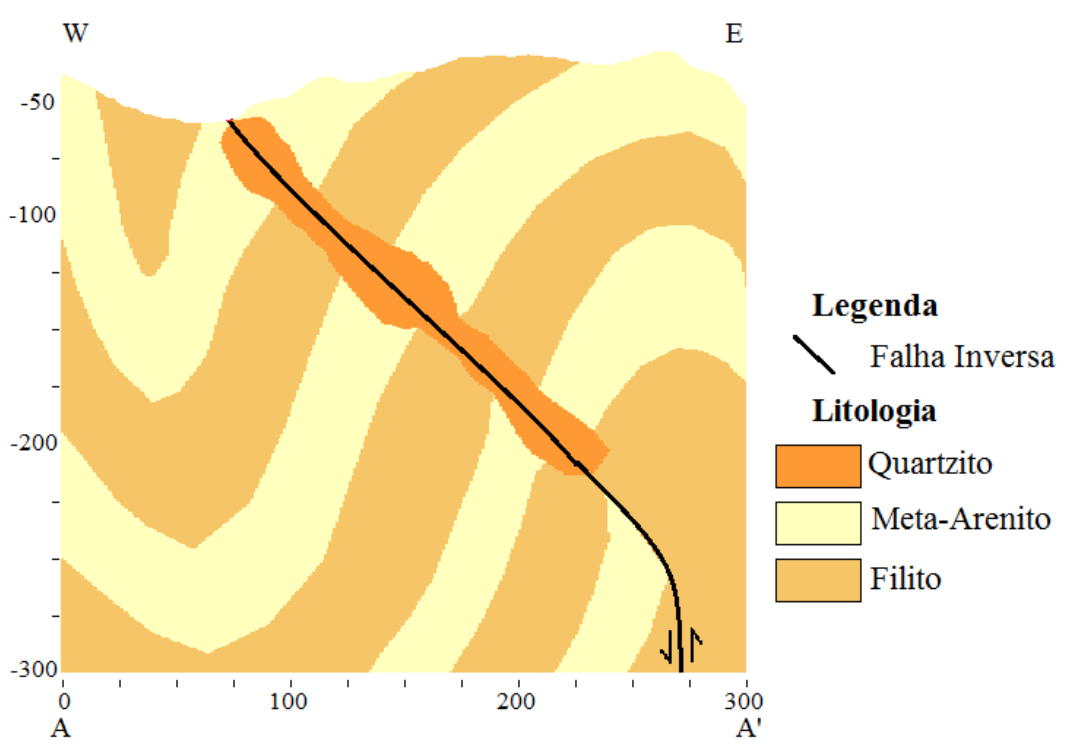

Figura 18 - Perfil A-A' do mapa geológico. 


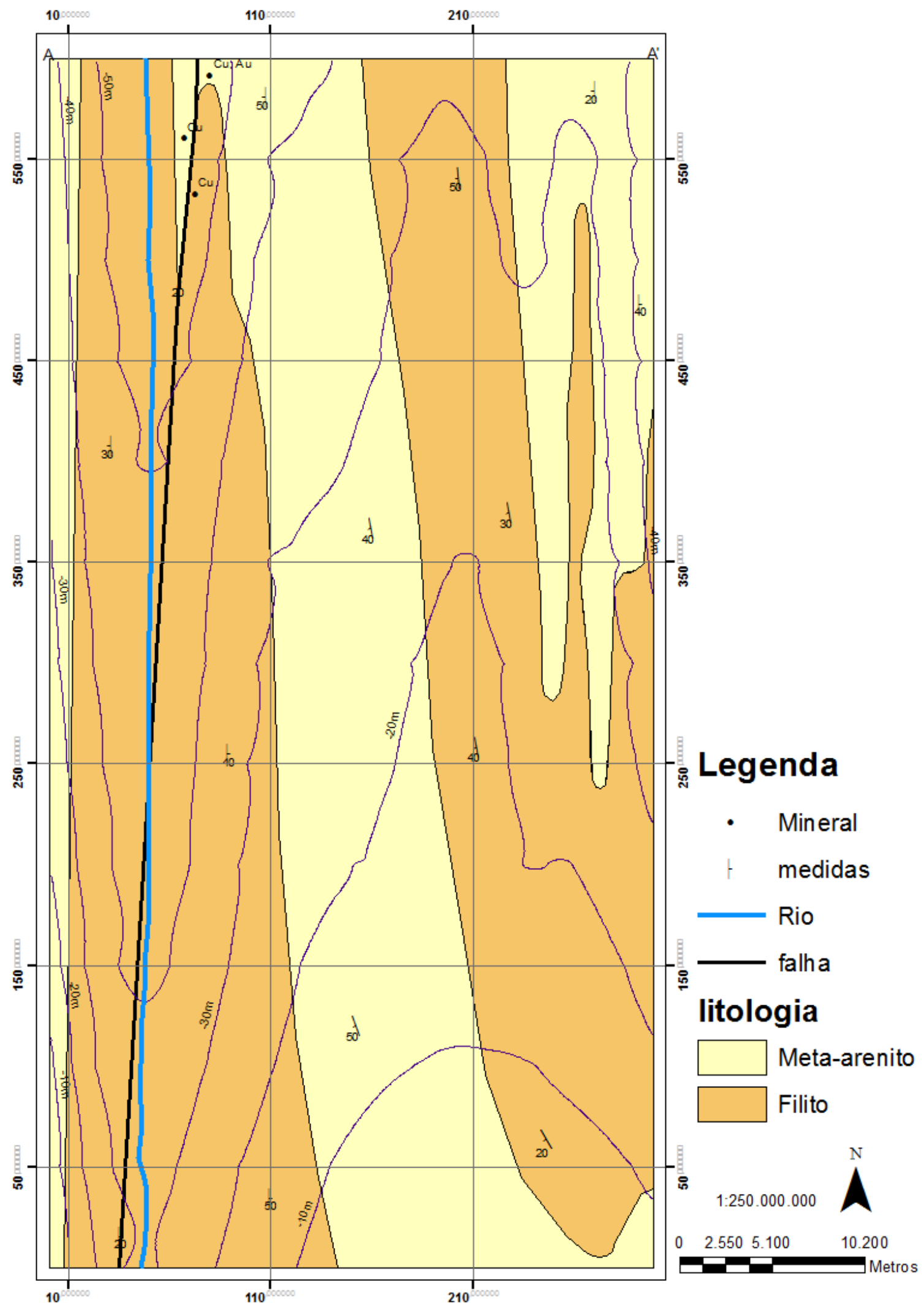

Figura 19-Mapa geológico do depósito sintético. 


\section{Resultados}

\subsection{Amostragem}

A amostragem reproduz furos de sonda coletados a cada 40 metros, aproximadamente. As amostras, ao longo dos furos possuem tamanhos irregulares com comprimento médio de $60 \mathrm{~cm}$. As amostras foram regularizadas por bancadas, com bancadas de 5 metros e, a partir destas informações, o corpo de minério foi delineado considerando o teor de cobre como fator de definição do minério.

A Figura 20 apresenta uma seção com a legenda de litologia e o corpo de minério enquanto a Figura 21 mostra uma imagem tridimensional a topografia, distribuição das sondagens e o do corpo de minério definido a partir da análise dos furos.

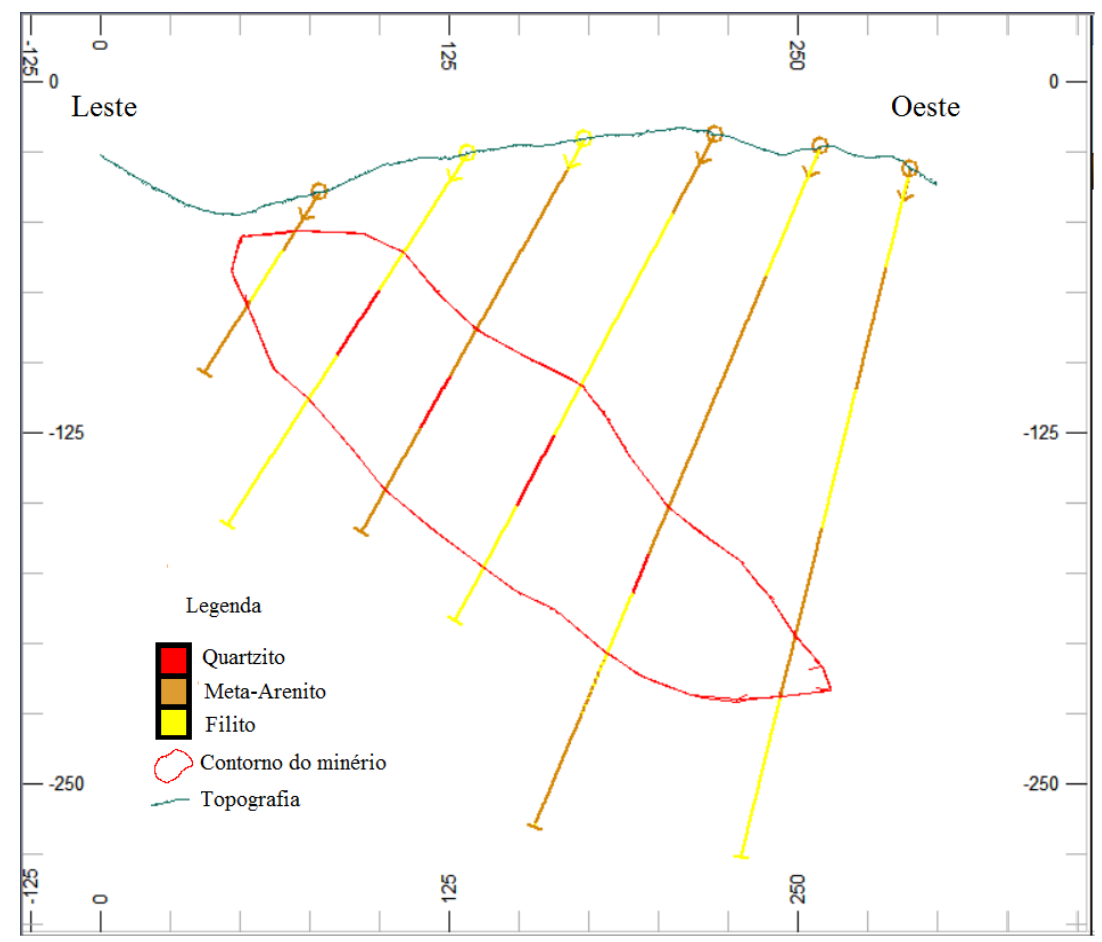

Figura 20 - Perfil representando as litologias e o perímetro do corpo de minério interpretado. 


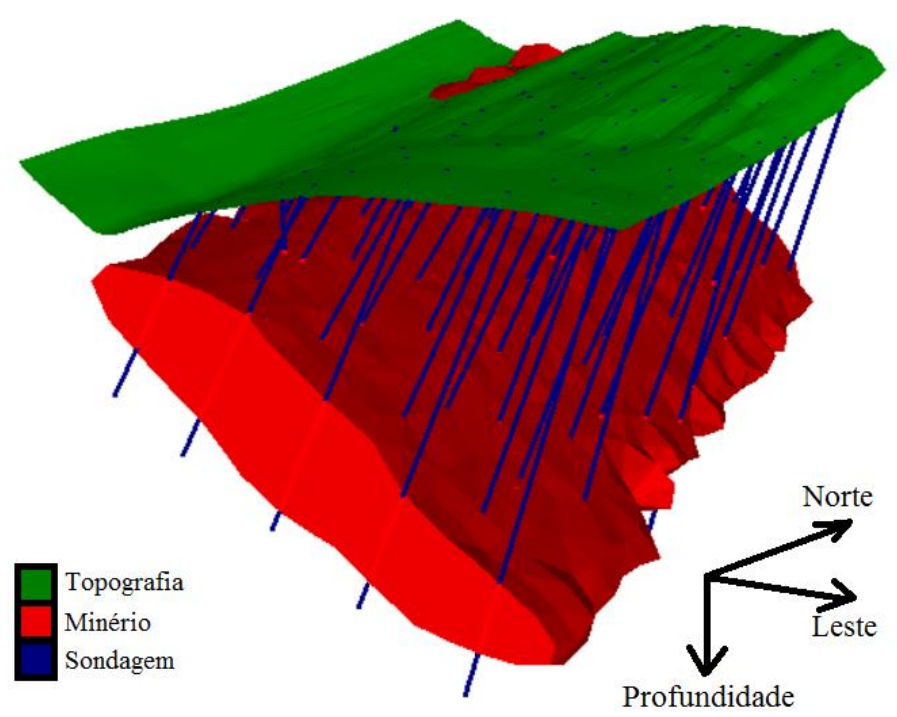

Figura 21 - Modelo tridimensional do corpo de minério, em vermelho, definido a partir das sondagens, em azul e em verde é mostrado a topografia.

Na Tabela 2 são apresentadas as estatísticas descritivas de cobre do modelo real de todos os blocos dentro do volume do corpo de minério e a Figura 22 o histograma desta distribuição.

MODELO REAL

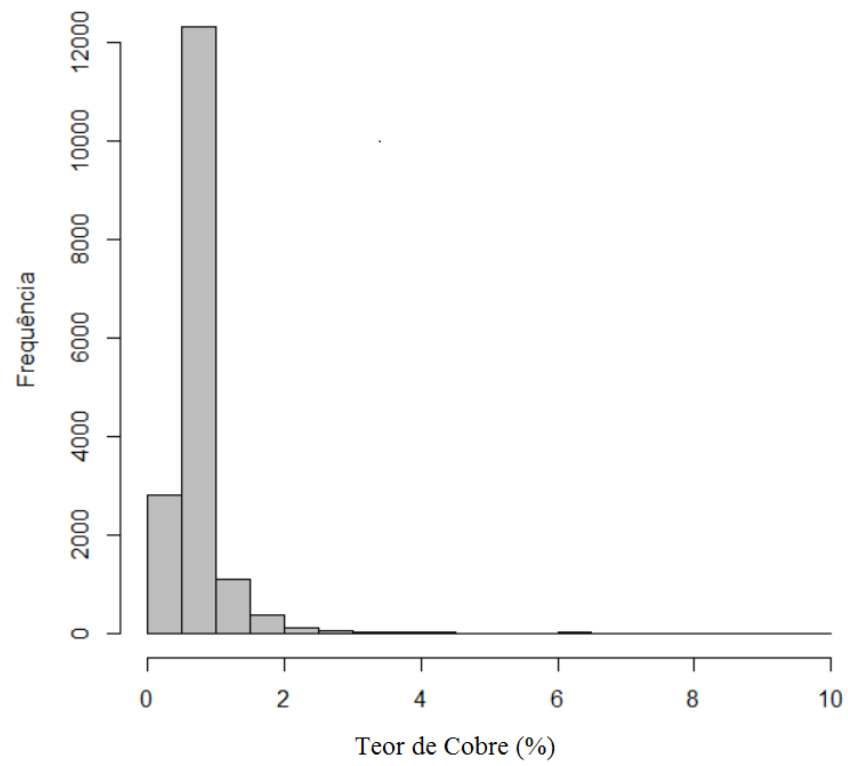

Figura 22 - Histograma dos dados reais de cobre dentro do corpo mineralizado. 
Tabela 2 - Estatísticas descritivas dos dados reais de cobre em toda a zona mineralizada.

\begin{tabular}{cccccccc}
\hline \multicolumn{7}{c}{ REAL } \\
\hline Mínimo & Primeiro & Mediana & Média & $\begin{array}{c}\text { Desvio } \\
\text { padrão }\end{array}$ & $\begin{array}{c}\text { Terceiro } \\
\text { Quartil }\end{array}$ & Máximo & $\begin{array}{c}\text { Coeficiente } \\
\text { de Variação }\end{array}$ \\
0 & 0,5 & 0,5 & 0,7 & 0,4 & 0,7 & 9,8 & 58,7 \\
\hline
\end{tabular}

As estatísticas descritivas do modelo real podem ser comparadas às dos dados dos furos regularizados (Tabela 3), a partir da comparação, conclui-se que a amostragem com 40 metros de distância entre furos foi adequada, uma vez que ambas estatísticas descritivas são iguais ou similares. O histograma dos furos de sonda é apresentado na Figura 23, onde pode ser observada a assimetria positiva.

Tabela 3 - Estatísticas descritivas dos dados amostrados nos furos de sonda dentro do corpo de minério.

\begin{tabular}{cccccccc}
\hline \multicolumn{8}{c}{ FUROS } \\
\hline \multirow{2}{*}{ Mínimo } & $\begin{array}{c}\text { Primeiro } \\
\text { Quartil }\end{array}$ & Mediana & Média & $\begin{array}{c}\text { Desvio } \\
\text { padrão }\end{array}$ & $\begin{array}{c}\text { Terceiro } \\
\text { Quartil }\end{array}$ & Máximo & $\begin{array}{c}\text { Coeficiente } \\
\text { de Variação }\end{array}$ \\
0,2 & 0,5 & 0,5 & 0,7 & 0,4 & 0,7 & 5,8 & 55,6 \\
\hline
\end{tabular}

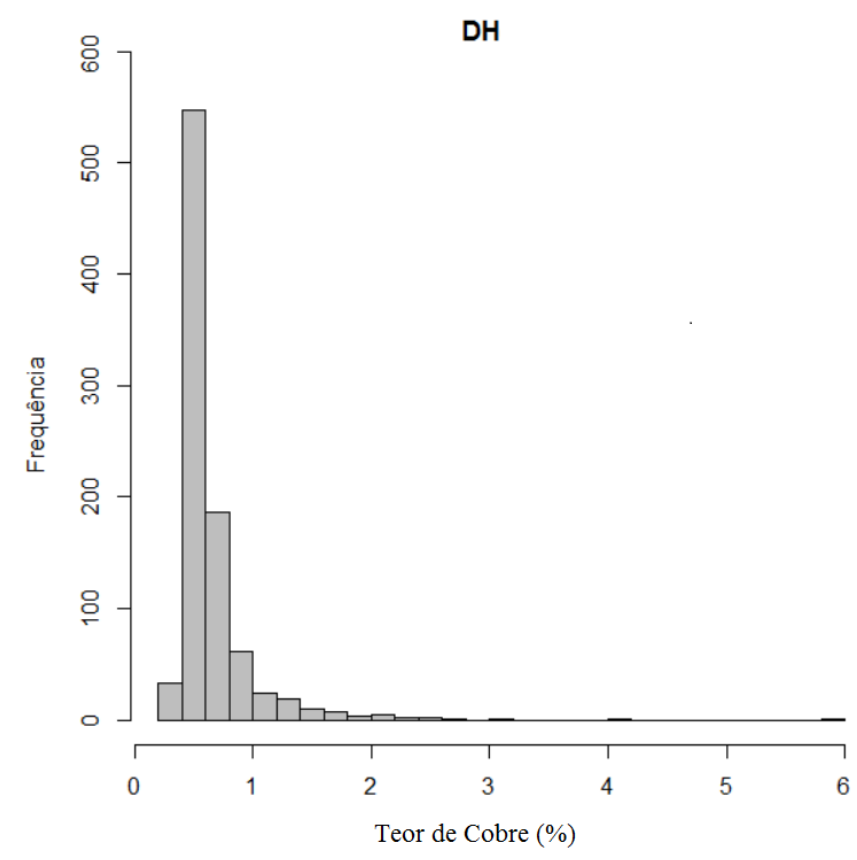

Figura 23 - Histograma dos dados amostrados em furos de sonda (DH - drill hole) de cobre dentro do corpo mineralizado. 
Outra comparação para aferir a qualidade da sondagem foi realizada por meio de gráficos do tipo boxplots dos valores reais e dos valores amostrados, ambos (com e sem outliers) dentro do corpo de minério (Figura 24), observando-se a figura pode-se concluir que a amostragem é representativa. Ou seja, a distribuição dos dados amostrados é adequada para a representação do corpo de minério do depósito sintético.

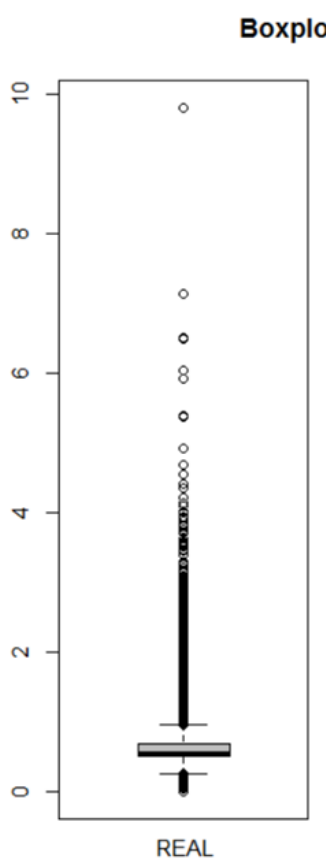

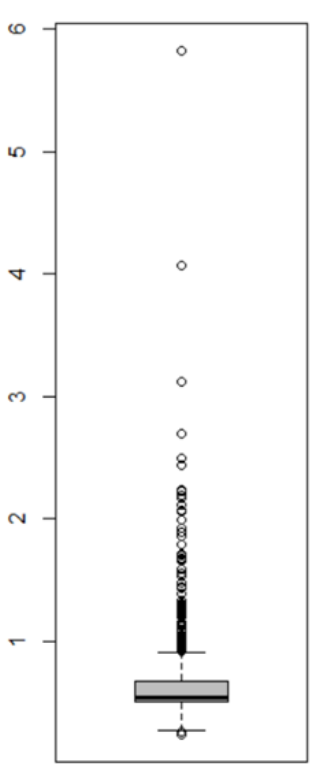

$\mathrm{DH}$

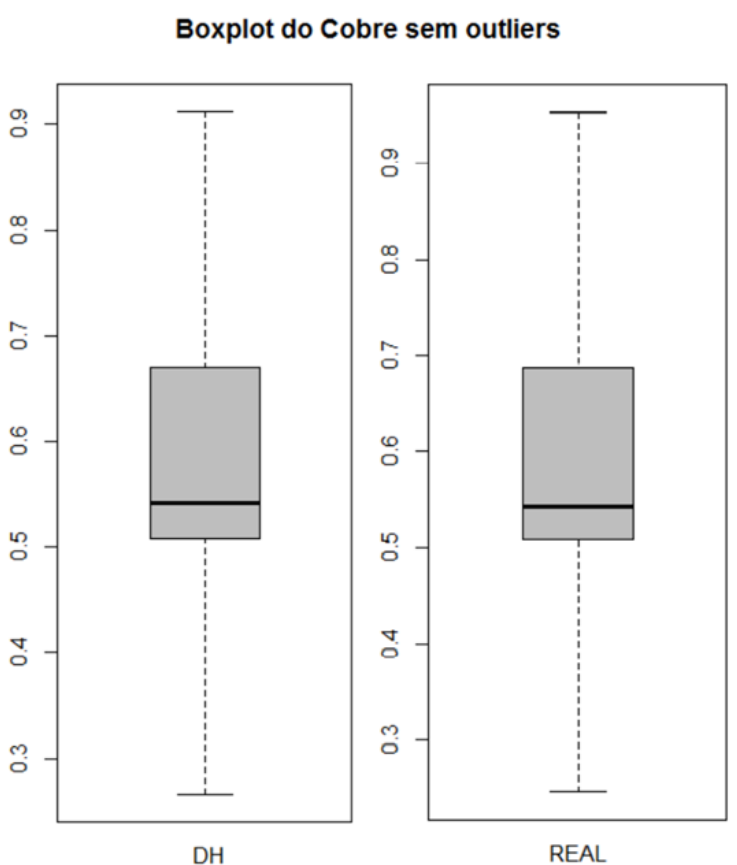

Figura 24 - Boxplot dos dados reais e dos amostrados com e sem outliers.

\subsection{Análise geoestatística}

A geoestatística realizada foi dividida em três etapas. A primeira, para a realização da krigagem ordinária das variáveis cobre e densidade aparente. A segunda etapa foi a Simulação Sequencial Gaussiana dos dados de cobre e, finalmente na terceira etapa, foi realizada a Simulação Baseada em Wavelets (Wavesim) dos dados de cobre, para tal, o resultado da krigagem ordinária da variável cobre foi utilizado como imagem de treinamento. Os resultados de todas estas análises foram utilizados na análise de lucro por bloco, que gera o valor potencial esperado de cada bloco. 


\subsubsection{Krigagem}

A krigagem ordinária da densidade aparente, apresentada em detalhe no Anexo 1, foi realizada para que o valor potencial de cada bloco pudesse ser calculado. A variável cobre foi analisada de dois modos diferentes e o modelo de blocos foi estimado por krigagem ordinária para cada um dos modos. A primeira estimativa foi realizada para criar uma imagem de treinamento da Simulação Baseada em Wavelets e a segunda estimativa, apresentada no Anexo 2, foi calculada a partir das amostras contidas no corpo de minério e utilizada para comparação com os métodos de simulação.

A análise geoestatística iniciou-se pela análise exploratória da variável cobre e interpretou-se a presença de anisotropia mista representada por um elipsoide com eixo maior no azimute $0^{\circ}$ e mergulho também igual a $0^{\circ}$, o eixo médio posicionado em $90^{\circ}$ de azimute e $45^{\circ}$ de mergulho, enquanto o eixo menor tem posição $270^{\circ} / 45^{\circ}$.

Na Figura 25 são apresentados o variograma experimental e seu respectivo modelo teórico da variável cobre. Os valores ajustados para o modelo teórico de variograma podem ser observados na Tabela 4.

Tabela 4 - Modelo teórico de variograma da variável cobre.

\begin{tabular}{ccc}
\hline \multicolumn{3}{c}{ Modelo do Variograma do Cobre } \\
\hline Efeito pepita & \multicolumn{3}{c}{0,05} \\
Tipo & \multicolumn{1}{c}{ Esférico } \\
Estrutura & 1 & 2 \\
Patamar & 0,1 & 0,02 \\
Eixo Maior & 208 & $\infty$ \\
Eixo Médio & 160 & $\infty$ \\
Eixo Mínimo & 95 & 95 \\
Rotação em Z & 0 & 0 \\
Rotação em X & 0 & 0 \\
Rotação em Y & 45 & 45
\end{tabular}



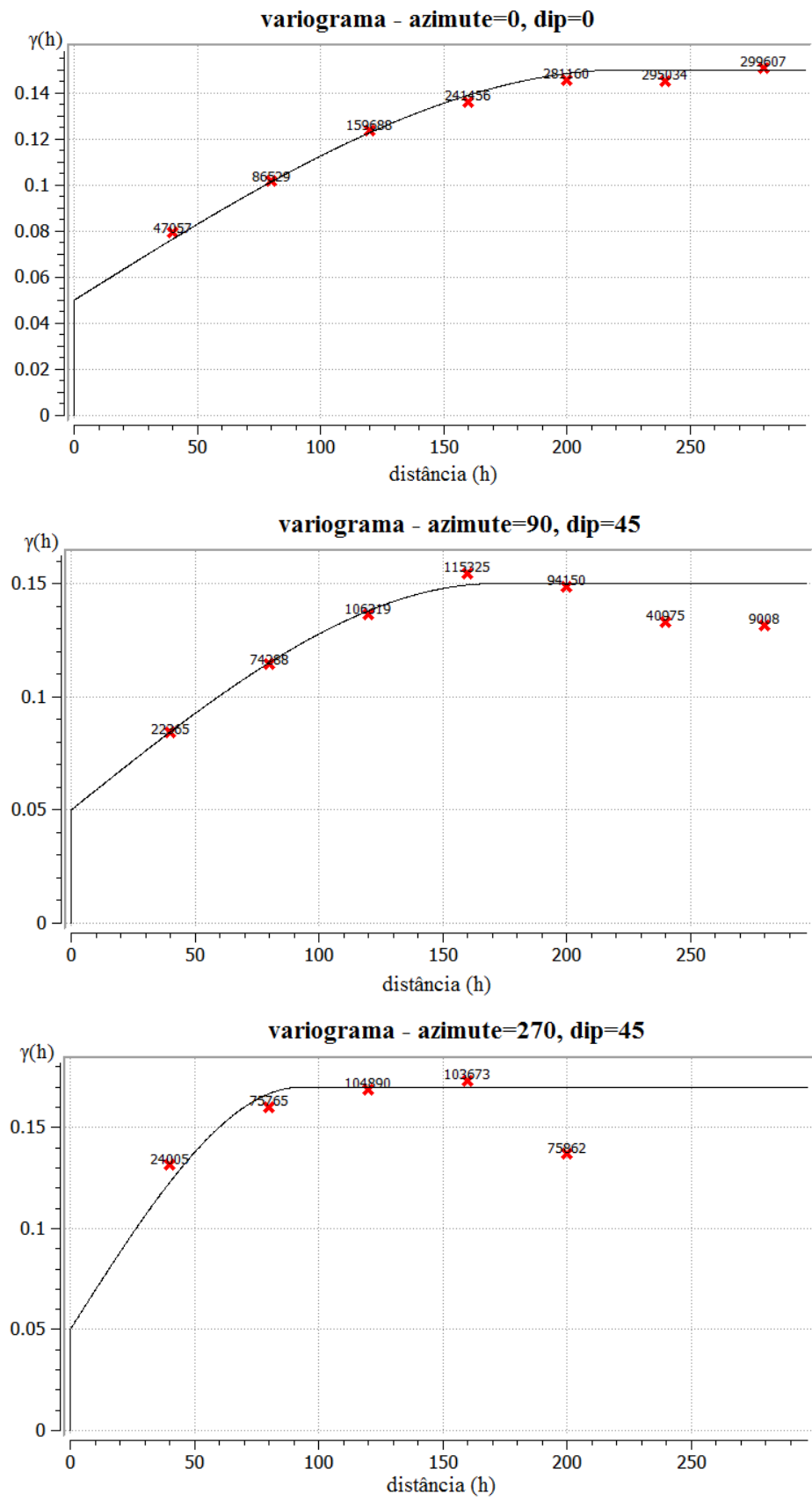

Figura 25 - Variogramas experimentais com a quantidade de pares utilizados para seu cálculo e modelos teóricos de variograma do cobre ajustados.

Com o modelo teórico de variograma definido, a krigagem ordinária foi calculada utilizando a vizinhança caracterizada pela busca por octantes, com no mínimo 3 octantes preenchidos com amostras, 1 amostra por octante e 2 no máximo. $\mathrm{O}$ elipsoide de busca é rotacionado em $45^{\circ}$ no eixo $\mathrm{Y}$, deixando seus eixos nas mesmas direções definidas no elipsoide que representa a anisotropia, os raios de busca têm 208 metros no eixo maior, 160 
metros no eixo médio e 95 metros no eixo menor. O modelo de blocos utilizado possui blocos com 10 metros nas direções X e Y e 5 metros na direção $\mathrm{Z}$ e 30 blocos ao longo de X e 60 blocos ao longo Y e Z. O resultado da krigagem ordinária do Cu é apresentado na Figura 26, onde à esquerda pode-se observar toda a estimativa e à direita apenas a região compreendida pelo corpo de minério.

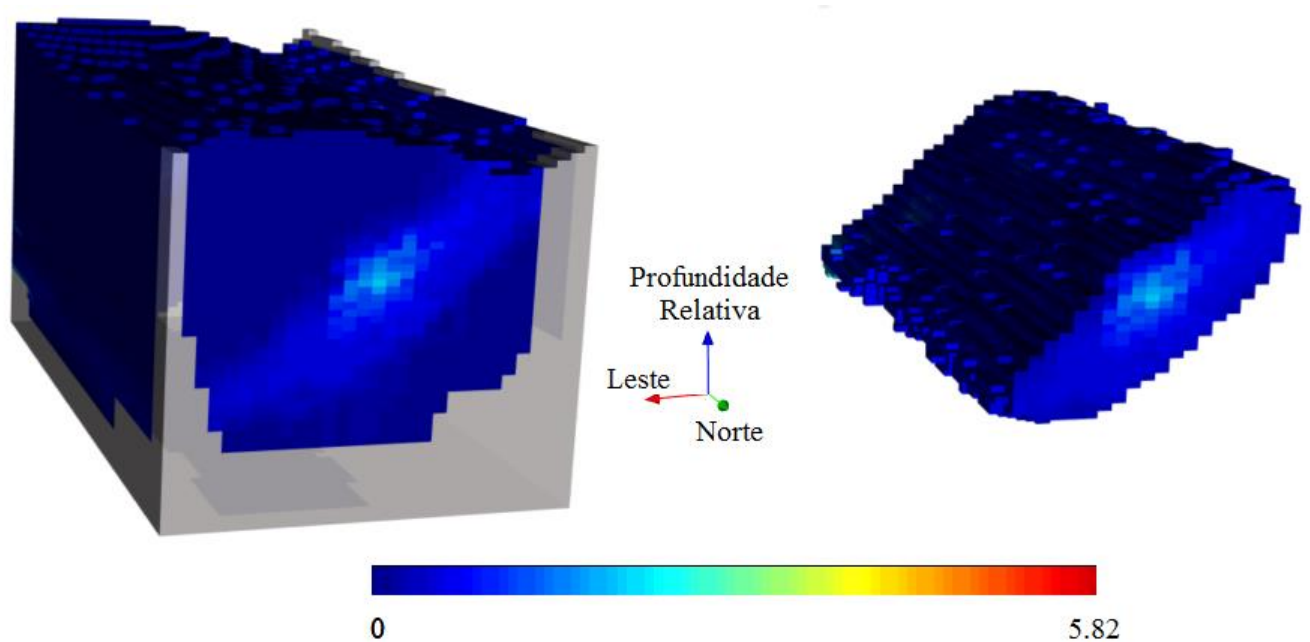

Figura 26 - Resultado da krigagem para o volume do depósito inteiro (Imagem de Treinamento) e a imagem da direita é a região considerada como corpo do minério deste volume .

Para verificar o resultado da krigagem foram comparadas as estatísticas descritivas dos teores estimados no modelo de blocos (Tabela 5) àquelas dos furos de sonda (Tabela 3 ). Os quartis avaliados (primeiro e terceiro) são iguais em ambas as distribuições e as medidas de tendência central são equivalentes, assim como o desvio padrão. Devido à suavização inerente à krigagem, o coeficiente de variação é menor, bem como o valor máximo obtido pela krigagem. O histograma dos teores de cobre estimados (Figura 27) também possui assimetria positiva, porém menos pronunciada do que a observada no histograma da Figura 23.

Tabela 5 - Estatística descritiva dos dados krigados.

\begin{tabular}{cccccccc}
\hline \multicolumn{7}{c}{ Krigagem } & Ordinária (Imagem de Treinamento) \\
\hline \multirow{2}{*}{ Mínimo } & $\begin{array}{c}\text { Primeiro } \\
\text { Quartil }\end{array}$ & Mediana & Média & $\begin{array}{c}\text { Desvio } \\
\text { padrão }\end{array}$ & $\begin{array}{c}\text { Terceiro } \\
\text { Quartil }\end{array}$ & Máximo & $\begin{array}{c}\text { Coeficiente } \\
\text { de Variação }\end{array}$ \\
& 0.5 & 0.6 & 0.6 & 0.3 & 0.7 & 2.2 & 42.3 \\
\hline
\end{tabular}




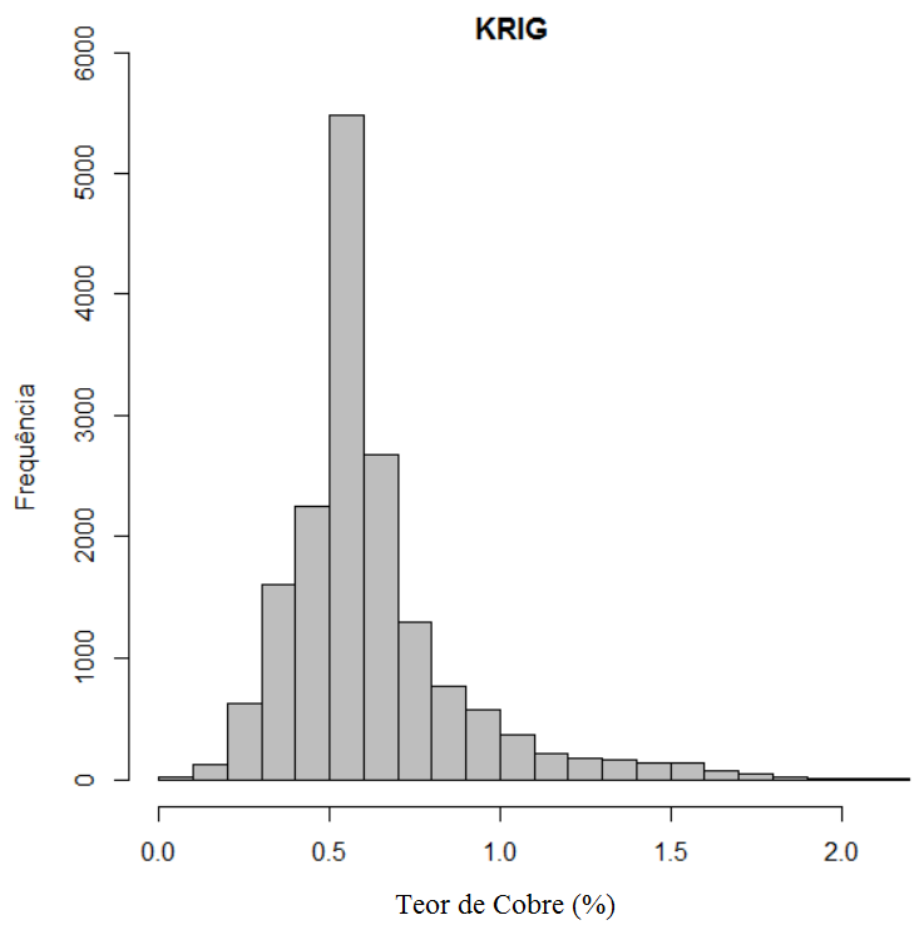

Figura 27- Histograma dos teores de cobre estimados por krigagem ordinária que serão utilizados como Imagem de Treinamento.

\subsubsection{Simulação Sequencial Gaussiana}

Para a simulação, os dados foram transformados em uma gaussiana normal com média zero e variância igual a um $(\mathrm{N}[0,1])$, para isto foi utilizado o método de transformação por Normal Score, que gera a distribuição a partir da comparação das funções densidades acumuladas dos dados e de uma distribuição gaussiana conhecida.

Com os dados transformados, a análise exploratória foi realizada e, a partir dos resultados, interpretou-se como os eixos principais do elipsoide que representa a anisotropia as direções norte com mergulho $0^{\circ}$, oeste com mergulho $45^{\circ}$ e leste com mergulho $45^{\circ}$ como, respectivamente, os eixos maior, intermediário e menor. Apresenta-se, na Figura 28, o variograma experimental calculado e seu respectivo modelo teórico de variograma. 

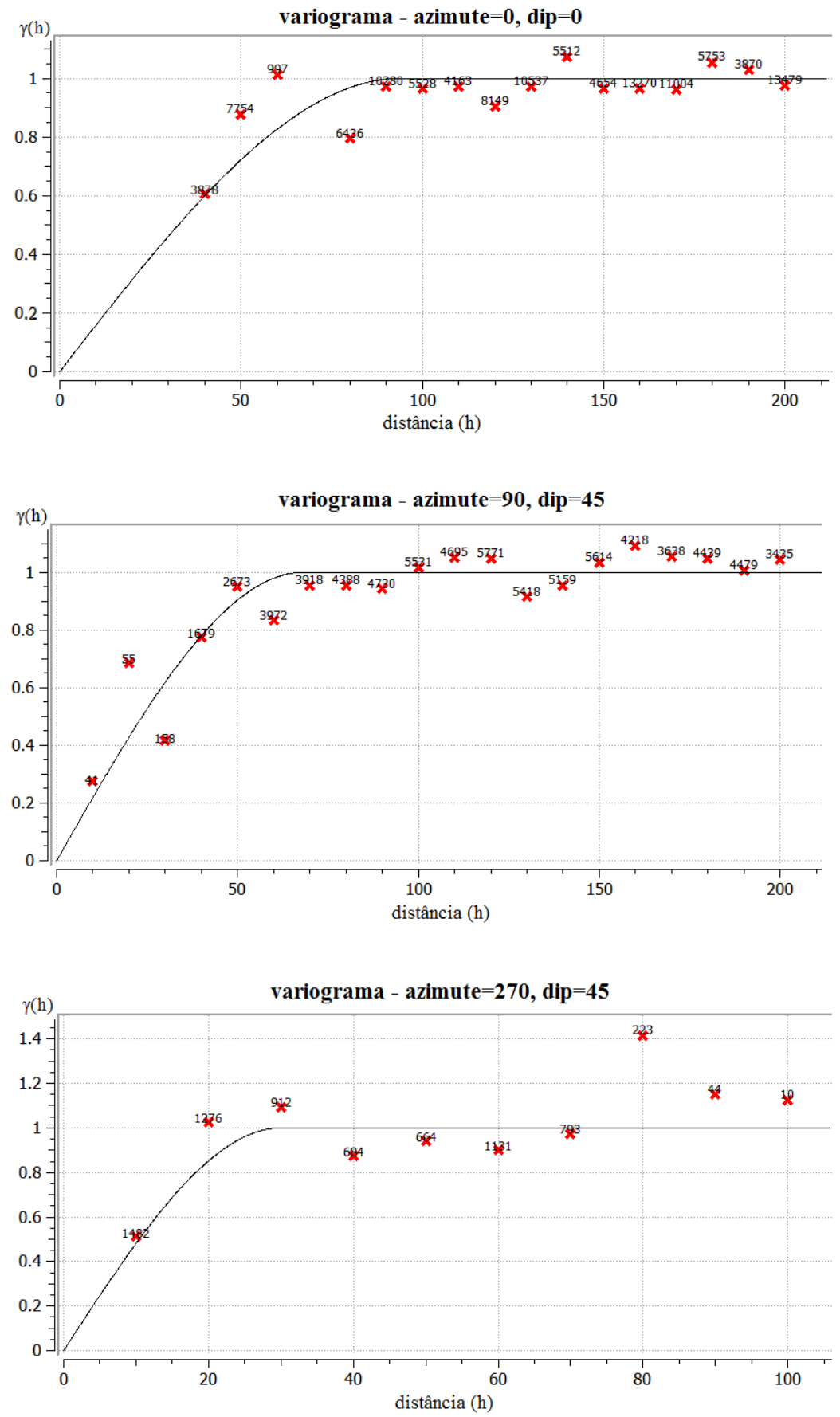

Figura 28 - Variograma experimental com a quantidade de pares utilizados para seu cálculo $e$ modelo teórico de variograma da variável cobre transformada em uma Gaussiana Normal [0,1].

Os parâmetros do modelo teórico de variograma ajustado são apresentados na Tabela 6. 
Tabela 6 - Parâmetros do modelo teórico de Variograma do cobre transformado em uma Gaussiana Normal $[0,1]$.

\begin{tabular}{cc}
\hline \multicolumn{2}{c}{ Modelo do Variograma do Cobre } \\
Transformado em Gaussiana [0,1] \\
\hline Tipo & Esférico \\
Efeito pepita & 0,0 \\
Patamar & 1 \\
Eixo Maior & 103 \\
Eixo Médio & 69 \\
Eixo Mínimo & 30 \\
Rotação em Z & 0 \\
Rotação em X & 0 \\
Rotação em Y & 45
\end{tabular}

A vizinhança para a simulação foi definida por um elipsoide de busca com os eixos rotacionados conforme as direções interpretadas na análise exploratória e dimensões de 103 m, $69 \mathrm{~m}, 30 \mathrm{~m}$ como eixos maior, intermediário e menor respectivamente. A busca foi dividida em octantes com ao menos 3 octantes preenchidos, e com no mínimo 1 e máximo 2 amostras por octante. Foram utilizadas, no máximo, 5 pontos amostrais e 4 nós previamente simulados, para a simulação de novos nós.

Após a simulação os resultados foram transformados para sua distribuição original. Para ilustrar os resultados obtidos, escolhidas as realizações 100, 1 e 65 conforme pode-se observar na Figura 29, Figura 30 e Figura 31 respectivamente. 


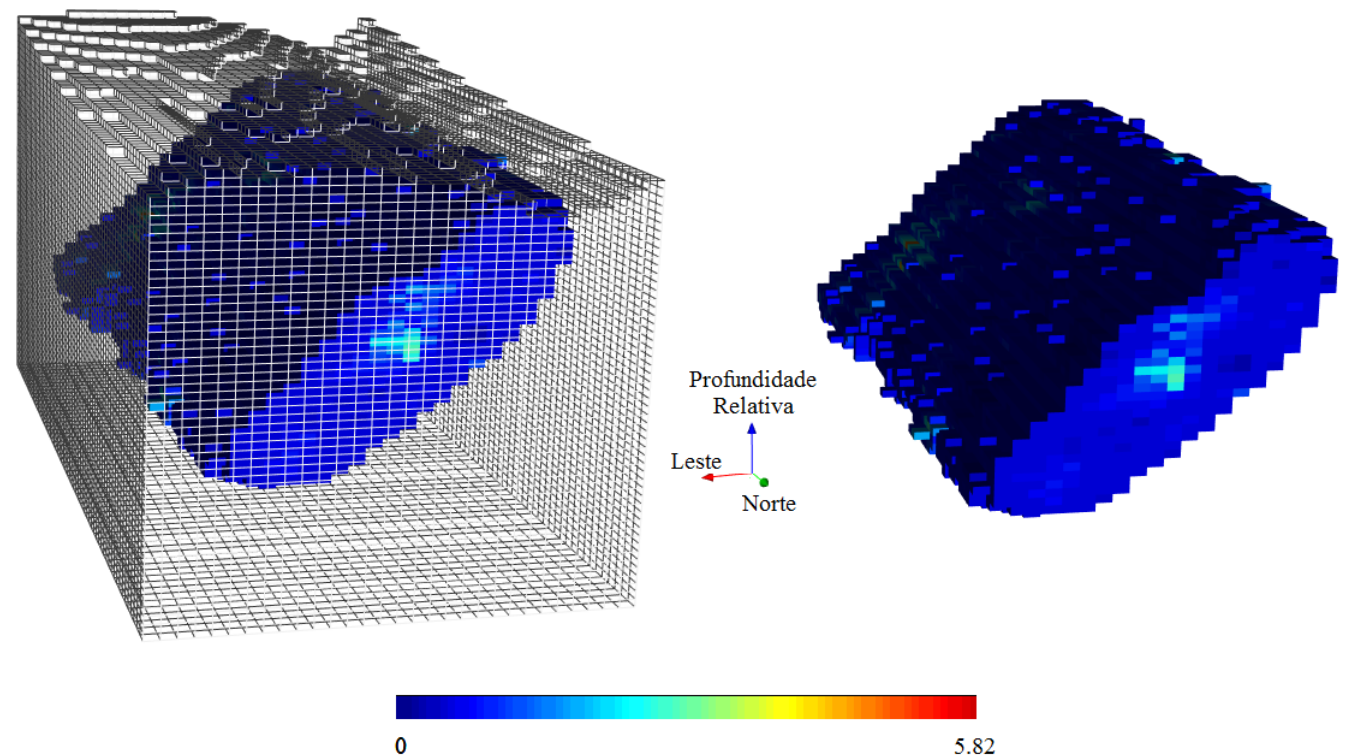

Figura 29 - Realização noo0 da Simulação Sequencial Gaussiana para os dados de cobre do depósito sintético. A imagem da esquerda mostra o modelo de blocos total e da direita apenas do corpo de minério.

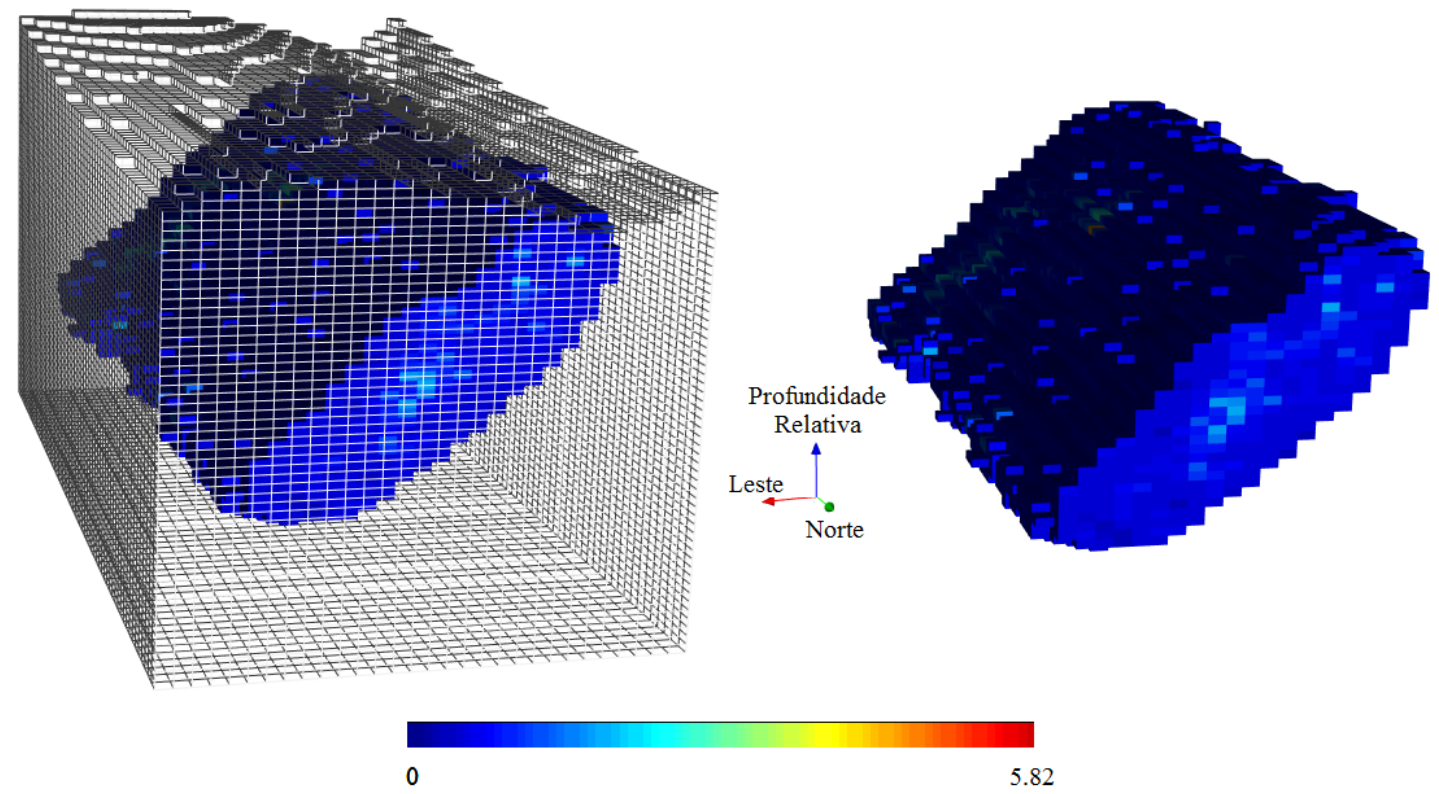

Figura 30 - Realização $n^{\circ} 1$ da Simulação Sequencial Gaussiana. A imagem da esquerda mostra o modelo de blocos total e da direita apenas do corpo de minério. 


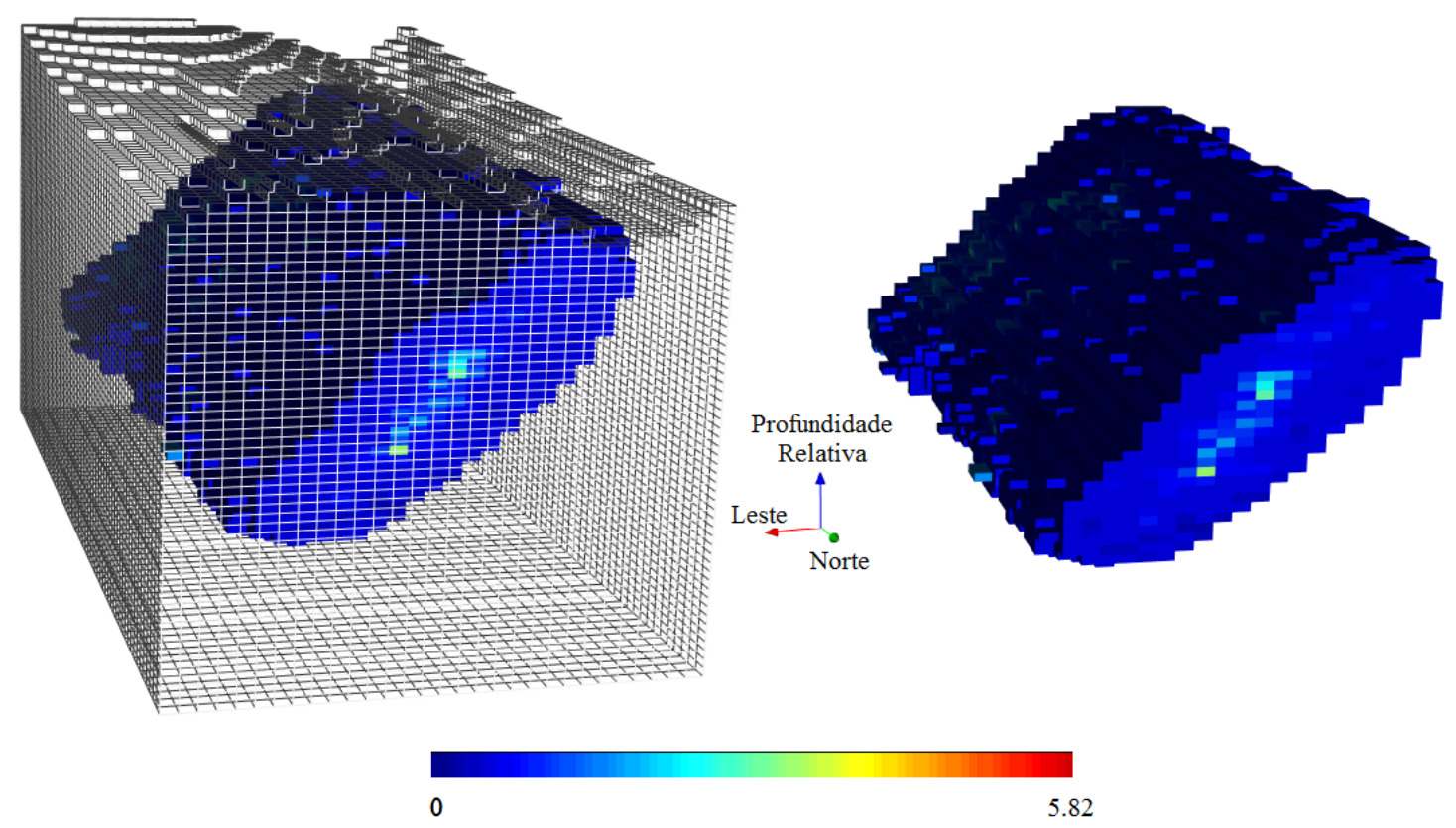

Figura 31 - Realização $n^{\circ} 65$ da Simulação Sequencial Gaussiana. A imagem da esquerda mostra o modelo de blocos total e da direita apenas do corpo de minério.

Com os resultados destas 100 realizações, foi feita a média de valores para cada bloco (e-type) e suas estatísticas descritivas são apresentadas na Tabela 7. Comparando as estatísticas descritivas da média das simulações (e-type) àquelas dos furos de sonda (Tabela 3) e aos dados reais (Tabela 2) observam-se algumas diferenças, mas, de modo geral, todas as distribuições são semelhantes, o que pode ser conferido pela observação do histograma apresentado na Figura 32.

Tabela 7 - Estatísticas descritivas do e-type dos blocos simulados para teores de cobre.

\begin{tabular}{cccccccc}
\hline \multicolumn{8}{c}{ SGS } \\
\hline \multirow{2}{*}{ Mínimo } & Primeiro & Mediana & Média & $\begin{array}{c}\text { Desvio } \\
\text { padrão }\end{array}$ & $\begin{array}{c}\text { Terceiro } \\
\text { Quartil }\end{array}$ & Máximo & $\begin{array}{c}\text { Coeficiente } \\
\text { de Variação }\end{array}$ \\
& 0,3 & 0,6 & 0,7 & 0,2 & 0,7 & 3,7 & 35,9 \\
\hline
\end{tabular}




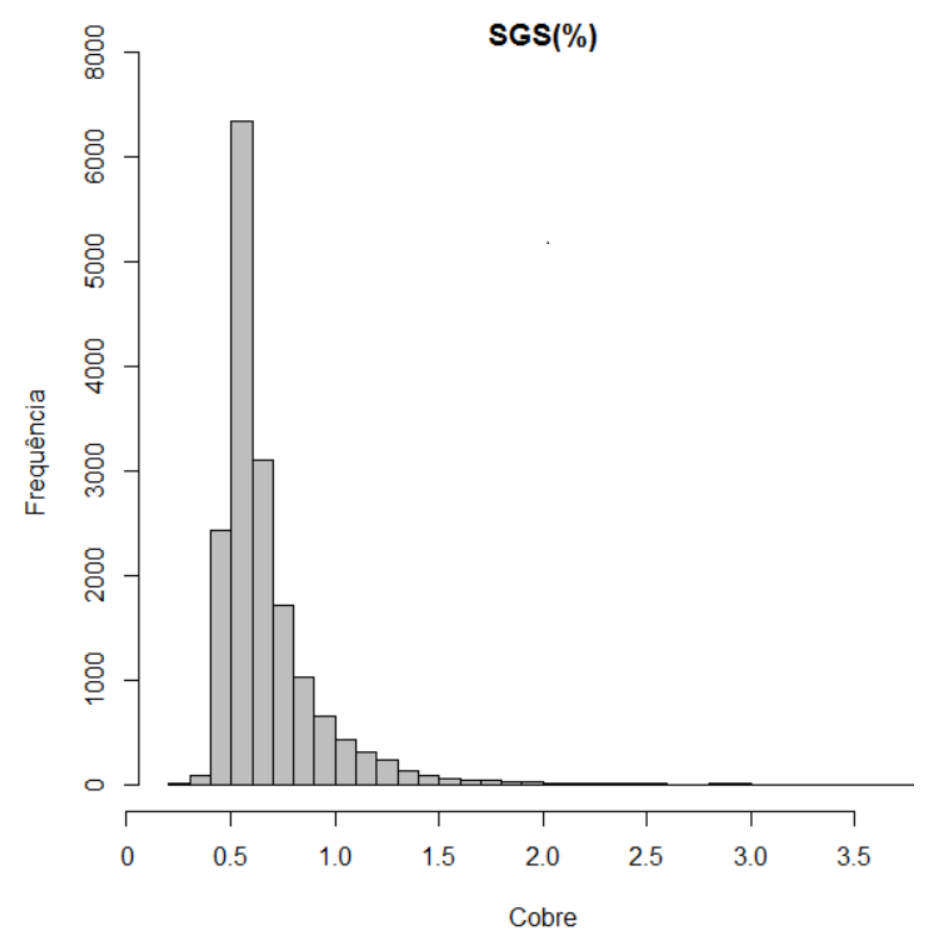

Figura 32 - Histograma do e-type dos teores de cobre nos blocos simulados pela Simulação Sequencial Gaussiana.

\subsubsection{Simulação Baseada em Wavelets (Wavesim)}

A Wavesim utiliza como base a imagem de treinamento, de onde são coletados todos os possíveis padrões a serem considerados na simulação. A imagem de treinamento utilizada foi criada por krigagem ordinária conforme apresentado em 7.2.1 e este resultado pode ser observado na Figura 26.

A vizinhança de busca é em unidades matriciais - cada unidade matricial é representada por um bloco, ou seja $10 \mathrm{~m}$ para X e Y e $5 \mathrm{~m}$ para Z - e foi utilizada uma busca isométrica com 11 unidades para as três direções. Este número foi escolhido para que a busca encontre ao menos 2 furos de sonda distintos em todos os blocos a serem simulados, uma vez que os furos estão distanciados em 4 unidades. Além disso, o tamanho dos modelos (ou retalhos) que serão alocados no centro do bloco que será simulado é de 5 unidades.

Foram feitas 100 realizações e o número de grupos de classes escolhido foi de 350 este número é idealmente o número de possíveis padrões que existem. Uma vez que a quantidade de padrões é muito alta foi escolhido um número elevado que não comprometesse 
demasiadamente o tempo de processamento. Além disso, a verificação visual dos resultados foi considerada satisfatória.

Outro ponto a ser destacado é que a simulação ocorre apenas quando o número de blocos em cada direção é constante. Neste caso a topografia e o corpo de minério, como estão apresentados na Figura 33, Figura 34 e Figura 35, foram recortadas posteriormente. A Figura 33 mostra a realização número 100, nela pode-se observar que nos locais não amostrados a simulação criou um corpo de minério artificial. Isto ocorre, pois não há o controle dos dados naquele local e, sem amostragem, qualquer padrão pode aparecer. Além disso, tratando-se de uma simulação sequencial, ou seja, que utiliza os dados previamente simulados, esta feição tende a crescer por propagação. A Figura 34 e a Figura 35 mostram, respectivamente, as realizações $n^{\circ} 1$ e $n^{\circ} 65$ onde o corpo de minério está definido da maneira esperada.

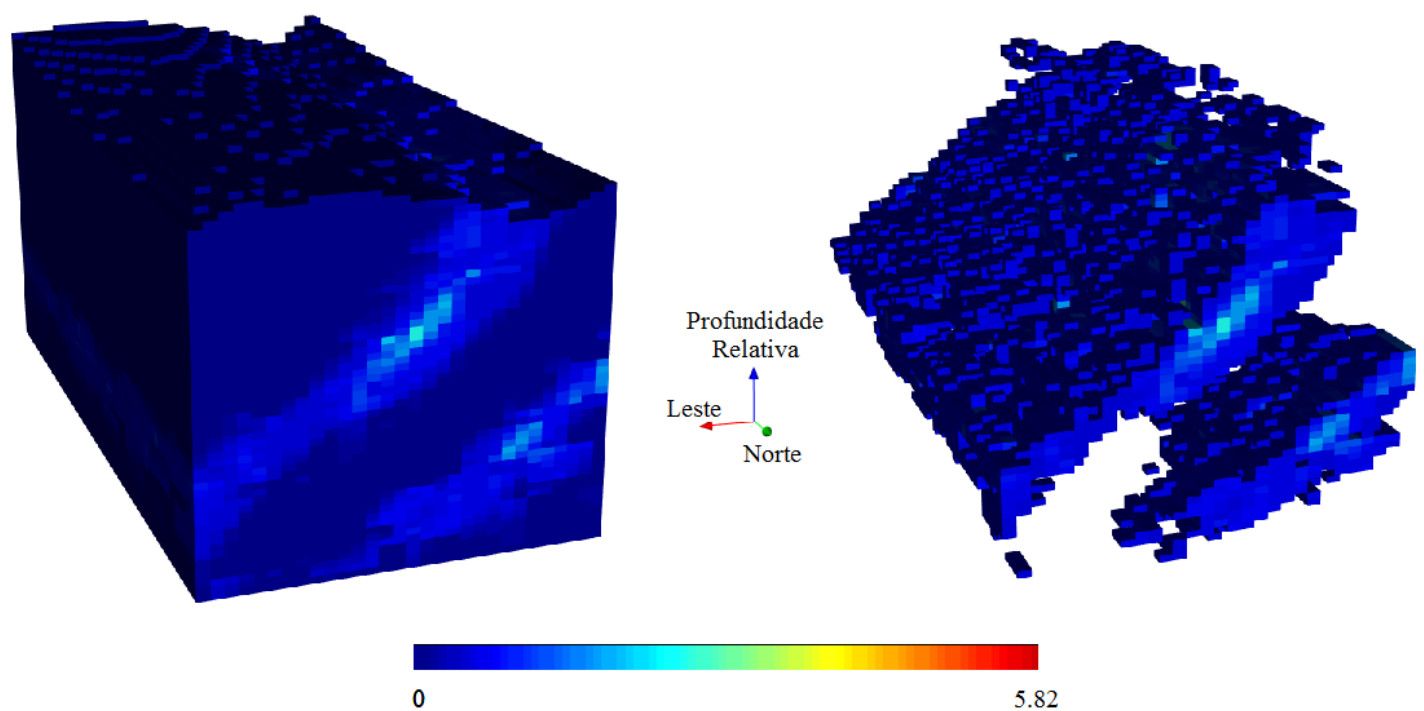

Figura 33 - Realização no 100 da Wavesim para os dados de cobre do depósito sintético. Observa-se a presença de um corpo mineralizado que não encontra correspondência amostral. 


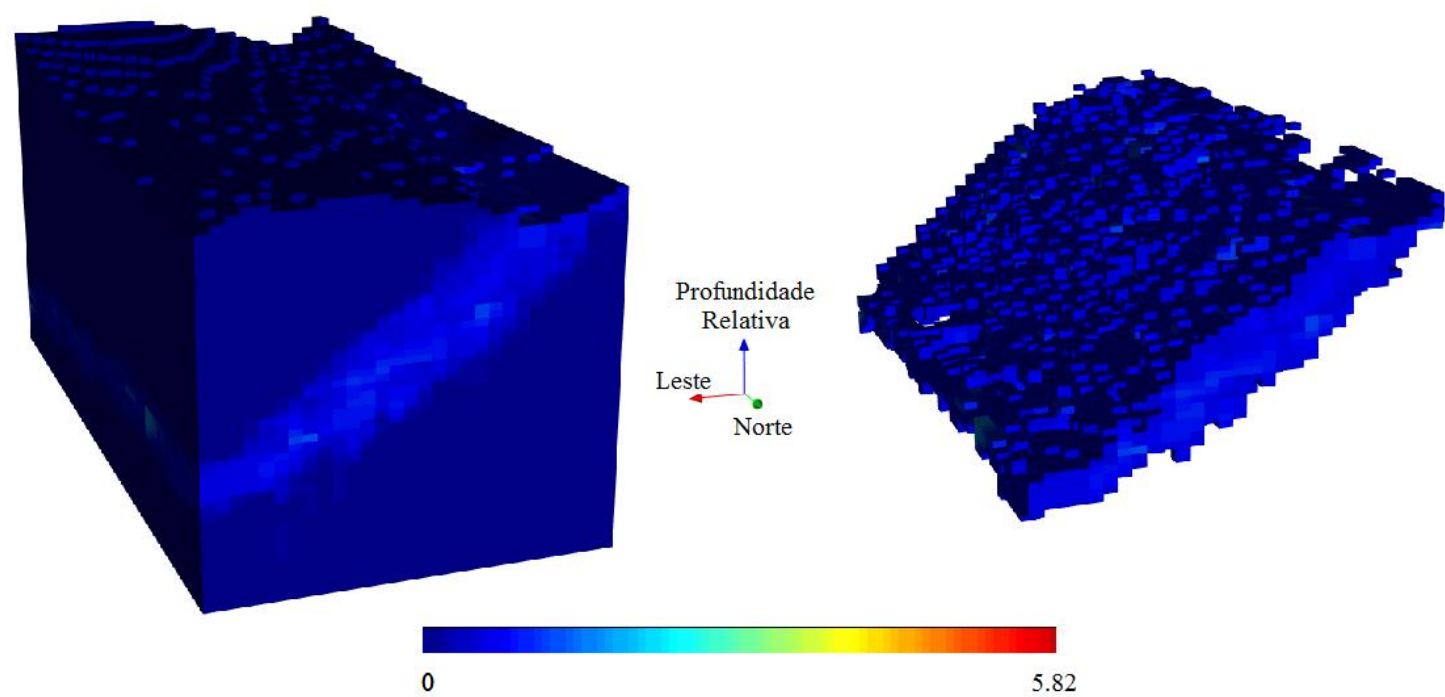

Figura 34 - Realização $n^{\circ} 1$ da Wavesim para os dados de cobre do depósito sintético. A imagem da esquerda mostra o modelo de blocos total e da direita apenas do corpo de minério.

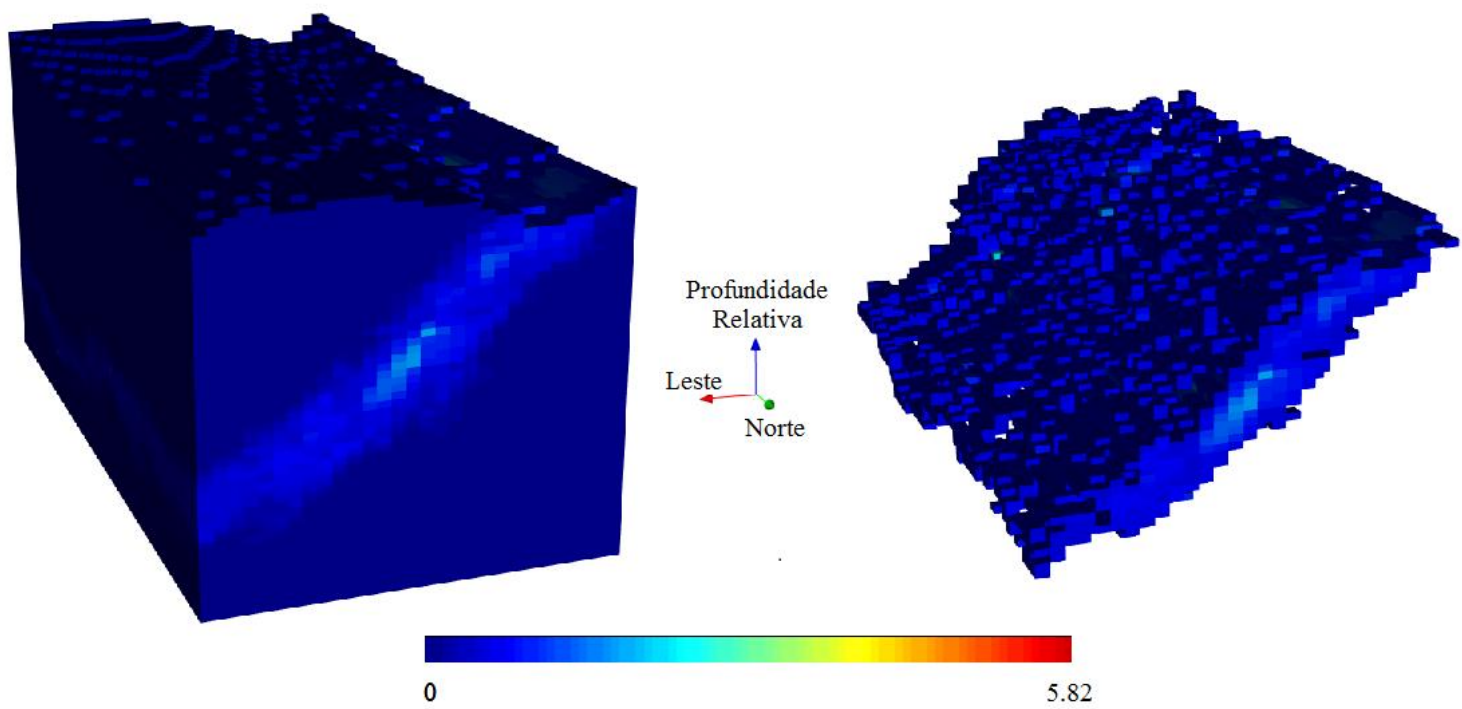

Figura 35 - Realização n65 da Wavesim para os dados de cobre do depósito sintético. A imagem da esquerda mostra o modelo de blocos total e da direita apenas do corpo de minério.

Com os resultados da simulação a média de cada bloco simulado (e-type) foi calculada a fim de compará-las aos resultados obtidos por krigagem, SGS e aos furos de sonda. As estatísticas descritivas estão apresentadas na Tabela 8 e é possível observar que os resultados são semelhantes aos resultados da krigagem, com quartis (primeiro, mediana e 
terceiro) e média idênticos, enquanto o valor máximo é igual ao dos furos e da simulação, ou seja, os resultados não foram suavizados como na krigagem.

Tabela 8 - Estatísticas descritivas do e-type do Wavesim para os teores de cobre.

\begin{tabular}{|c|c|c|c|c|c|c|c|}
\hline \multicolumn{8}{|c|}{ WS } \\
\hline Mínimo & $\begin{array}{c}\text { Primeiro } \\
\text { Quartil }\end{array}$ & Mediana & Média & $\begin{array}{l}\text { Desvio } \\
\text { padrão }\end{array}$ & $\begin{array}{c}\text { Terceiro } \\
\text { Quartil }\end{array}$ & Máximo & $\begin{array}{l}\text { Coeficiente } \\
\text { de Variação }\end{array}$ \\
\hline 0 & 0,5 & 0,6 & 0,6 & 0,2 & 0,7 & 5,8 & 31,3 \\
\hline
\end{tabular}

O histograma da média das realizações da Simulação Baseada em Wavelets (Figura 36) é assimétrico positivo e apresenta concentração de dados próximos do teor 0,5 , assim como os histogramas da Simulação Sequencial Gaussiana, da krigagem, da amostragem e dos dados originais.

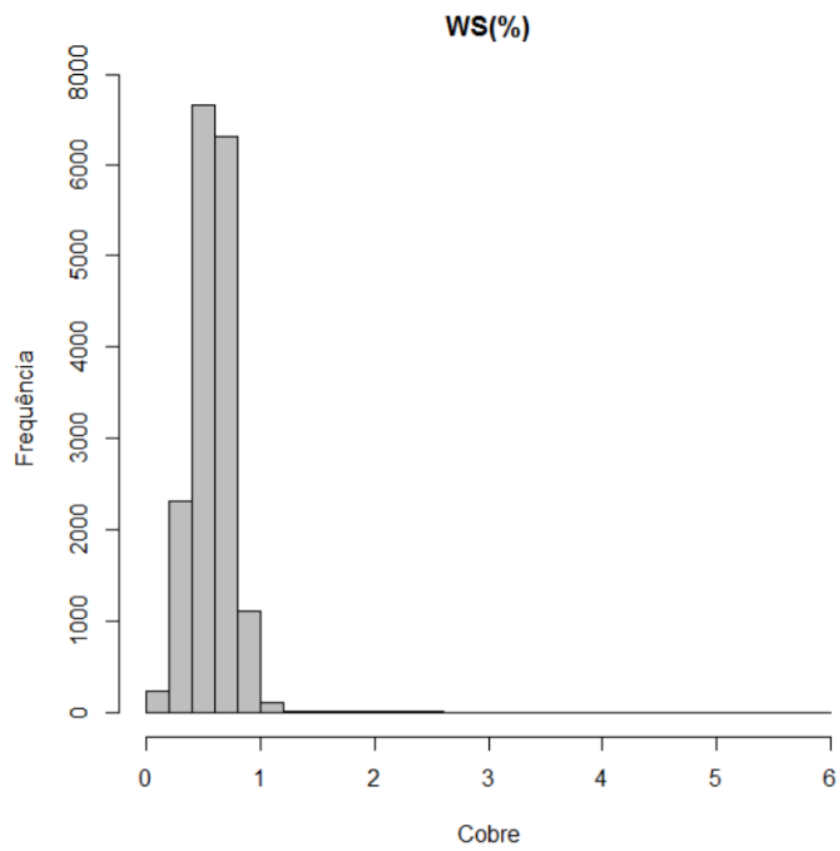

Figura 36 - Histograma da média do teor de cobre dos blocos simulados pelo método Wavesim.

\subsection{Análise do lucro por bloco}

Para a realização da análise de lucro por bloco foi escrito um programa de computador na linguagem Python utilizando o algoritmo apresentado no item 5. Para isto, o 
preço do minério (MP) de cobre foi considerado como $\mathrm{R} \$ 0,012$ por grama. A recuperação da pilha de minério rico (pilha $\mathrm{i}=0$ ) é $92 \%$ e o custo total de lavra para cada bloco é de $\mathrm{R} \$ 7727,00$. A pilha de minério pobre (pilha $\mathrm{i}=1$ ) tem com recuperação de $75 \%$ e o custo por bloco é igual a $\mathrm{R} \$ 6075,00$. A terceira pilha é de estéril (pilha $\mathrm{i}=2$ ), na qual todo material é descartado e o custo é de $\mathrm{R} \$ 1000,00$ por bloco.

O volume do bloco (V) apresenta $500 \mathrm{~m}^{3}$. A densidade do minério é considerada variável e específica para cada bloco, seu valor foi calculado por krigagem ordinária a partir da densidade das amostras contidas na sondagem como apresentado no Anexo 1. Outra variável é o valor simulado em cada bloco.

O programa calcula o valor potencial (VP) de cada bloco e a saída são dois arquivos, o primeiro com valor potencial de cada bloco e o segundo em qual pilha cada bloco deve ir.

Para os valores reais dos blocos do depósito, a média, valor mínimo e valor máximo do valor potencial resultaram, respectivamente, em $\mathrm{R} \$ 2.748,60$, $\mathrm{R} \$-1.000,00$, $\mathrm{R} \$ 318.160,60$. Enquanto a média das realizações da Simulação Sequencial Gaussiana apresentou valores $\mathrm{R} \$ 2.692,40, \mathrm{R} \$-1.000,00, \mathrm{R} \$ 59.994,40$ e a média das realizações da Wavesim $\mathrm{R} \$ 1.776,50, \mathrm{R} \$-1.000,00, \mathrm{R} \$ 98.379,40$, respectivamente como valor médio, mínimo e máximo. Isto mostra que a Wavesim conseguiu reproduzir melhor os valores altos apresentados no depósito. Os histogramas destes valores potenciais calculados para a média de cada simulação é apresentado na Figura 37 e os histogramas dos valores médios da SGS e da Wavesim estão na Figura 38 e na Figura 39. A comparação destes resultados mostra que o formato da distribuição é semelhante e que a quantidade de blocos do Wavesim representou melhor os blocos com valor mais baixo.

Por outro lado, ao comparar a quantidade de blocos que foram para cada pilha a SGS alocou em média 6947 na primeira pilha (minério rico), 8135 na segunda pilha (minério pobre) e 1685 na terceira (estéril). E o Wavesim colocou em média 6684 blocos na primeira, 5437 na segunda e 4645 na terceira, enquanto os valores corretos são 6423, 7641, 2703 , respectivamente. 


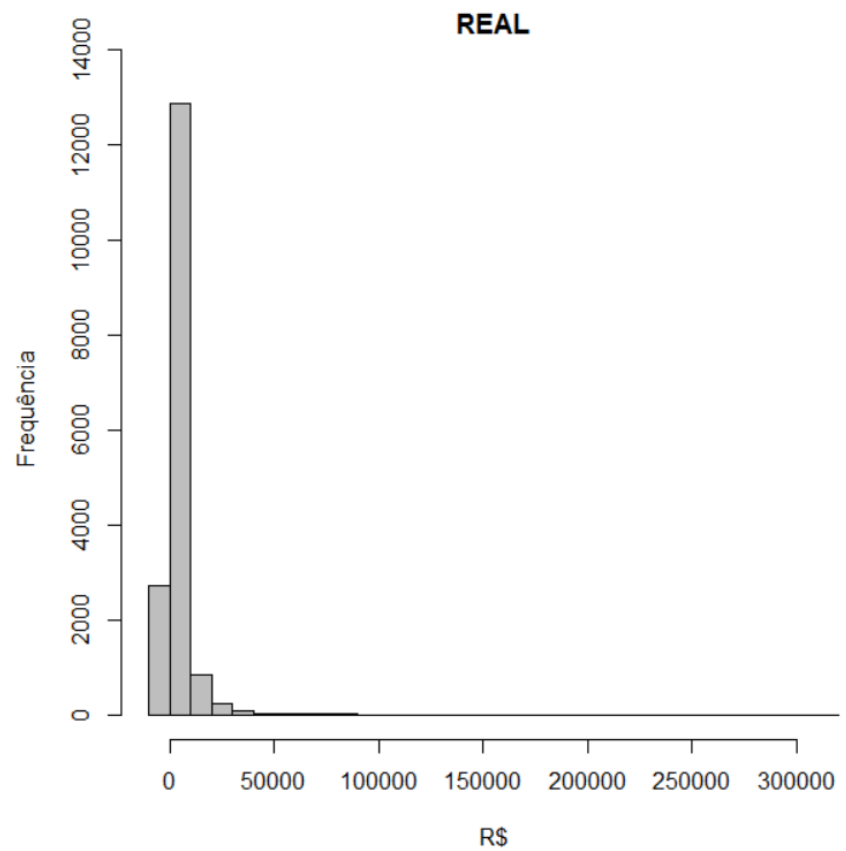

Figura 37 - Histograma dos valores reais de cada bloco do depósito.

SGS

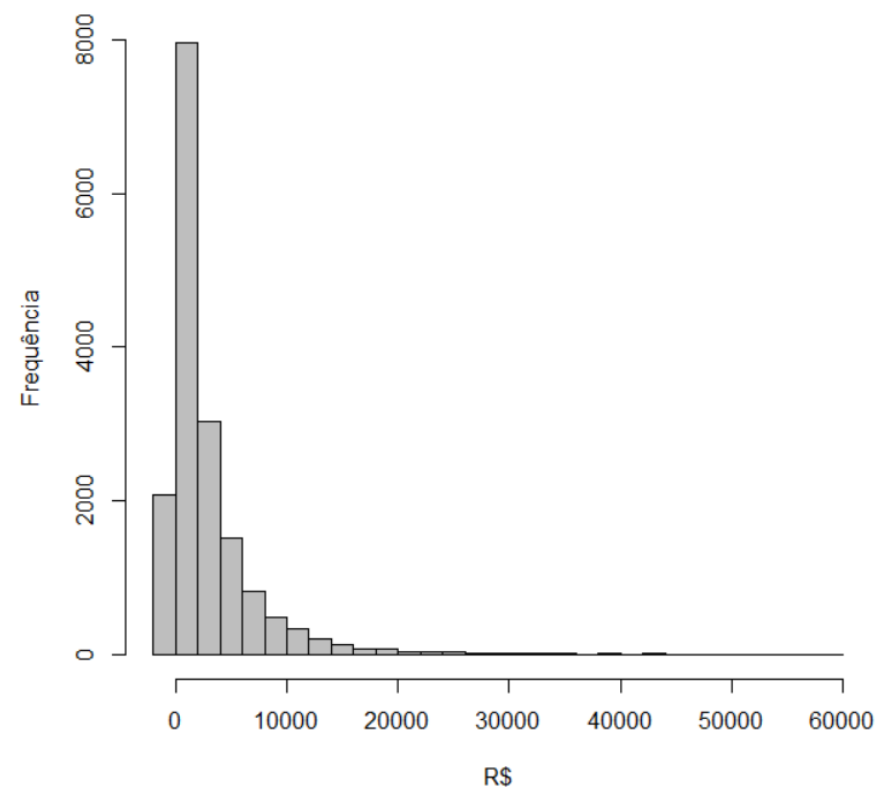

Figura 38 - Histograma da media dos valores potenciais de cada bloco simulado por SGS. 


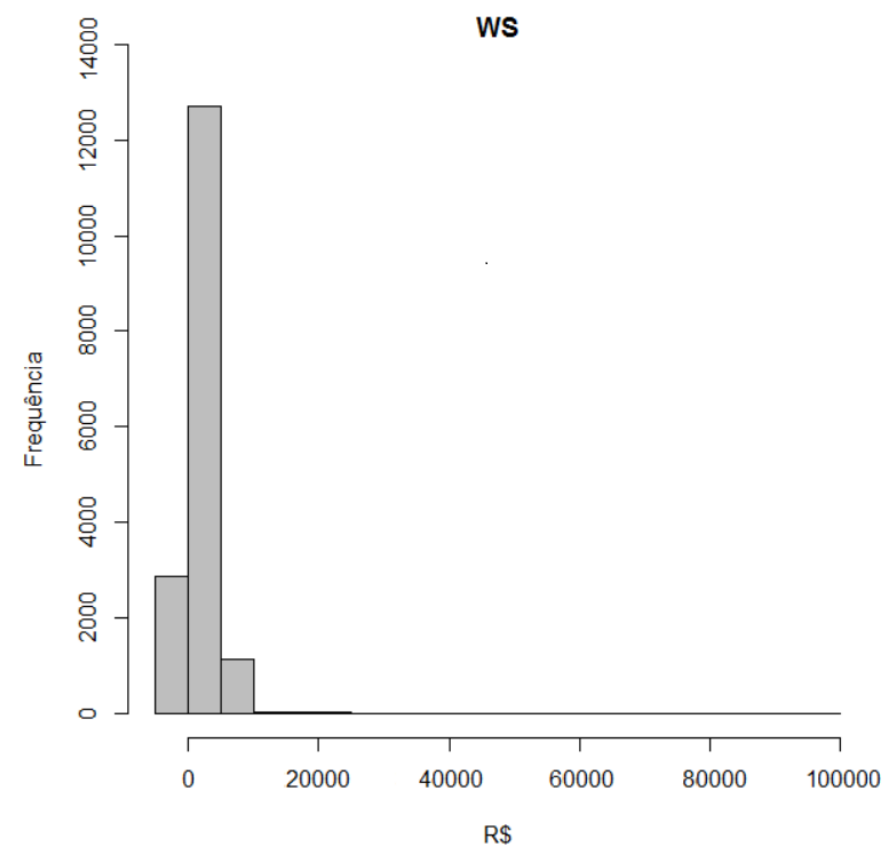

Figura 39 - Histograma da media dos valores potenciais de cada bloco simulado por Wavesim.

\section{Discussão dos Resultados}

Apresentam-se na Figura 40 os boxplots dos teores de cobre dos dados reais e dos teores de cobre calculados por krigagem ordinária, Simulação Sequencial Gaussiana e Simulação Baseada em Wavelets. Os boxplots à esquerda, na Figura 40, ilustram toda a distribuição de frequências e à direita ilustram as distribuições dos teores de cobre sem os outliers, porém todos os valores da distribuição são utilizados para os cálculos. Comparandose estes gráficos pode-se inferir que a distribuição dos resultados e dos dados reais são similares e nenhuma técnica de predição reproduziu as caudas da distribuição. 

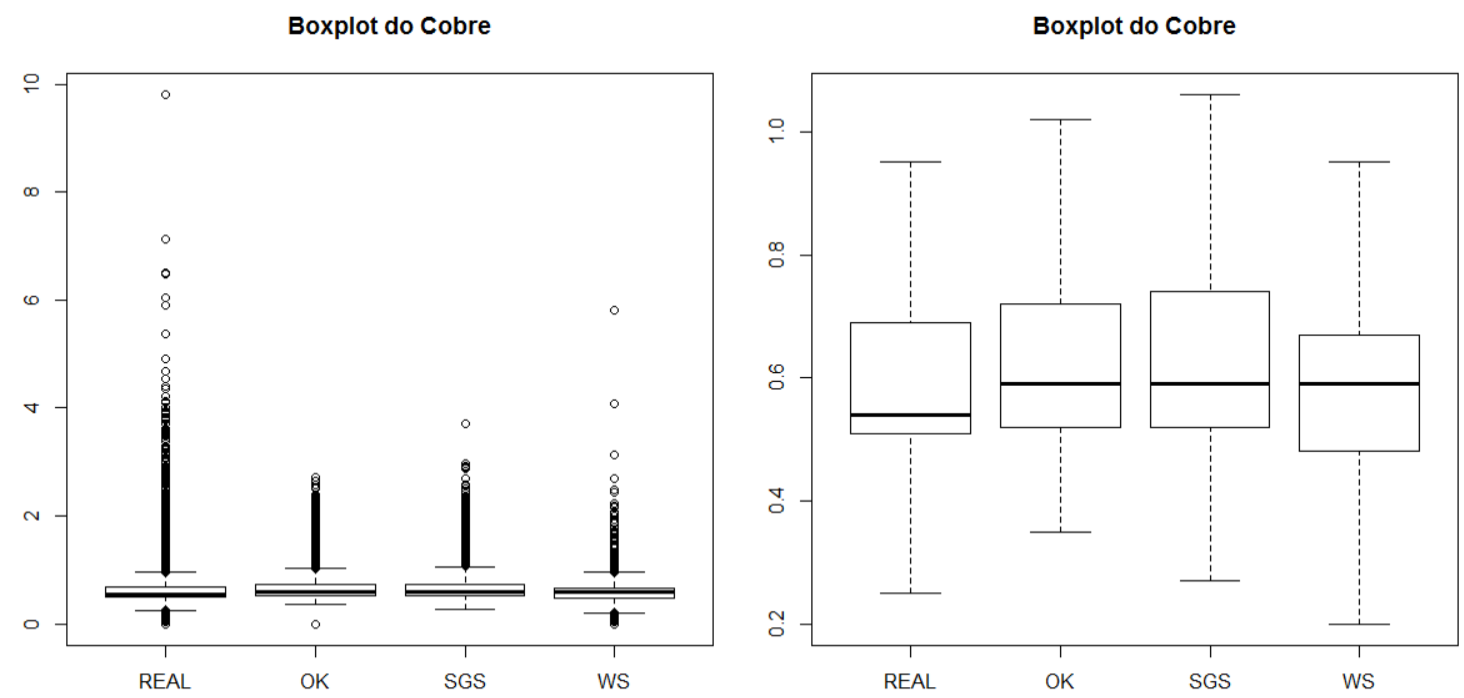

Figura 40 - Boxplot da quantidade de cobre real, krigada (OK) e simulada pelos métodos de Simulação Sequencial Gaussiana (SGS) e Wavesim (WS).

Outra maneira de comparar os métodos foi calcular a soma cumulativa dos valores potenciais dos blocos para todas as realizações, estes gráficos são apresentados na Figura 41. A linha vermelha mostra a evolução do lucro potencial, atingindo o pico ao redor de $\mathrm{R} \$ 46$ milhões. A linha verde mostra o crescimento do lucro potencial dos blocos resultantes da krigagem ordinária do corpo de minério e seu valor máximo é de $\mathrm{R} \$ 43,7$ milhões. As linhas pretas (Figura 41a) representam a evolução dos lucros de cada realização da Simulação Sequencial Gaussiana, com lucro máximo de R \$50,9 milhões, mínimo de R \$39,6 milhões e média de R \$45,1 milhões. Enquanto as linhas azuis (Figura 41b) são referentes às realizações da Simulação Baseada em Wavelets. Sua gama de possibilidades é muito maior e a realização com maior soma do valor potencial apresenta $\mathrm{R} \$ 43$ milhões de lucro, a mínima é de $\mathrm{R} \$ 13,8$ milhões de lucro e média de $\mathrm{R} \$ 29,8$ milhões de lucro. A linha amarela representa a evolução dos dados de cobre krigados no depósito inteiro (imagem de treinamento) e teve máximo de R $\$ 34,7$ milhões de lucro. Na Figura 41c pode-se comparar todos os resultados justapostos. 
(a)

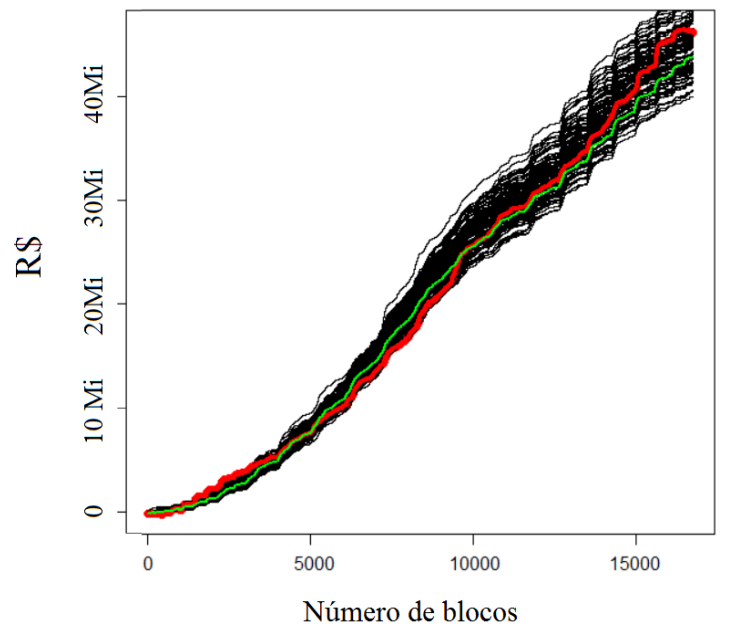

(b)

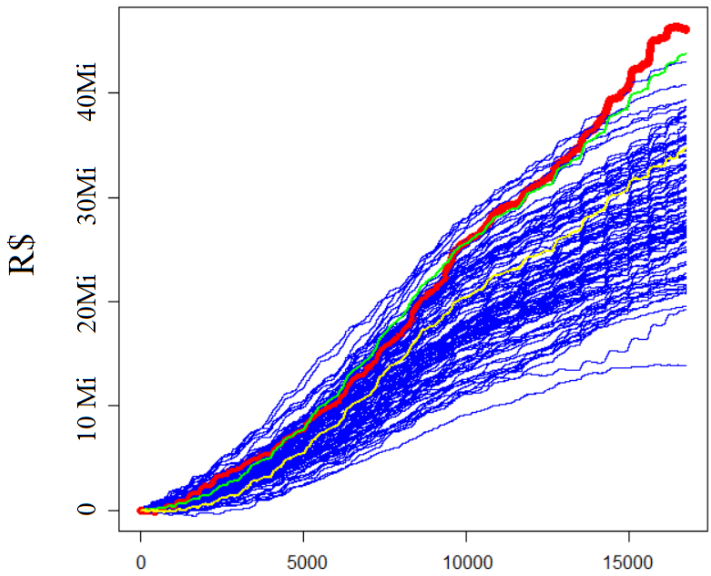

(c)

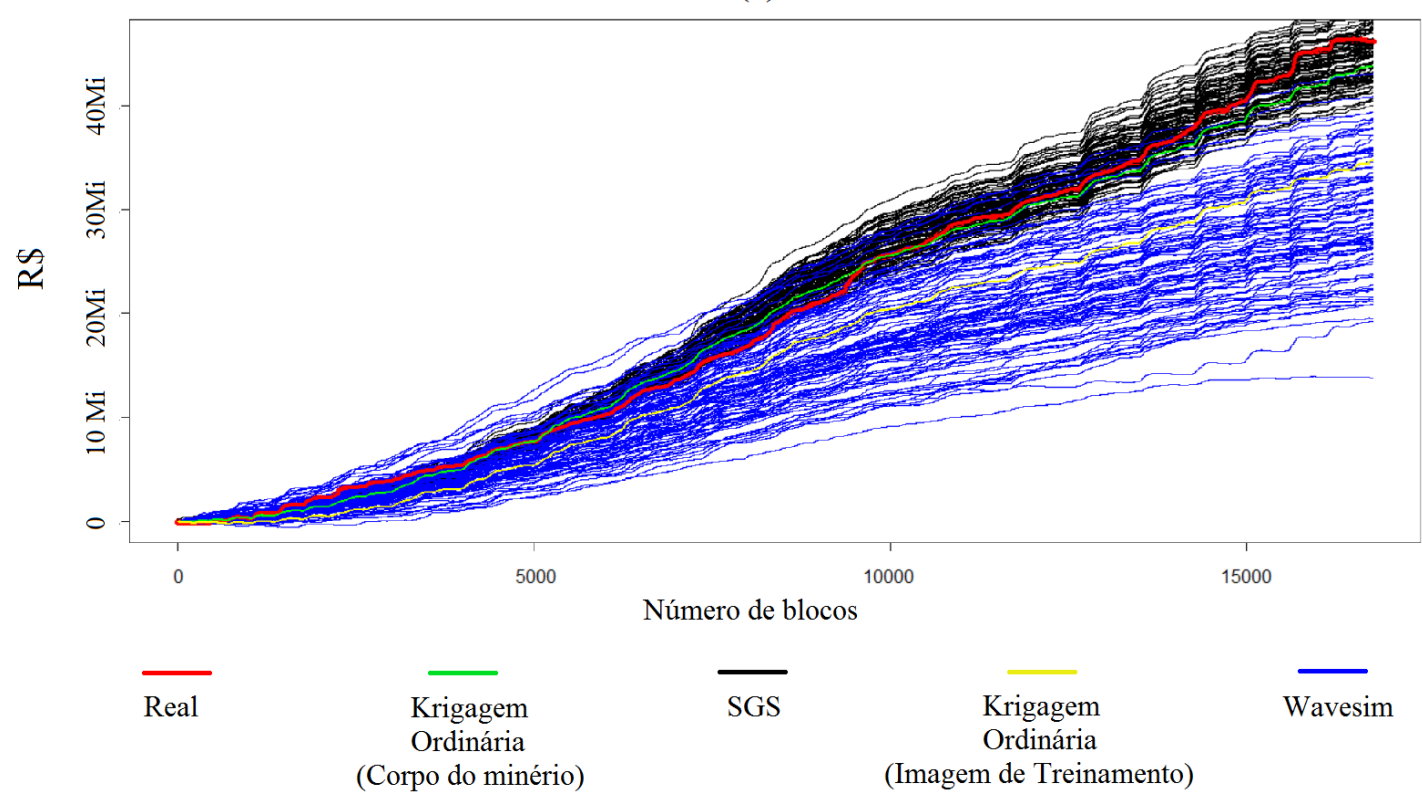

Figura 41 - Soma cumulativa dos valores potenciais de cada bloco para todas as realizações da Simulação Sequencial Gaussiana e da Simulação Baseada em Wavelets, dos blocos reais e dos blocos de krigados. A imagem (a) são os valores dos lucros potenciais de cada realização da SGS. A imagem (b) são os valores dos lucros potenciais de cada realização da Wavesim. Enquanto a imagem (c) é a justaposição de (a) $e(b)$.

Com os resultados referentes à locação de cada bloco em pilhas, é possível fazer a comparação de ambos métodos de simulação, uma vez que é conhecido o valor real de cada bloco. Assim, foram verificados quantos blocos foram para as pilhas corretas, quantos blocos de estéril foram considerados como minério e quantos blocos de minério foram considerados como estéril. Estes resultados estão apresentados na Figura 42. 

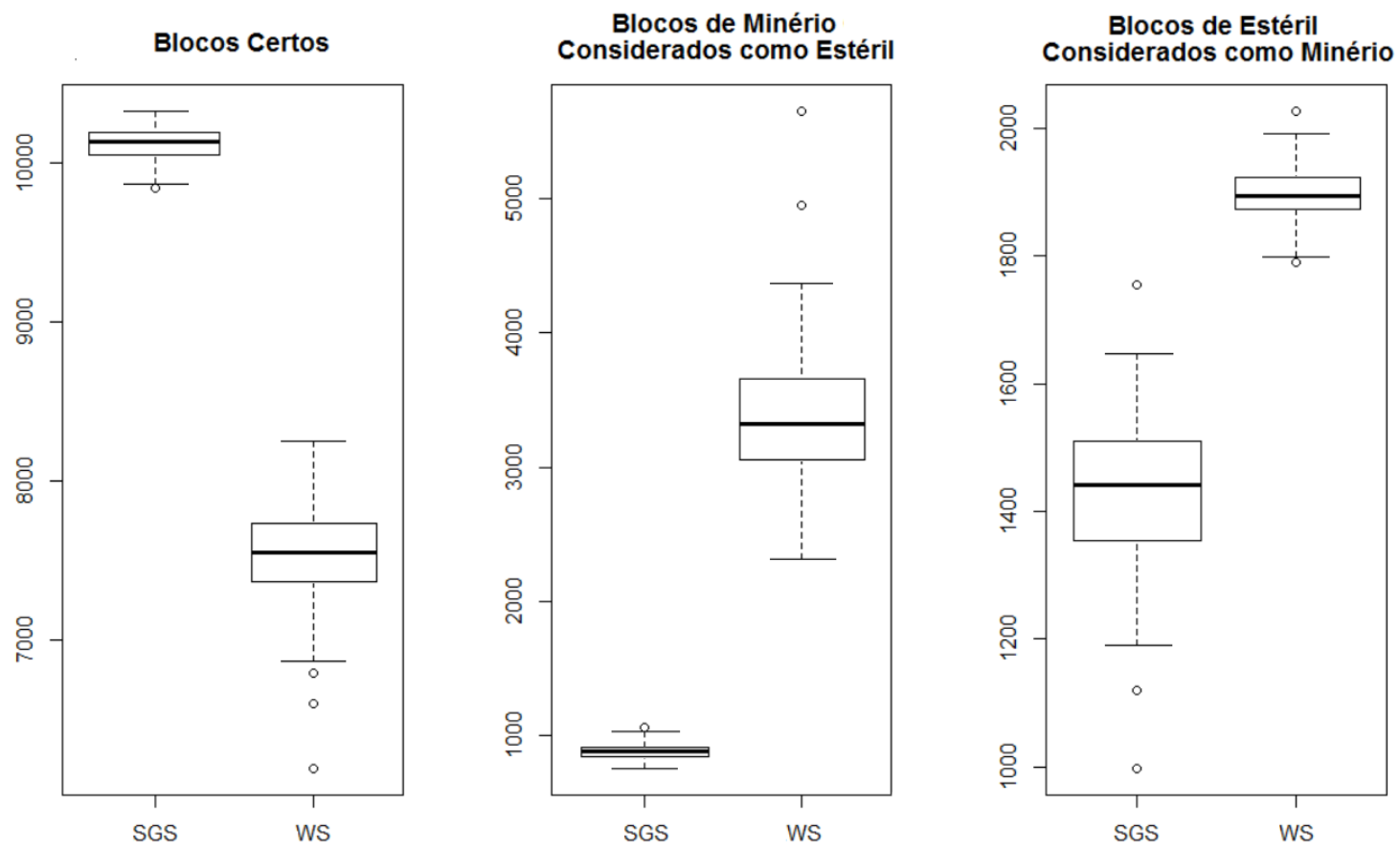

Figura 42 - Boxplot da distribuição da quantidade de blocos alocados nas pilhas corretas, blocos de estéril considerados como minério e blocos de minério considerados como estéril.

Para melhor comparação entre as simulações, as estatísticas descritivas da quantidade de blocos alocados corretamente em cada realização são apresentadas na Tabela 9. É notável que o número de blocos corretos, em média, é superior no método Simulação Sequencial Gaussiana (SGS). Entretanto, o coeficiente de variação é muito maior para a Simulação Baseada em Wavelets.

Tabela 9 - Estatística descritiva da quantidade de blocos que cada realização acertou, para a Simulação Sequencial Gaussiana (SGS) e Wavesim (WS).

\begin{tabular}{ccccccccc}
\hline Método & Mínimo & $\begin{array}{c}\text { Primeiro } \\
\text { Quartil }\end{array}$ & Mediana & Média & $\begin{array}{c}\text { Desvio } \\
\text { padrão }\end{array}$ & $\begin{array}{c}\text { Terceiro } \\
\text { Quartil }\end{array}$ & Máximo & $\begin{array}{c}\text { Coeficiente } \\
\text { de Variação }\end{array}$ \\
\hline SGS & 9838 & 10052,8 & 10130 & 10123 & 103 & 10190,2 & 10324 & 1 \\
WS & 6189 & 7360,8 & 7543 & 7532,9 & 349,5 & 7728,2 & 8245 & 4,6 \\
\hline
\end{tabular}


As estatísticas descritivas dos dados de blocos de estéril considerados como minério por ambos os métodos são apresentados Tabela 10 e como já observado no boxplot o método SGS em média superestimou menos blocos. Além disso, novamente, o coeficiente de variação é considerado alto.

Tabela 10 - Estatística descritiva da quantidade de blocos que cada realização acertou, para a Simulação Sequencial Gaussiana (SGS) e Wavesim (WS).

\begin{tabular}{ccccccccc}
\hline \multicolumn{8}{c}{ Blocos de estéril considerados como minério } \\
Método & Mínimo & $\begin{array}{c}\text { Primeiro } \\
\text { Quartil }\end{array}$ & Mediana & Média & $\begin{array}{c}\text { Desvio } \\
\text { padrão }\end{array}$ & $\begin{array}{c}\text { Terceiro } \\
\text { Quartil }\end{array}$ & Máximo & $\begin{array}{c}\text { Coeficiente } \\
\text { de Variação }\end{array}$ \\
\hline SGS & 998 & 1355,8 & 1441 & 1426,8 & 123,3 & 1509,5 & 1755 & 8,6 \\
WS & 1791 & 1874 & 1895 & 1898 & 41,5 & 1922,5 & 2027 & 2,2 \\
\hline
\end{tabular}

As estatísticas descritivas da quantidade de blocos de minério considerados como estéril podem ser observadas na Tabela 11. A quantidade de bloco de minério que foram considerados como estéril é maior na Wavesim, e o coeficiente de variação é notavelmente maior no Wavesim. Isto ocorre nas três comparações da distribuição dos blocos em cada realização, uma vez que esta simulação produz um leque de possibilidades maior. Consequentemente, a gama de possíveis rendimentos futuros é maior, como foi ilustrado na Figura 41 (leque de possibilidades).

Tabela 11 - Estatística descritiva da quantidade de blocos que cada realização acertou para a Simulação Sequencial Gaussiana (SGS) e Wavesim (WS).

\begin{tabular}{ccccccccc}
\hline \multicolumn{8}{c}{ Blocos de minério considerados como estéril } \\
Método & Mínimo & $\begin{array}{c}\text { Primeiro } \\
\text { Quartil }\end{array}$ & Mediana & Média & $\begin{array}{c}\text { Desvio } \\
\text { padrão }\end{array}$ & $\begin{array}{c}\text { Terceiro } \\
\text { Quartil }\end{array}$ & Máximo & $\begin{array}{c}\text { Coeficiente } \\
\text { de Variação }\end{array}$ \\
\hline SGS & 758 & 842,2 & 883,5 & 880,4 & 58,3 & 917,2 & 1065 & 6,6 \\
WS & 2315 & 3053,5 & 3323 & 3369,7 & 507,5 & 3652,5 & 5650 & 15,1 \\
\hline
\end{tabular}

Outra abordagem de comparação dos resultados destes métodos foi verificar quanto dinheiro, em Reais, foi deixado de ganhar, ou seja, minério sendo considerado como estéril (perda real). E quanto prejuízo se teve com blocos simulados como minério que eram blocos de estéril (diluição). Esta análise foi feita com a soma dos valores potencias dos blocos alocados indevidamente, tanto superestimados, quanto subestimados. 
Pelo gráfico boxplot (Figura 43) nota-se que os resultados de ambos os métodos considerou aproximadamente a mesma quantidade de estéril como minério. Além disso, ressalta-se a quantidade de minério considerado como estéril pelo método Wavesim. A Simulação Sequencial Gaussiana mostrou menor subestimação dos blocos e superestimação equivalente.
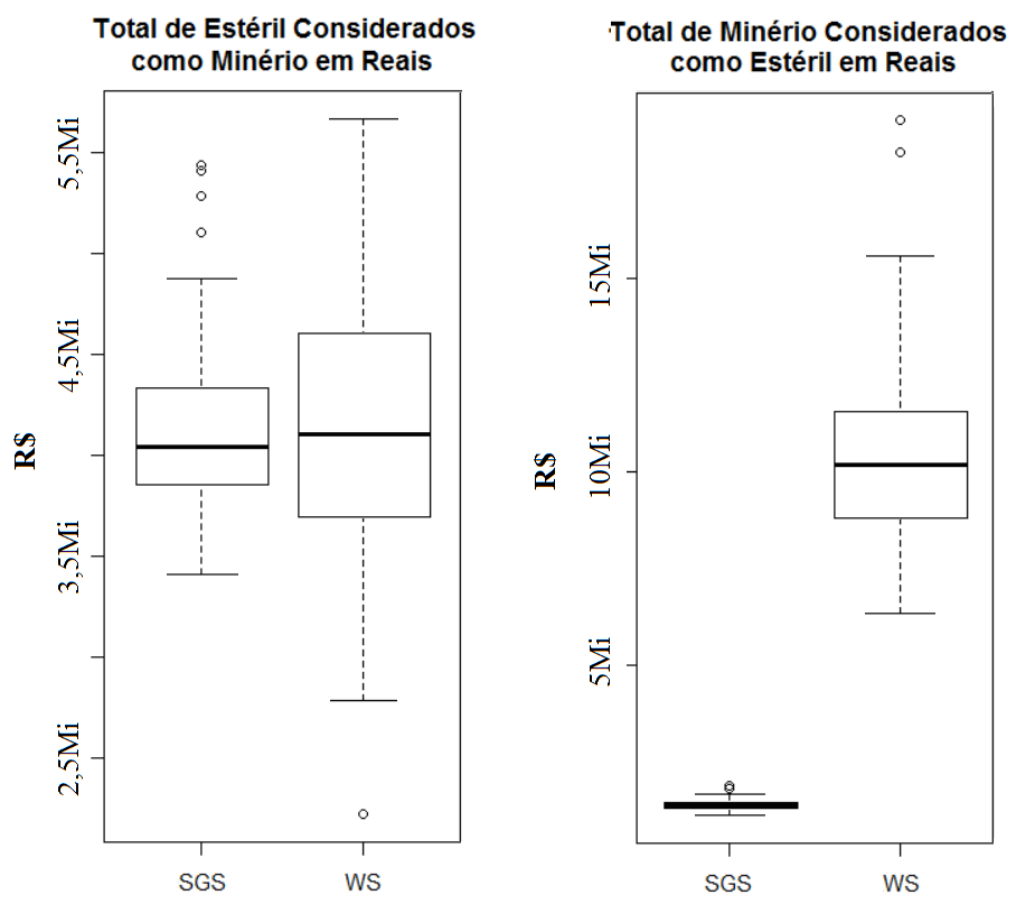

Figura 43 - Gráfico boxplot de quantos Reais de minério real foram classificados como estéril e quantos Reais esperados eram estéril.

Os resultados da estatística descritiva dos valores monetários que foram equivocadamente considerados minério pelas simulações são apresentados na Tabela 12. Os valores de mínimo e primeiro quartil são consideravelmente menores, enquanto, o terceiro quartil e máximo são consideravelmente maiores na Wavesim. E as médias diferem em apenas $\mathrm{R} \$ 17.329,00$. 
Tabela 12 - Estatística descritiva do total de Reais que foram considerados como lucro e eram prejuízo.

\begin{tabular}{ccccccccc}
\hline \multicolumn{9}{c}{ Total de estéril considerado como minério (R\$) } \\
Método & Mínimo & $\begin{array}{c}\text { Primeiro } \\
\text { Quartil }\end{array}$ & Mediana & Média & $\begin{array}{c}\text { Desvio } \\
\text { padrão }\end{array}$ & $\begin{array}{c}\text { Terceiro } \\
\text { Quartil }\end{array}$ & Máximo & $\begin{array}{c}\text { Coeficiente } \\
\text { de Variação }\end{array}$ \\
\hline SGS & $3,4 \times 10^{6}$ & $3,9 \times 10^{6}$ & $4,0 \times 10^{6}$ & $4,1 \times 10^{6}$ & $4,1 \times 10^{5}$ & $4,3 \times 10^{6}$ & $5,4 \times 10^{6}$ & 9,9 \\
WS & $2,2 \times 10^{6}$ & $3,7 \times 10^{6}$ & $4,1 \times 10^{6}$ & $4,1 \times 10^{6}$ & $6,7 \times 10^{5}$ & $4,6 \times 10^{6}$ & $5,7 \times 10^{6}$ & 16 \\
\hline
\end{tabular}

As estatísticas descritivas do total de Reais dos blocos considerados como estéril e na verdade gerariam lucro são apresentadas na Tabela 13. Desta vez a diferença da quantidade de dinheiro sendo considerado como estéril é enorme e todos os resultados da estatística descritiva apontam a Simulação Sequencial Gaussiana como o método que menos errou. Como já mencionado, os valores de coeficiente de variação são elevados no método Wavesim pois a série de possíveis valores é maior.

Tabela 13 - Estatística descritiva do total de Reais que foram considerados como estéril e gerariam lucro.

\begin{tabular}{ccccccccc}
\hline \multicolumn{2}{c}{ Total de minério considerado como estéril (R\$) } \\
Método & \multirow{2}{*}{ Mínimo } & $\begin{array}{c}\text { Primeiro } \\
\text { Quartil }\end{array}$ & Mediana & Média & $\begin{array}{c}\text { Desvio } \\
\text { padrão }\end{array}$ & $\begin{array}{c}\text { Terceiro } \\
\text { Quartil }\end{array}$ & Máximo & $\begin{array}{c}\text { Coeficiente } \\
\text { de Variação }\end{array}$ \\
\hline SGS & $1,2 \times 10^{6}$ & $1,3 \times 10^{6}$ & $1,4 \times 10^{6}$ & $1,4 \times 10^{6}$ & $1,3 \times 10^{5}$ & $1,5 \times 10^{6}$ & $1,9 \times 10^{6}$ & 9,4 \\
WS & $6,4 \times 10^{6}$ & $8,9 \times 10^{6}$ & $1,0 \times 10^{7}$ & $1,0 \times 10^{7}$ & $2,2 \times 10^{5}$ & $1,2 \times 10^{7}$ & $1,9 \times 10^{7}$ & 20,8 \\
\hline
\end{tabular}

\section{Considerações Finais}

A Simulação Sequencial Gaussiana é amplamente conhecida, utilizada e consagrada nas análises geoestatísticas. Por outro lado, as simulações de multiponto estão ganhando espaço principalmente na análise de dados categóricos. Para dados contínuos discute-se muito sobre a qualidade da imagem de treinamento e como esta deve ser construída. Neste trabalho foi utilizada a krigagem ordinária dos dados, uma vez que este é o melhor estimador linear não enviesado, ou seja, é o melhor estimador para precisão local dos dados.

A comparação matemática indica que a Simulação Sequencial Gaussiana é favorável para estimar a quantidade de minério. Esta simulação mostrou maior exatidão e precisão nas 
realizações, uma vez que todos os seus resultados estão mais próximos do real que os resultados das realizações da Simulação Baseada em Wavelets. Além disso, suas realizações resultam na destinação dos blocos significativamente melhor dos blocos nas pilhas de processamento, consequentemente, considerou menos blocos de minério como estéril e menos estéril como minério.

No entanto, é possível observar que os resultados das realizações da Simulação Baseada em Wavelets é um leque ao redor da imagem de treinamento. Isto mostra que o método é promissor, sempre que o usuário seja capaz de criar uma imagem de treinamento adequada, porém a criação do banco de padrões com valores e variabilidade espacial reais para cada depósito é a maior dificuldade deste método.

Outro grande problema é que ainda há uma certa complexidade em parametrizar adequadamente o Wavesim, uma vez que, obrigatoriamente, deve-se conhecer cada conceito da técnica - que possivelmente são conceitos novos para o geoestatístico tradicional. Além disso, a preparação do banco de dados e da imagem de treinamento é demasiadamente demorada comparada ao tempo de preparo dos dados para a Simulação Sequencial Gaussiana. Outro ponto negativo é a escolha da quantidade de agrupamentos necessária para a realização da simulação. Teoricamente, deve-se utilizar a quantidade de possíveis padrões, entretanto, na prática, este número é muito grande, portanto, deve-se escolher um número que seja grande o suficiente para representar os padrões desejados e, ao mesmo tempo, pequeno o suficiente para a simulação não consumir muito tempo de processamento. Devido a estes fatores, este método é usualmente mais demorado que a Simulação Sequencial Gaussiana.

Por último, a Simulação Baseada em Wavelets demonstrou que a evolução das estatísticas multiponto para dados contínuos é viável e os resultados obtidos apresentam uma gama de possibilidades maiores que os resultados apresentados na Simulação Sequencial Gaussiana. Isto pode ocorrer devido à utilização de estatística de alta ordem, capturadas na decomposição das imagens de treinamento. 


\section{Referências Bibliográficas}

Armstrong M., 1998, Basic linear geostatistics, Springer, Berlin, p. 1-12; 59-63.

Arpat B. e Caers J., 2005, A multiple scale, pattern-based approach to sequential simulation, in Leuangthong, O. e Deutsch, C. V., eds., Geostatistics Banff 2004, Springer, Dordrecht, p. 255-264.

Arpat B. e Caers J., 2007, Conditional simulation with patterns. Mathematical Geology 39, p. 181-182

Caers J., 2011, Modeling uncertinty in the Earth Sciences, Wiley-Blackwell, p.104106

Caers J. e Zhang, T., 2002, Multiple-point geostatistics: a quantitative vehicle for integrating geologic analogs into multiple reservoir models, Stanford University, Stanford Center for Reservoir Forecasting, Stanford, CA, p.1-9

Chatterjee S., Dimitrakopoulos R., 2011, Multi-scale Stochastic Simulation with a wavelet-based approach, Computers \& Geosciences 45, p.177-189

Chatterjee S., Dimitrakopoulos R. e Mustapha H., 2012, Dimensional Reduction of Pattern-Based Simulation Using Wavelet Analysis, Mathematical Geosciences 44, p. 343374

Chatterjee S., Mustapha H. e Dimitrakopoulos R., 2015, Fast wavelet-based stochastic simulation using training images, Computers and Geoscience

Chilès J.P. e Delfiner P., 1999, Geostatistics: Modeling Spatial Uncertainty, WileyInterscience Publication, p.449-592

Deutsch C. V., 2002, Geostatistical Reservoir Modeling, Oxford University Press, p. 131-138; p. 165

Deutsch C. V. e Journel A.G., 1998, GSLIB: Geostatistical Software Library and User's Guide, Oxford University Press, p.18-19; 119-147. 
Dimitrakopoulos R., Mustapha H. e Gloaguen E., 2010, High-order statistics of spatial random fields: exploring spatial cumulants for modelling complex, non-Gaussian and non-linear phenomena, Mathematical Geosciences v.42, p. 65-99

Duarte O. O., 2003, Dicionário enciclopédico Inglês-Português de Geofísica e Geologia, $2^{\mathrm{a}}$ Edição, Sociedade Brasileira de Geofísica, Rio de Janeiro, p. 115; 144; 264 265

Gloaguen E. e Dimitrakopoulos R., 2009, Two-dimensional conditional simulations based on the wavelet decomposition of training images, Mathematical Geosciences, v. 41, no. $6, \mathrm{pp}, 679-701$

Goovaerts P., 1997, Geostatistics for National Resources Evaluation, Oxford University Press, New York, p.369-404

Grapes A., 1995, An introduction to wavelets, IEEE Computational Science and Engineering, vol. 2, num. 2, p. 50-61.

Guardiano F. e Srivastava M., 1993, Multivariate Geostatistics: Beyond Bivariate Moments. In: Soares A., 1993, Geostatistics-Tróia '92, Kluwer Academic Publishers, Dordrecht, p. 133-144

Honarkhah M. e Caers J., 2010, Stochastic Simulation of Patterns Using DistanceBased Pattern Modeling, Mathematical Geosciences 42, p. 487 - 517

Isaaks E. H. e Srivastava R. M., 1989, An Introduction to Applied Geostatistics. Oxford University Press, p. $278-279$.

Journel A. G., 1980, Geostatistical Simulation: method for exploration and Mine Planning. In: Geostatistics, McGraw Hill, New York, p. 93-106

Journel A. G., 1989, Fundamentals of Geostatistics in Five Lessons, American Geophysical Union, Washington D.C., p. 10-13

Journel A.G. e Deutsch C.V., 1993, Entropy and Spatial Disorder, Mathematical Geology 25, p. 336-354 
Journel A. e Zhang T., 2006, The necessity of a Multiple-Point Prior Model, Mathematical Geology 38, p. 591-592; p. 597-600

Landim, P. M. B., 1997, Análise estatística de dados geológicos, Editora UNESP, p. $156-158$

Lyster S., Deutsch C. V. e Ortiz J. M., 2004, Shot Note: Some Implementation Aspects of Multiple-Point Simulation, CCG Annual Report Papers, p. 1-2

Magalhães N. M., 2011, Probabilidade e Variáveis Aleatórias, $3^{\text {a }}$ Edição, EDUSP, São Paulo, p. 241

Matheron G., 1963, Principles of Geostatistics, Economic Geology 58. In VanLandinghan S. L., 1983, Economic Evaluation of Mineral Property (Benchmark papers in geology), Hutchinson Ross Publishing Company, p. 157-177

Miesch A. T., 1975, Variograms and Variance Components in Geochemistry and Ore Evaluation, Quantitative Studies in the Geological Sciences, E.H. Whitten, ed., Geol. Soc. America Mem. 142, 1975, p. 333-340. In VanLandinghan S. L., 1983, Economic Evaluation of Mineral Property (Benchmark papers in geology), Hutchinson Ross Publishing Company, p. $124-131$

Mustapha H., Chatterjee S., Dimitrakopoulos R. e Graf T., 2013, Geologic heterogeneity recognition using discrete wavelet transformation for surface flow solute transport simulations, Advances in Water Resources, vol. 54, p 22-37

Olea R. A., 2003, Geostatistics for Engineers and Earth Scientists, Kluwer Academic Publishers, p. 141-162

Ortiz J. M., 2003, Selected Aspects of Multiple-Point Statistics, CCG Annual Report Papers, p. 2-6

Ouahabi A., 2012, Introduction to Multiresolution Analysis. In: Signal and Image Multiresolution Analysis, ISTE, London, p. 16- 32

Remy N., Boucher A. e Wu J., 2011, Applied Geostatistics with SGeMS - A User's Guide, Cambridge University Press, p. 168-214 
Rendu J.M., 1976, Bayesian Decision Theory Applied to Mineral Exploration and Mine Validation, Advanced Geostatistics in the Mining Industry, M. Guarascio, M. David e C. Huibregts, eds., D. Reidel, Dordrecht, Holland, 1976, p.435-445. In VanLandinghan S. L., 1983, Economic Evaluation of Mineral Property (Benchmark papers in geology), Hutchinson Ross Publishing Company, p. 132-142

Royle A. G., 1980, Why Geostatistics?. In: Geoestatistics, McGraw Hill, New York, p. $1-16$

Sinclair A.J. e Blackwell G.H., 2004, Applied Mineral Inventory Estimation, Combridge University Press, p. 284-292

Strebelle S., 2002, Conditional simulation of complex geological structures using multiple point statistics, Mathematical Geosciences 34 p. 1-22

Yamamoto J. K., 2001a, Análise Geoestatística. In: Yamamoto, J. K. , 2001, Avaliação e Classificação de Reservas Minerais, Edusp, p. 72-78

Yamamoto J. K., 2001b, Métodos Computacionais. In: Yamamoto, J. K. , 2001, Avaliação e Classificação de Reservas Minerais, Edusp, p. 131

Yamamoto J. K. e Landim P., M., B., 2013, Geoestatística: Conceitos e Aplicações, Oficina de Textos, São Paulo, p. 64-65

Zhang T., Switzer P. e Journel A., 2006, Filter-Based Classification of Training Image Patterns for Spatial Simulation, Mathematical Geosciences 38, p. 63-80 
ANEXO 1 - Cálculo da Densidade Aparente

A variável densidade aparente foi calculada para o depósito inteiro através do método de krigagem ordinária. A importância desta variável é para o cálculo do valor potencial. Nesta análise, foram utilizados os dados de densidade nos furos de sonda. Primeiramente foi feita a análise exploratória dos dados o ajuste do modelo teórico de variograma (Tabela A1 e Figura A1).

Tabela A1 - Modelo teórico de Variograma da densidade aparente.

\begin{tabular}{cc}
\hline \multicolumn{2}{c}{ Modelo do Variograma da } \\
Densidade Aparente
\end{tabular}

A krigagem ordinária para a densidade aparente foi realizada a partir da vizinhança com uma busca realizada por octantes, com no mínimo 3 octantes preenchidos com amostras, no mínimo 1 amostra por octante e 2 no máximo. O elipsoide de busca da densidade aparente é rotacionado em $90^{\circ}$ no eixo $\mathrm{Z}$ e $45^{\circ}$ no eixo $\mathrm{X}$, deixando o elipsoide de busca na mesma direção que seu elipsoide de anisotropia. Estes eixos tem comprimentos de 148, 78 e 62 metros no eixo maior, intermediário e menor, respectivamente. 

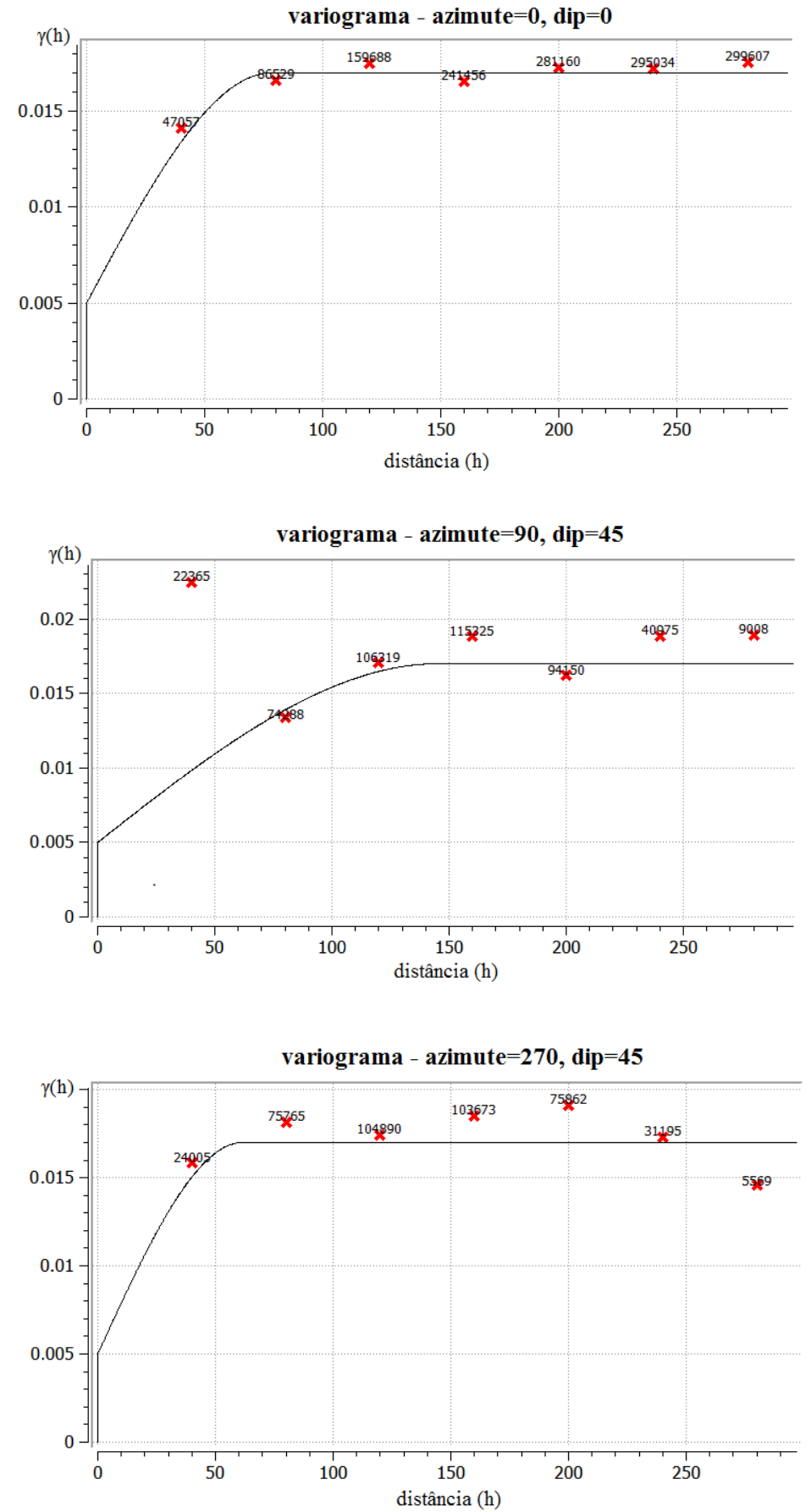

Figura Al - Variogramas experimentais com a quantidade de pares utilizados para seu cálculo e modelo do variograma teóricos de variograma do cobre ajustado. 
ANEXO 2 - Krigagem Ordinária dos Dados Dentro do Corpo de Minério

A krigagem ordinária dos dados de cobre restritos ao corpo do minério foi feita apenas para que os resultados possam ser comparados com os resultados da Simulação Sequencial Gaussiana e da Simulação Baseada em Wavelets. Neste estudo foi feita a análise exploratória dos dados, definido o modelo teórico de variograma (Tabela A2 e Figura A2), estatística descritiva dos resultados (Tabela A3), histograma dos resultados (Figura A3) e a representação tridimensional dos resultados pode ser vista na Figura A4.

A vizinhança utilizada nesta estimativa dividiu o domínio em octantes, com no mínimo 3 octantes preenchidos com amostras, no mínimo 1 amostra por octante e 2 no máximo. O elipsoide de busca da variável cobre é rotacionado em $45^{\circ}$ no eixo $\mathrm{Y}$ apenas. Os eixos da busca tem comprimento de 80, 68 e 25 metros no eixo maior, intermediário e menor, respectivamente.

Tabela A2 - Modelo teórico de Variograma do cobre dentro do corpo de minério.

\begin{tabular}{cc}
\hline \multicolumn{2}{c}{ Modelo do Variograma do Cobre } \\
Dentro do Corpo de Minério \\
\hline Tipo & Esférico \\
Efeito pepita & 0,05 \\
Patamar & 0,07 \\
Eixo Maior & 80 \\
Eixo Médio & 68 \\
Eixo Mínimo & 25 \\
Rotação em Z & 0 \\
Rotação em X & 0 \\
Rotação em Y & 45
\end{tabular}



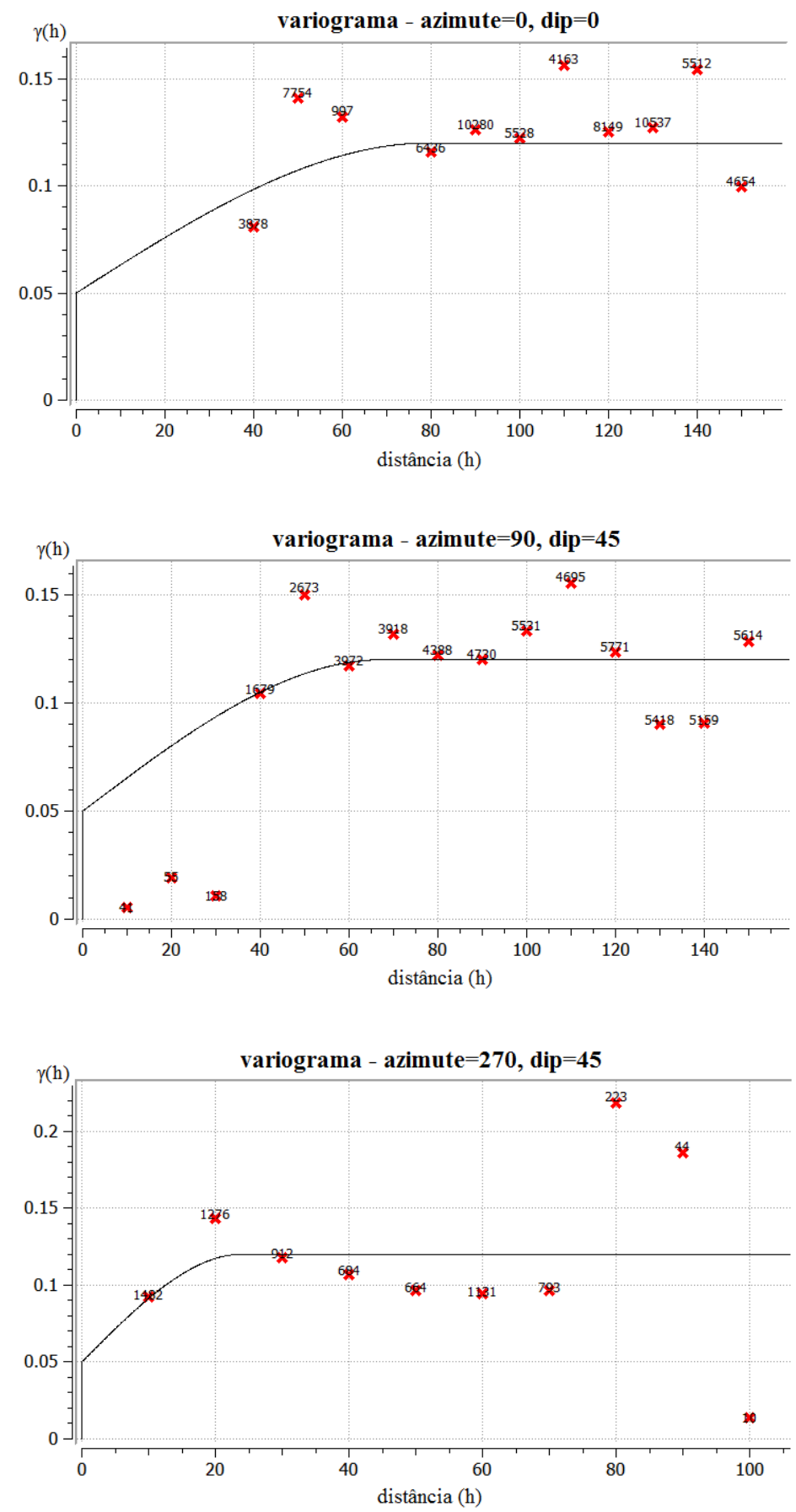

Figura A2 - Variogramas experimentais com a quantidade de pares utilizados para seu cálculo e modelo do variograma teóricos de variograma do cobre ajustado. 


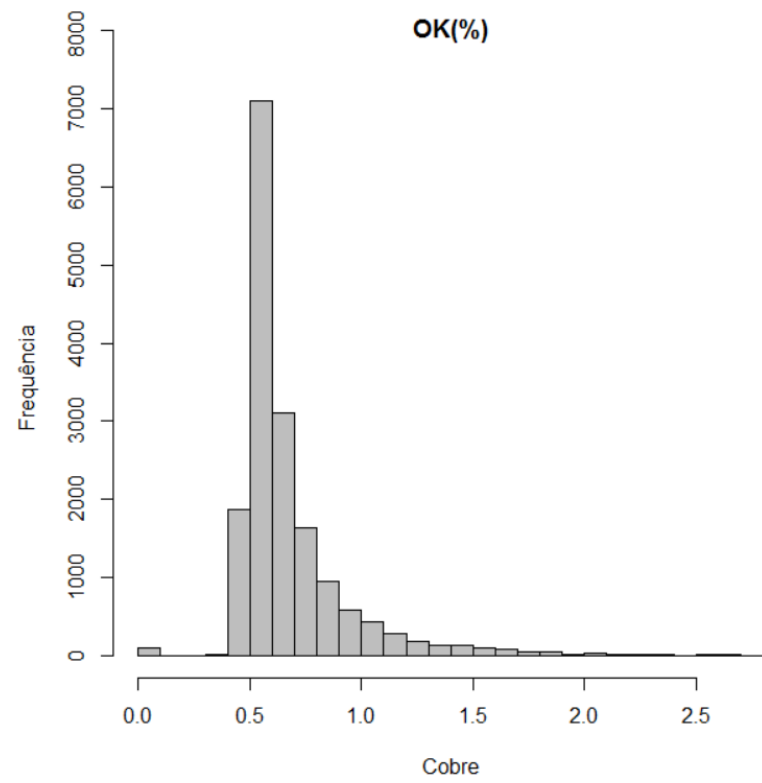

Figura A3 - Histograma do resultado da krigagem ordinária do cobre dentro do corpo de minério.

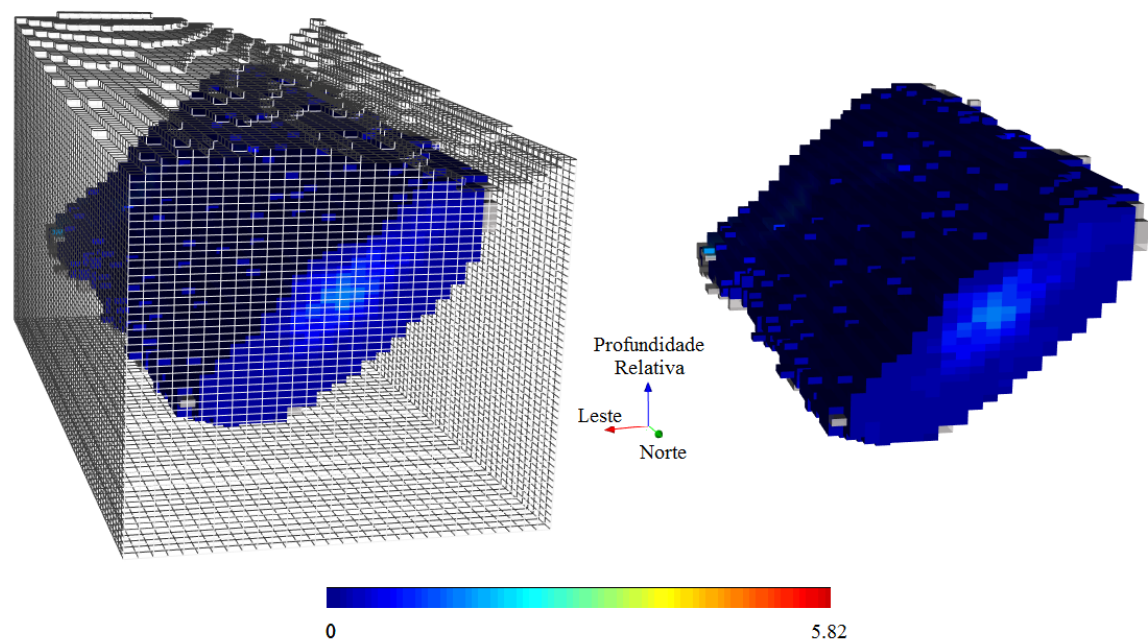

Figura A4 - Resultado da krigagem para o corpo de minério.

Tabela A3 - Estatística descritiva do resultado da krigagem ordinária do cobre dentro do corpo de minério.

\begin{tabular}{|c|c|c|c|c|c|c|c|}
\hline \multicolumn{8}{|c|}{$\mathrm{OK}$} \\
\hline Mínimo & $\begin{array}{c}\text { Primeiro } \\
\text { Quartil }\end{array}$ & Mediana & Média & $\begin{array}{l}\text { Desvio } \\
\text { padrão }\end{array}$ & $\begin{array}{c}\text { Terceiro } \\
\text { Quartil }\end{array}$ & Máximo & $\begin{array}{l}\text { Coeficiente } \\
\text { de Variação }\end{array}$ \\
\hline 0 & 0,5 & 0,6 & 0,7 & 0,3 & 0,7 & 2,7 & $37,3^{3}$ \\
\hline
\end{tabular}

